\author{
UNIVERSIDADE DE BRASÍLIA \\ FACULDADE DE CIÊNCIAS DA SAÚDE \\ PROGRAMA DE PÓS-GRADUAÇÃO EM BIOÉTICA
}

BRUNO LEONARDO ALVES DE ANDRADE

\title{
A PRODUÇÃO DO CONHECIMENTO EM DOENÇAS NEGLIGENCIADAS NO BRASIL: UMA ANÁLISE BIOÉTICA DOS DISPOSITIVOS NORMATIVOS E DA ATUAÇÃO DOS PESQUISADORES BRASILEIROS
}




\author{
UNIVERSIDADE DE BRASÍLIA \\ FACULDADE DE CIÊNCIAS DA SAÚDE \\ PROGRAMA DE PÓS-GRADUAÇÃO EM BIOÉTICA
}

BRUNO LEONARDO ALVES DE ANDRADE

\title{
A PRODUÇÃO DO CONHECIMENTO EM DOENÇAS NEGLIGENCIADAS NO BRASIL: UMA ANÁLISE BIOÉTICA DOS DISPOSITIVOS NORMATIVOS E DA ATUAÇÃO DOS PESQUISADORES BRASILEIROS
}

\begin{abstract}
Tese apresentada ao Programa de Pós Graduação em Bioética da Universidade de Brasília como requisito parcial para obtenção do título de Doutor.
\end{abstract}




\section{ANDRADE, BRUNO}

A553p A PRODUÇÃO DO CONHECIMENTO EM DOENÇAS NEGLIGENCIADAS NO BRASIL: UMA ANÁLISE BIOÉTICA DOS DISPOSITIVOS NORMATIVOS E DA ATUAÇÃO DOS PESQUISADORES BRASILEIROS / BRUNO ANDRADE; orientador DAIS ROCHA. -- Brasília, 2015. 169 p.

Tese (Doutorado - Doutorado em Bioética) -- Universidade de Brasília, 2015.

1. BIOÉTICA. 2. DOENÇAS NEGLIGENCIADAS. 3. PRODUÇÃO DO CONHECIMENTO EM SAÚDE. I. ROCHA, DAIS, orient. II. Título. 


\section{A PRODUÇÃO DO CONHECIMENTO EM DOENÇAS NEGLIGENCIADAS NO BRASIL: UMA ANÁLISE BIOÉTICA DOS DISPOSITIVOS NORMATIVOS E DA ATUAÇÃO DOS PESQUISADORES BRASILEIROS}

Tese apresentada ao Programa de Pós Graduação em Bioética da Universidade de Brasília como requisito parcial para obtenção do título de Doutor.

Aprovada em: 26/04/2015

\section{BANCA EXAMINADORA}

Profa. Dra. Dais Gonçalves Rocha - Presidente Universidade de Brasília

Prof. Dr. Cláudio Fortes Garcia Lorenzo

Universidade de Brasília

Profa. Dra. Marcia Mocellin Raymundo Universidade Federal do Rio Grande do Sul

Profa. Dra. Maria Inez Montagner Universidade de Brasília

Profa. Dra. Leonor Maria Pacheco Santos Universidade de Brasília 
Aos meus pais. 


\section{AGRADECIMENTOS}

Aos professores, funcionários e colegas do Programa de Pós-Graduação em Bioética da Universidade de Brasília pelo acolhimento e aprendizado.

À Profa. Dra. Dais Gonçalves por suas insistências e por sempre perceber o brilho nos meus olhos.

Aos Professores Cláudio Lorenzo, Inez Montagner e Helena Shimizu pelas contribuições no Exame de Qualificação.

Aos Professores que, gentilmente, aceitaram compor a banca examinadora de defesa desta tese.

À Profa. Dra. Ângela Almeida pelas ideias indispensáveis.

À Juliana Harumi pelo apoio com o ALCESTE.

À Fiocruz Brasília, especialmente à Janne Carvalho, pelas ausências necessárias.

À Juliana Mota pelas intermináveis leituras e contribuições.

À Fernanda Layunta, Maria Amélia Sampaio, Fabiana Damásio e Cecilia Andrade pela amizade, doces e gargalhadas.

Aos meus pais, Possidonio e Ivanilda, por sempre respeitarem as minhas escolhas.

Ao meu irmão Eduardo, sua esposa Catherine e meus sobrinhos Artur e Valentina pelo acolhimento quando se fez necessário.

À Karina, minha irmã, que de longe sempre se faz tão perto.

Ao André por sempre me mostrar que tudo se encaixa.

Enfim, a Deus por ter colocado todos vocês e muitos outros no meu caminho. 


\section{RESUMO}

As doenças negligenciadas são demonstradas como um flagelo persistente no histórico das populações excluídas, portanto de interesse da bioética. São classificadas como um grupo de doenças infecciosas que estão fortemente associadas às condições de pobreza verificadas, em sua grande maioria, nos países de baixa e média renda. Na intenção de aproximar duas áreas do conhecimento por meio de um diálogo a fim de demonstrar que, apesar de específicas, elas podem atuar de maneira sinérgica, esta tese teve como objetivo principal a análise quantitativa e qualitativa da produção do conhecimento em doenças negligenciadas no Brasil, considerando os dispositivos normativos relativos ao tema e a atuação dos pesquisadores da área. O presente estudo utilizou documentos públicos e dados estatísticos para obtenção dos seus resultados, que foram os seguintes: as ações de indução para as doenças negligenciadas tornou-se uma prioridade para Agenda Nacional de Prioridades de Pesquisa em Saúde, instrumento construído a partir da instituição da Política Nacional de Ciência, Tecnologia e Inovação em Saúde. 140 projetos foram contemplados pelos dois editais. Houve uma equiparação na participação do gênero masculino e feminino na coordenação das pesquisas. $\mathrm{O}$ maior número de projetos contemplados foi procedente das instituições de ensino superior e institutos de pesquisa que, na sua grande maioria, tinham caráter público. A maior parte dos estudos foi proveniente da área das ciências da saúde e concentrou-se principalmente nas instituições situadas na região Sudeste e não naquelas regiões de maior prevalência das doenças negligenciadas (Norte, Nordeste e Centro-Oeste). No primeiro edital, os estudos biomédicos corresponderam a maior parte dos projetos. No caso do segundo, as pesquisas clínicas foram lideraram do ranking dos estudos realizados por meio de apoio público. Em relação à atuação dos pesquisadores analisados por esta tese, ela ocorreu por um enfoque biológico e individualizado acerca da doença, que foi o hegemônico, e por um enfoque social e coletivo. Os autores expoentes da área da saúde também demonstraram influência na atuação do grupo dos pesquisadores analisados por esta tese. Apesar das iniquidades relacionadas à distribuição regional do número de projetos e da hegemonia da atuação constatada, concluiu-se que a ação de enfrentamento assumida pelo Estado brasileiro conjuntamente com parte dos integrantes da comunidade científica nacional pode ser considerada como uma ação moralmente justificada e eticamente comprometida. A atitude tomada pelo país trouxe para o centro das atenções da pesquisa em saúde um tema que, apesar de relevante para as condições de desenvolvimento de uma nação, tem sido vilipendiado,

principalmente, pelos que julgam que aqueles que se encontram sob o estado de vulnerabilidade social devam ser negados do acesso aos cuidados à saúde de qualidade e a medicamentos que sejam essenciais a sua sobrevivência.

Palavras-chaves: Doenças negligenciadas; bioética; pobreza; vulnerabilidade social; agenda de pesquisa em saúde. 


\begin{abstract}
Neglected diseases have been demonstrated over the years as a persisting scourge for excluded population, thus, they have been a bioethical interest. They are classified as a group of infectious diseases, which are strongly linked with the poverty conditions verified in most of low and middle-income countries. In intention to approach two knowledge areas through a dialogue in order to demonstrate that despite being very specific, they can operate synergistically, the main purpose of this dissertation was to analyze quantitative and qualitative the knowledge production of in neglected diseases in Brazil, taking into account normative devices concerning to the topic and the researchers acting area. The present research used public documents and statistical data to obtain the results, which were the inducted actions to neglected diseases became a priority to National Health Researches Priority Agenda which started from Science, Technology and Health Innovation National Politics. 140 projects have been included in two issues. There was an equalization in male and female participation in researches coordination. Most included projects were from higher education institutions and researcher institutions, which were public institutions. Most of the researches became health and science area and concentrated more particularly in institutions from Southeastern region in spite of regions which neglected diseases happened mostly (North, Northeast and Midwest regions). In the first issue, biomedical studies represented the most part of the projects. In second issue, clinical researches were leading the study ranking which were developed by public support. In relation to the researchers' activities analyzed by this dissertation, it happened in biological and individualized focus about the disease, which was hegemonic and through a social and collective focus. The health exponent authors also have shown influence in researchers group analyzed by this dissertation. In spite of iniquities related to the regional distribution of the number of projects and hegemonic focus made, it was concluded that plain of action assumed by Brazilian State and part of national scientific community might been considered as morally justified and ethically compromised. The attitude taken by the country brought to the center of health research attention an issue that, despite relevant to the developing conditions of a nations, has been vilified, especially, by the ones who believes that the people who live in a social vulnerability state might have been denied to the access of a quality health care and medication which are necessary for the survival.
\end{abstract}

Key words: Neglected diseases; bioethics; poverty; social vulnerability; health research agenda. 


\section{LISTA DE FIGURAS}

Figura 1 - Modelo de Triangulação dos Dados...

Figura 2 - Pesquisadores contemplados nos anos de 2006 e 2008 por editais de apoio às atividades de pesquisa direcionadas ao estudo das doenças

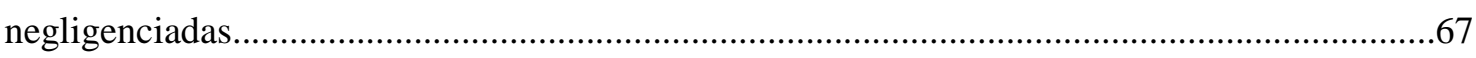

Figura 3 - Categorias que emergiram após análise das classes............................................74

Figura 4 - Relação das classes do corpus 2006 português.................................................. 96 


\section{LISTA DE TABELAS}

Tabela 1 - Grandes editais temáticos na área das doenças negligenciadas e recursos destinados entre os anos 2003 e 2008.

Tabela 2 - Distribuição das instituições contempladas no edital de apoio à pesquisa para doenças negligenciadas por regiões do país no ano de 2006.

Tabela 3 - Distribuição das instituições contempladas no edital de apoio à pesquisa para doenças negligenciadas por regiões do país no ano de 2008.

Tabela 4 - Palavras significativas da classe 2 do corpus 2006 português para subcategoria A.

Tabela 5 - Ausências significativas da classe 2 do corpus 2006 português para subcategoria A....... 139

Tabela 6 - Variáveis significativas da classe 2 do corpus 2006 português para subcategoria A 140

Tabela 7 - Palavras significativas da classe 2 do corpus 2008 português para subcategoria A 140

Tabela 8 - Ausências significativas da classe 2 do corpus 2008 português para subcategoria A.

Tabela 9 - Variáveis significativas da classe 2 do corpus 2008 português para subcategoria A. 141

Tabela 10 - Palavras significativas da classe 1 do corpus 2006 inglês para subcategoria A 142

Tabela 11 - Variáveis significativas da classe 1 do corpus 2006 inglês para subcategoria A 142

Tabela 12 - Palavras significativas da classe 2 do corpus 2006 inglês para subcategoria A.

Tabela 13 - Palavras significativas da classe 1 do corpus 2008 inglês para subcategoria A. 143

Tabela 14 - Palavras significativas da classe 4 do corpus 2008 inglês para subcategoria A....... 144

Tabela 15 - Ausências significativas da classe 4 do corpus 2008 inglês para subcategoria A. 144

Tabela 16 - Palavras significativas da classe 3 do corpus 2006 português para subcategoria B.

Tabela 17 - Ausências significativas da classe 3 do corpus 2006 português para subcategoria B. 
Tabela 18 - Variáveis significativas da classe 3 do corpus 2006 português para subcategoria B. 145

Tabela 19 - Palavras significativas da classe 4 do corpus 2006 português para subcategoria B 146

Tabela 20 - Variáveis significativas da classe 4 do corpus 2006 português para subcategoria B. 147

Tabela 21 - Palavras significativas da classe 3 do corpus 2008 português para subcategoria $\mathrm{B}$ 147

Tabela 22 - Ausências significativas da classe 3 do corpus 2008 português para subcategoria B.. 148

Tabela 23 - Palavras significativas da classe 3 do corpus 2008 inglês para subcategoria B.. 148

Tabela 24 - Variáveis significativas da classe 3 do corpus 2008 inglês para subcategoria B. 149

Tabela 25 - Variáveis significativas da classe 1 do corpus 2006 português para categoria 2 149 


\section{LISTA DE QUADROS}

Quadro 1 - Estimativas dos dispêndios mundiais com P\&D em saúde entre 1998 e 2003.

Quadro 2 - Corpus de análise documental relativo à visão do Estado sobre o problema das

DNs .50

Quadro 3 - Corpus de análise documental para normativas de apoio à produção do

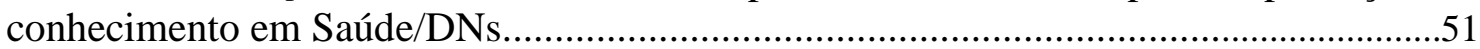

Quadro 4 - Corpus de análise documental relativo aos pesquisadores..................................51

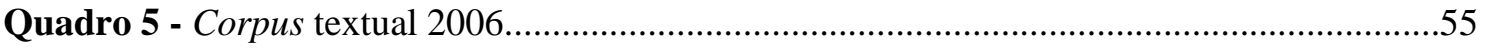

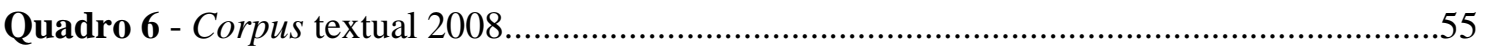

Quadro 7 - Histórico do fomento à pesquisa em DNs pelo Ministério da Saúde (2002 a

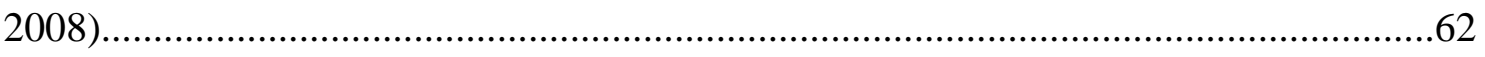

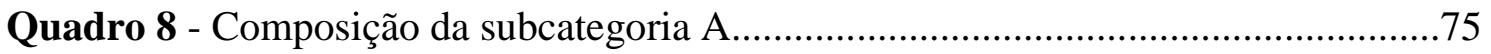

Quadro 9 - Síntese da obtenção do sentido dos corpus português 2006 e 2008 para a

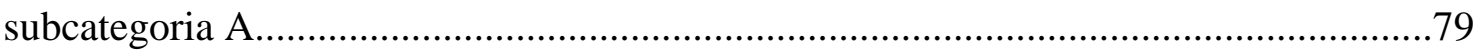

Quadro 10 - Síntese da obtenção do sentido dos corpus inglês 2006 e 2008 para a

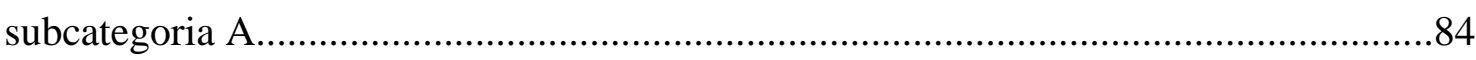

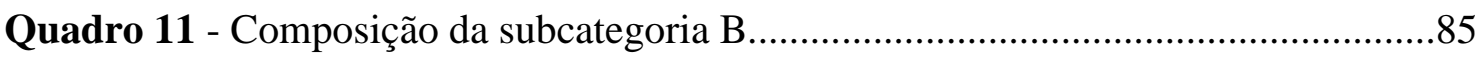

Quadro 12 - Síntese da obtenção do sentido do corpus português 2006 para a subcategoria B

Quadro 13 - Síntese da obtenção do sentido dos corpus português 2008 e inglês 2008 para a subcategoria $\mathrm{B}$

Quadro 14 - Síntese da obtenção do sentido do corpus português 2006 para a categoria Institucionalidades e Autorias. 


\section{LISTA DE GRÁFICOS}

Gráfico 1 - Distribuição dos tipos de pesquisas realizadas pelo edital de apoio às atividades de pesquisa científica, tecnológica e inovação para as doenças negligenciadas no ano de 2006 .65

Gráfico 2 - Distribuição dos tipos de pesquisas realizadas pelo edital de apoio às atividades de pesquisa científica, tecnológica e inovação para as doenças negligenciadas no ano de

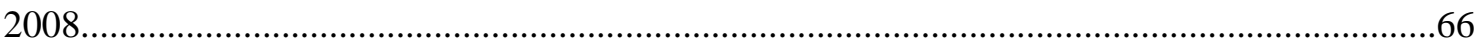

Gráfico 3 - Distribuição dos pesquisadores por gênero nos anos de 2006 e

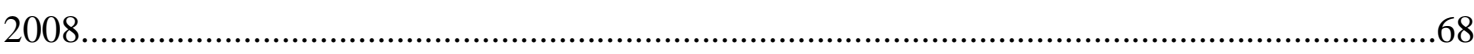

Gráfico 4 - Distribuição dos pesquisadores por área de formação no ano de 2006 . .68

Gráfico 5 - Distribuição dos pesquisadores por área de formação no ano de 2008 69

Gráfico 6 - Número e repartição percentual das UCE por classes do corpus 2006 português. .71

Gráfico 7 - Número e repartição percentual das UCE por classes do corpus 2008 português .72

Gráfico 8 - Número e repartição percentual das UCE por classes do corpus 2006 inglês.

Gráfico 9 - Número e repartição percentual das UCE por classes do corpus 2008 inglês. .73 


\section{LISTA DE ABREVIATURAS E SIGLAS}

ALCESTE - Análise Lexical de Coocorrências em Enunciados Simples de um texto ANPPS - Agenda Nacional de Prioridades de Pesquisa em Saúde

CNPq - Conselho Nacional de Desenvolvimento Científico e Tecnológico

CEP - Comitê de Ética em Pesquisa

C\&T - Ciência e Tecnologia

DECIT - Departamento de Ciência e Tecnologia

DNs - Doenças Negligenciadas

DUBDH - Declaração Universal sobre Bioética e Direitos Humanos

FS - Faculdade de Saúde

FIOCRUZ - Fundação Oswaldo Cruz

IAB - Associação Internacional de Bioética

MCT - Ministério da Ciência e Tecnologia

MS - Ministério da Saúde

MSF - Médicos Sem Fronteiras

OMS - Organização Mundial da Saúde

ONU - Organização das Nações Unidas

OPAS - Organização Panamericana da Saúde

P\&D - Pesquisa e Desenvolvimento

PNCTIS - Política Nacional de Ciência, Tecnologia e Inovação em Saúde

SCTIE - Secretaria de Ciência, Tecnologia e Insumos Estratégicos

SUS - Sistema Único de Saúde

UnB - Universidade de Brasília

UNESCO - Organização das Nações Unidas para a Educação, a Ciência e a Cultura. 


\section{SUMÁRIO}

1. INTRODUÇÃ

2. REFERENCIAL TEÓRICO.......................................................................................22

2.1 Panorama sobre as doenças neglignciadas ........................................................... 22

2.2 Doenças negligenciadas no contexto da produção do conhecimento em saúde..... 299

2.3 O diálogo do tema das doenças negligenciadas com a bioética ................................. 37

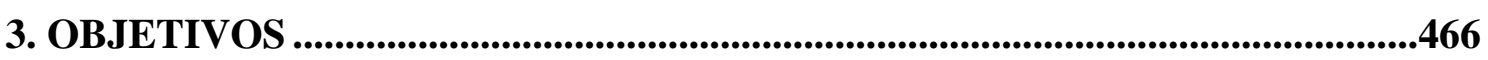

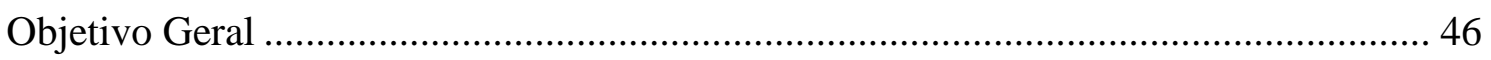

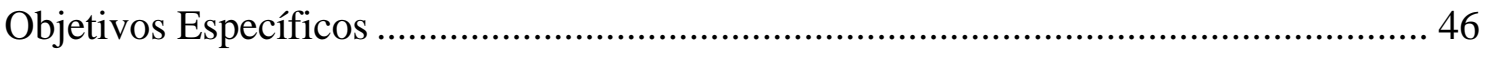

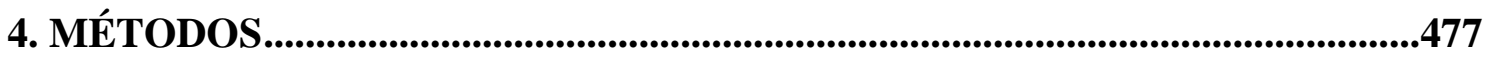

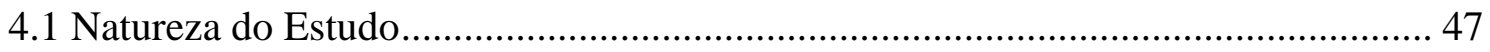

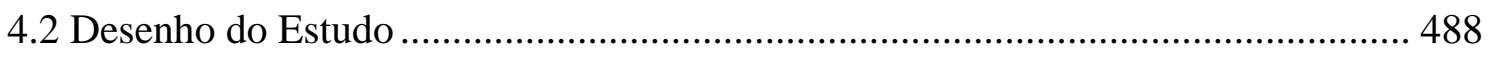

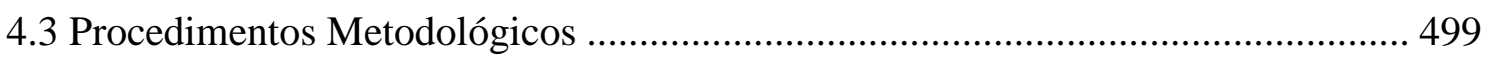

4.3.1 Levantamento bibliográfico:....................................................................... 49

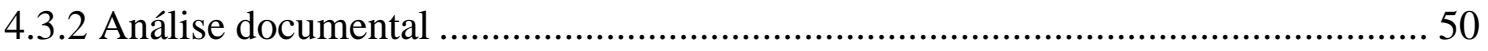

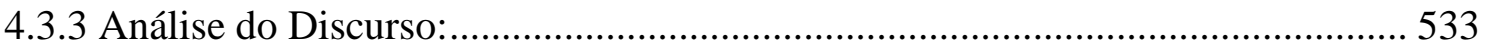

4.4 Processamento, análise e apresentação dos resultados ............................................. 588

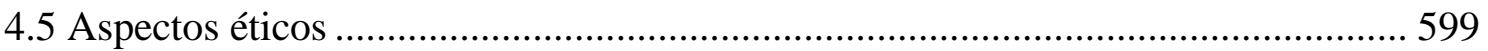

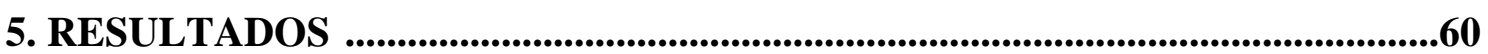

5.1 Dispositivos normativos das pesquisas em doenças negligenciadas .......................... 60

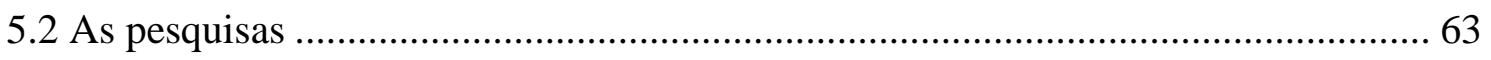

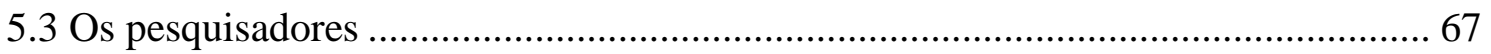

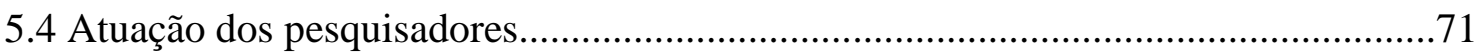

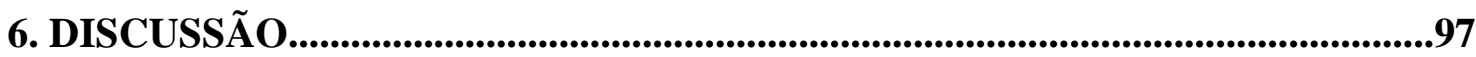

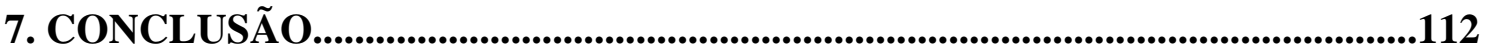

REFERÊNCIAS BIBLIOGRÁFICAS...............................................................115

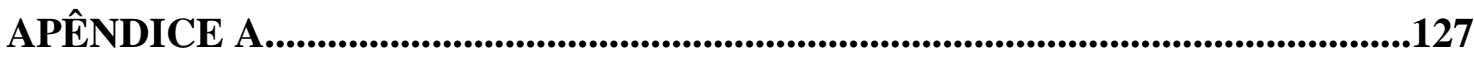

APÊNDICE B......................................................................................................139

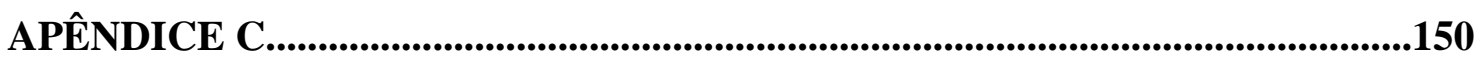

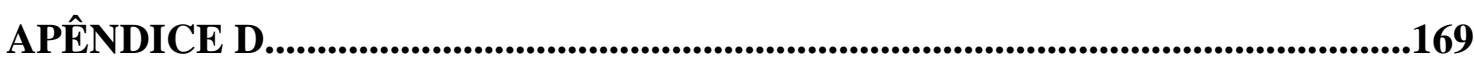




\section{INTRODUÇÃO}

O Primeiro Relatório da Organização Mundial da Saúde sobre Doenças Tropicais Negligenciadas (1) aponta que as doenças negligenciadas (DNs) atingem a vida de um bilhão de pessoas em todo mundo. Além disso, estabelece o consenso que a pobreza e a exclusão social estão relacionadas com tais doenças e que estas se apresentam de maneira mais evidente na realidade sanitária dos países periféricos.

A negligência verificada no histórico de determinadas doenças transmissíveis impacta diretamente nas condições sociais e econômicas de populações pobres e marginalizadas, concentradas em sua grande maioria no hemisfério sul do planeta. Tais evidências exigem da bioética um posicionamento que oriente a tomada de decisões e as práticas desenvolvidas pelo setor público e pelo setor privado no enfrentamento de tal problema, como está expresso na Declaração Universal sobre Bioéticas e Direitos Humanos publicada pela Organização das Nações Unidas para a Educação, a Ciência e a Cultura - DUBDH/UNESCO (2).

Mais do que falar em doenças negligenciadas, deve-se começar a discutir a condição negligenciada ou populações negligenciadas (3). Ao invés de lidar com as doenças, deve-se dar atenção e dirigir ações às necessidades de populações afetadas pelas doenças negligenciadas, visto que o debate que envolve essas doenças está além da sua condição biológica (1). Neste sentido, o autor do estudo defende que deve prevalecer um debate que tenha como ponto de partida a condição de esquecimento que se interpõe no caminho de indivíduos e coletivos que carregam as marcas da pobreza nos seus históricos de vida.

Para reforçar tal ideia, o Relatório sobre o Princípio da Responsabilidade Social e Saúde publicado pela UNESCO (4) afirma que em todo mundo, a população pobre e desfavorecida tem menos acesso a recursos de saúde, ficam mais doentes e morrem mais cedo do que aqueles em posições sociais mais privilegiadas. Ou seja, condições de saúde global são marcadas pelas desigualdades devido, principalmente, à pobreza e à falta de acesso as ações de saúde.

Deve-se atentar para as condições de negligência que vivem determinadas populações. Pois, se ignoradas pelo resto do mundo, levará a uma crise que dificilmente poderá ser revertida, lançando essas populações ainda mais para baixo (5). 
Com a intenção de tornar o tema menos negligenciado pela ciência, a Declaração da América Latina e Caribe para a sexta edição do Fórum Mundial da Ciência (6) estabeleceu em seu conteúdo que o conhecimento científico deve ser utilizado para a promoção da inclusão social, promoção do bem estar e redução da pobreza. Sendo assim, tal declaração recomenda que as pesquisas sobre as doenças negligenciadas devem ser fomentadas.

Há um reconhecimento cada vez maior de que o controle bem sucedido e sustentável das doenças negligenciadas depende do compromisso político e da apropriação das intervenções pelos governos dos países onde estas doenças são endêmicas (1). Nesse sentido, verifica-se que as doenças negligenciadas além de serem confirmadas como um flagelo enraizado e que persiste no histórico de saúde das populações excluídas, portanto de interesse para bioética $(7,8)$, constituem uma prioridade para a agenda mundial de pesquisa por refletir diretamente na vida de milhares pessoas que foram deixadas para trás pelo progresso socioeconômico e consequentemente privados dos avanços da ciência e da tecnologia.

O grande número de artigos científicos publicados em periódicos reconhecidos internacionalmente, a exemplo da revista especializada no assunto PLoS Neglected Tropical Diseases e da revista The Lancet, que sempre traz em seu conteúdo artigos relativos a temática das doenças negligenciadas, reforça a ideia que integrantes da comunidade científica além de estarem no compasso do contexto atual da ciência, também demonstram empenho para reverter o quadro de negligência que muitas doenças transmissíveis se encontram. Desta forma, a produção do conhecimento voltada ao enfrentamento e ao combate de doenças que afetam, na maioria das vezes, pobres e vulneráveis é um fato que pode ser confirmado tanto pelo volume de publicações nacionais e internacionais da área como também por ações públicas de indução à pesquisa em tal área do conhecimento.

Face ao exposto, uma nova perspectiva de estudo foi posta com a intenção de promover o diálogo de um tema vastamente abordado pela literatura científica, mas ainda pouco explorado pela lente da bioética. Assim, a partir do olhar da bioética, a presente tese teve como questão central do seu processo de investigação a seguinte pergunta condutora: como se deu a produção do conhecimento em doenças negligenciadas no Brasil, considerando os dispositivos normativos relativos ao tema (2006-2008) e a atuação dos pesquisadores responsáveis por essa produção? 
Deve ficar claro que a produção do conhecimento tratada por esta tese diz respeito às pesquisas realizadas com apoio dos editais públicos, que neste estudo foram denominados de dispositivos normativos. Além disto, por se tratar de uma investigação da produção do conhecimento que considera tanto as pesquisas quanto os pesquisadores envolvidos, foi de suma importância o estabelecimento dos conceitos a seguir descritos.

Para a presente tese, o conceito de pesquisa que foi adotado é o proposto por Minayo (9) que considera como uma atividade básica da ciência nos seus questionamentos e construção da realidade. Para a autora, a pesquisa alimenta a atividade de ensino e a atualiza diante da realidade do mundo. Portanto, embora seja uma prática teórica, a pesquisa conecta pensamento e ação. Ou seja, nada pode ser intelectualmente um problema se não tiver sido, em primeiro lugar, um problema da vida prática. Toda investigação se inicia por um problema com uma questão, com uma dúvida ou com uma pergunta, articuladas a conhecimentos anteriores, mas que também podem demandar a criação de novos referenciais.

No caso das pesquisas em saúde, os conceitos relativos ao seu tipo e à sua natureza adotados para esta tese são os propostos pelos Manuais do Programa Pesquisa para o Sistema Único de Saúde: Gestão compartilhada em saúde - PPSUS (10) e de Seleção de Prioridades de Pesquisa em Saúde Guia PPSUS (11), que a seguir serão descritos.

De acordo com os manuais anteriormente citados $(10,11)$ as pesquisas podem ser dos seguintes tipos:

- Pesquisa clínica - realizadas com seres humanos para responder questões relativas a diagnóstico, tratamento e prognóstico no nível individual;

- Pesquisa biomédica (strictu senso) - pesquisas cujos objetos de estudo são modelos, animais, secreções, tecidos, células, genes humanos, animais ou vegetais;

- Pesquisa em saúde coletiva - pesquisas sobre as dimensões materiais e simbólicas do processo saúde-doença e da resposta socialmente organizada aos problemas de saúde na dimensão coletiva;

- Pesquisa de desenvolvimento tecnológico - atividades relacionadas com o desenvolvimento ou implementação de novos produtos e processos ou com o aprimoramento de produtos e processos já existentes; 
- Pesquisa em ciências sociais e humanas aplicadas à saúde - pesquisas que relacionam os aspectos sociais das diversas realidades humanas com a saúde.

Em relação à natureza das pesquisas, a classificação ocorre da seguinte forma:

- Pesquisa aplicada/estratégica - qualquer investigação original realizada para obter novos conhecimentos, mas dirigida, originariamente, a um objetivo ou propósito prático e específico. Volta-se à necessidade de aplicação por parte de um indivíduo, grupo ou da sociedade;

- Pesquisa básica - trabalho teórico ou experimental realizado primordialmente com finalidade de adquirir novos conhecimentos sobre os fundamentos ou fenômenos e fatos observáveis sem o propósito de qualquer aplicação ou utilização específica. Tem por objetivo ampliar o campo de entendimento fundamental;

- Pesquisa tecnológica - qualquer trabalho sistemático apoiado no conhecimento existente obtido por pesquisa e/ou por experiência prática direcionada para produção de novos materiais, produtos, equipamentos, instalações de novos processos, sistemas, serviços, ou para melhorar significativamente aqueles já produzidos ou instalados.

Além da produção do conhecimento científico, também foram analisados os integrantes da comunidade científica, no caso, pesquisadores de uma mesma região ou distantes geograficamente que assumiram o compromisso de atuar dentro de normas socialmente construídas e valores culturais comuns, tendo por consequência o desenvolvimento de práticas científicas assemelhadas, voltadas a consecução de um único objeto, no caso, o enfrentamento das doenças negligenciadas pelo país.

Cabe destacar que o sentido de comunidade científica adotado pelo autor do estudo foi estabelecido a partir do conceito de Kuhn (12) que considera que a comunidade científica seria integrada por indivíduos que, além de compartilharem do mesmo paradigma (no seu sentido amplo, um sem número de crenças, valores, técnicas - definidos cognitivamente, que em determinado momento são adequados para a resolução do conjunto de problemas existentes), estariam comprometidos com uma maneira coletiva de se praticar ciência para solucionar problemas concretos.

Deve-se atentar que, para o presente estudo, os conceitos anteriormente descritos foram investigados pela lente da bioética desenvolvida por autores que, em sua grande 
maioria, são provenientes da América Latina e seguem a linha do pensamento bioético que é politicamente engajado e socialmente comprometido, que não se cala diante das consequências da pobreza e das injustiças que acometem, em sua grande maioria, os países situados no Hemisfério Sul do planeta.

Portanto, a linha de pensamento bioético defendido para o presente estudo é justamente aquele que centra a sua atuação na resolução de conflitos éticos que nascem das iniquidades e das injustiças que, em sua maioria, são provenientes das assimetrias de poder. No entanto, por se tratar de um tema que rompe fronteiras, o presente trabalho procurou não se aprisionar apenas às referências da América Latina, indo buscar outras fontes para promover um diálogo do seu objeto de estudo com a bioética, que não ficasse restrito e que pudesse ter uma dimensão internacional. Propõe-se, portanto, promover uma investigação na intenção de estabelecer um diálogo que envolva a bioética com um problema de relevância social cujo impacto reflete no desenvolvimento global.

A atitude adotada pelo autor desta tese é corroborada por Kottow (13) quando afirma que a bioética latino-americana não pode desconsiderar o discurso que parte dos países centrais, sob pena de ficar presa em coordenadas de pensamento desconectadas dos centros de decisão e vulneráveis ao embate dos interesses criados e que afetam de modo negativo o bem comum, sobretudo, das populações socialmente vulneráveis. Assim sendo, quanto mais divergentes e conflitantes se tornam as bioéticas de procedência moral diversa, mais importante é não perder o contato com os vários discursos bioéticos, inclusive daqueles originários dos países centrais que são considerados hegemônicos (13).

Deve ficar claro que a perspectiva bioética priorizada para este trabalho é justamente a que se constrói a partir das diversas visões morais, do diálogo estabelecido entre autores de diferentes fontes e que procura considerar o espaço geográfico e a dimensão social onde ocorrem os conflitos éticos (8). Para isto, o material selecionado procurou estabelecer conexões entre o objeto principal do estudo (doenças negligenciadas), seu recorte (produção do conhecimento) e sua lente de investigação (bioética).

Dito isto, o primeiro capítulo traz o marco teórico desta tese que é composto por três partes. Na primeira parte deste capítulo são delimitados conceitos acerca do objeto principal de estudo, suas consequências, o contexto de acometimento e sua íntima relação com as condições de vida das populações. A segunda parte é dedicada para 
investigar o comportamento da produção nacional e internacional do conhecimento científico das doenças negligenciadas diante do contexto da produção do conhecimento científico da área da saúde. Por fim, a terceira e última parte do capítulo tem por finalidade discorrer sobre o modo que os estudos teóricos da bioética percebem e explicitam o tema das doenças negligenciadas. Ou seja, o mote de investigação teórica principal da etapa final do capítulo é justamente a confirmação do diálogo de uma nova área do conhecimento com um velho problema cercado de conflitos morais. Cabe destacar que a última parte do primeiro capítulo corresponde à resposta do primeiro objetivo específico proposto para esta tese.

O segundo capítulo traz no seu conteúdo a descrição dos procedimentos metodológicos utilizados para atingir os demais objetivos específicos propostos para esta tese. Nesse capítulo, o autor situa a pesquisa como uma abordagem quantiqualitativa, discorrendo sobre a natureza e o desenho do estudo, as fontes de dados, técnicas de análise, meios de apresentação dos resultados e os aspectos éticos que conduziram o desenvolvimento do estudo.

O terceiro capítulo da tese trata dos seus resultados que foram estruturados em quatro partes para responder ao segundo, terceiro e quarto objetivos específicos propostos para esta tese. Nesse capítulo, o autor se propôs analisar as pesquisas em doenças negligenciadas realizadas por meio das ações de apoio propostas pelo país, considerando: os dispositivos normativos das pesquisas (2006 - 2008); as pesquisas que foram realizadas com o apoio destes dispositivos; o perfil e a atuação dos pesquisadores responsáveis por essas pesquisas.

No quarto capítulo, o autor do presente estudo discute os seus resultados a partir das convergências, das divergências e das singularidades que surgiram ao longo das etapas quantitativa e qualitativa da presente tese. Finalmente, no quinto capítulo o autor descreve as conclusões obtidas juntamente com as suas considerações para a temática. 


\section{REFERENCIAL TEÓRICO}

\subsection{PANORAMA SOBRE AS DOENÇAS NEGLIGENCIADAS}

Antigas doenças que assolam a humanidade funcionam como um verdadeiro flagelo para as suas condições de saúde há séculos. A concentração de tais doenças nos trópicos fez com que elas ficassem conhecidas ao mundo pela terminologia de doenças tropicais negligenciadas, sendo corriqueira a abreviação NTDs (do inglês Neglected Tropical Diseases) na literatura internacional.

A denominação "doenças tropicais" vem sendo utilizada desde o século XIX, pois, de acordo com Camargo (14), o termo já constava no vocabulário médico da época. $\mathrm{O}$ autor citado anteriormente refere que o surgimento do termo ocorreu sem uma data fixa e foi sendo consolidado à medida que microrganismos eram reconhecidos como os responsáveis pelas causas de doenças e tinham seus mecanismos de transmissão elucidados.

O processo de colonização realizado pela Inglaterra, França e em menor escala pelos Estados Unidos ao longo do século XIX pela região do Caribe e do Pacífico, revelou ao mundo um conjunto de doenças consideradas curiosas e até mesmo exóticas por muitos pesquisadores da época. Até então desconhecidas ou quase desconhecidas pela ciência, as tais doenças que acometiam as colônias que se situavam nos trópicos, passaram a ser chamadas de "doenças tropicais" (14).

Para unir o conhecimento ao redor das patologias dos trópicos foram criadas sociedades médicas: The Society of Tropical Medicine of Philadelphia, transformada em seguida em American Society of Tropical Medicine, em 1903, e The Royal Society of Tropical Medicine and Hygiene, em 1909. Patrick Manson, considerado o "pai da medicina tropical" foi o responsável pela "mosquito theory", fundou em 1899 a London School of Hygiene and Tropical Medicine e foi o primeiro presidente da Royal Society. Essas instituições consagraram a designação "doenças tropicais" como terminologia para a área da saúde (14).

\footnotetext{
${ }^{1}$ Por meio dessa teoria ficou demonstrado que a malária não passaria de pessoa a pessoa, sendo o mosquito consagrado como vetor da doença.
} 
A primeira metade do século $\mathrm{XX}$ assiste ao acirramento de posições conflitantes, médicas e leigas, sobre as raízes das "doenças tropicais". Essas posições se cristalizavam em duas visões antagônicas sobre as doenças tropicais: a) "são doenças de populações colonizadas, exploradas, miseráveis, que por acaso se concentram nos trópicos"; b) "são doenças de regiões insalubres, caniculares, sujas e propícias a todas as formas de doenças estranhas ao mundo civilizado”. Nas doenças tropicais, há certamente um forte componente de subdesenvolvimento $(14, \mathrm{p} .2)$.

Em 1975, o Special Programme for Research \& Training in Tropical Diseases $(\mathrm{TDR})^{2}$ da Organização Mundial da Saúde (OMS) (15) já observava e apontava para indisponibilidade de tratamentos eficazes ou adequados para as doenças vinculadas à pobreza que acometiam, em sua grande maioria, populações presentes nos trópicos.

As constatações atinentes a tais doenças fizeram com que, logo em seguida, fosse instituído pela Fundação Rockefeller o Programa Grandes Doenças Negligenciadas da Humanidade (Great Neglected Diseases of Mankind - 1977/2000), que passou a ser considerado o marco inicial da discussão sobre as doenças negligenciadas no mundo (16).

A menção aos trópicos atrelada à perspectiva colonizadora descrita na citação acima, que por hora passou a soar preconceituosa e pouco científica (17), deu espaço para que as doenças infecciosas que se tornaram mais conhecidas a partir da ocupação dos trópicos, como mencionado nos parágrafos anteriores, ganhassem terminologias que conseguiriam retratar mais a sua relação com as condições de vida das populações do que com a sua localização geográfica, como as terminologias que a seguir serão descritas.

As iniquidades verificadas em escala mundial associadas à carga de doenças fizeram com que a Organização Mundial da Saúde (OMS) e os Médicos Sem Fronteiras (MSF) propusessem uma classificação para as doenças utilizando as seguintes terminologias (18):

\footnotetext{
${ }^{2}$ Trata-se do Programa Especial para Pesquisa e Treinamento em Doenças Tropicais (TDR), de caráter independente de colaboração científica, que ajudou a coordenar, apoiar e influenciar esforços globais no combate das principais doenças que afetam os pobres e desfavorecidos. Fundado em 1975, o TDR é patrocinado pelo Fundo das Nações Unidas para a Infância (UNICEF), pelo Programa de Desenvolvimento das Nações Unidas (PNUD), do Banco Mundial e da Organização Mundial da Saúde (OMS).
} 
I - Doenças globais (ocorrem em todo mundo);

II - Negligenciadas (mais prevalentes nos países periféricos);

III - Extremamente negligenciadas (exclusivas dos países periféricos).

No caso das duas últimas terminologias adotadas, além de representarem uma evolução do termo "doenças tropicais", denominaram uma condição presente na realidade das populações que vivem a margem do desenvolvimento socioeconômico (19).

Ou seja, o grande número de pessoas sem acesso à água potável, escolaridade, saneamento básico, moradia ou a tratamentos de saúde, que sobrevivem em áreas urbanas, áreas rurais remotas e em regiões de conflitos com menos de US\$ 2 por dia configuram o verdadeiro retrato da condição de negligência imposta a doenças e doentes (20).

Riley e colaboradores (21) reforçam as terminologias quando afirmam que as condições socioeconômicas presentes nos centros urbanos, mais especificamente nos bolsões de pobreza dessas áreas, criam um ambiente favorável para manutenção da transmissão de muitas doenças infecciosas.

Para Franco-Paredes e Santos-Apreciado (22), a pobreza pode ser considerada o início e o desfecho quando se trata das doenças negligenciadas. Para os referidos autores, considerar a pobreza apenas como baixa renda é insuficiente, pois, fatores como o analfabetismo, a desnutrição, as más condições de vida, o desemprego e o fracasso das relações de propriedade verificadas em todo mundo também estão fortemente associadas ao histórico das populações acometidas por tais das doenças. O olhar sobre a pobreza deve ser amplo e encarado como privação das liberdades e capacidades fundamentais dos seres humanos expostos ao ciclo vicioso da miséria que, por sua vez, tem a capacidade de produzir a incapacidade, a desfiguração, o estigma e a mortalidade prematura.

Dos 580 milhões de pessoas que vivem na América Latina e no Caribe, a cerca de 195 milhões que vivem na pobreza (definida como ganham menos de dois dólares por dia) e 71 milhões vivem em extrema pobreza (definida como ganham menos de um dólar por dia). A maioria deles, incluindo as populações indígenas, populações rurais pobres, moradores de favelas, os trabalhadores migrantes, idosos, mulheres e crianças, vivem em condições desfavoráveis e sofrem uma carga maior de doenças infecciosas (23). 
A maioria dessas doenças são crônicas e podem reduzir a capacidade de aprendizado, produtividade e capacidade de ganho de renda. Assim, as doenças negligenciadas são simultaneamente uma causa e uma consequência da pobreza (24).

Ainda que o componente pobreza seja o mais forte no histórico de acometimento das doenças negligenciadas, ele não é o único fator determinante para o risco de se adquirir essas doenças na América Latina e no Caribe. Iniquidades relacionadas à etnia, como no caso de grupos indígenas e pessoas de ascendência africana, idade e gênero são fatores predisponentes para tais doenças. Ou seja, crianças, mulheres e condições ecológicas são fatores quando associados fortalecem o aparecimento das doenças negligenciadas (25).

Há evidências suficientes para afirmar que as doenças negligenciadas são um verdadeiro flagelo na vida de um bilhão de pessoas ao redor do mundo e são uma ameaça premente na vida de outros milhões (26). Nesse sentido, milhares de mortes ocorrem em decorrência da contaminação de vários indivíduos por tais doenças (27).

São patologias predominantemente, mas não exclusivas, de países tropicais e provocam um alto impacto na morbidade e mortalidade desses países (28). No entanto, o ônus proveniente das doenças negligenciadas não pode ser calculado considerando apenas a mortalidade provocada. Em geral, causam muito mais incapacidades do que mortalidade (29).

Vale destacar que o termo "doenças negligenciadas" torna-se extremamente explícito quando autoridades mundiais elegem como prioridade o investimento de bilhões de dólares na contenção de uma possível pandemia de gripe aviária e ignora a existência de epidemias de doenças tropicais de alta morbidade, que incapacita e mata prematuramente indivíduos de populações que se encontram em estado de vulnerabilidade social (21).

As doenças negligenciadas são classificadas como um grupo heterogêneo de 17 enfermidades (23) que afetam, quase que exclusivamente, as populações socialmente excluídas e impotentes que vivem em áreas degradadas pela pobreza (30). Nessa relação estão incluídas as seguintes enfermidades (23):

1) Tracoma;

2) Úlcera de Buruli;

3) Tripanossomose africana (doença do sono);

4) Doença de Chagas (tripanossomíase americana);

5) Dengue; 
6) Dracunculíase;

7) Cisticercose;

8) Leishmaniose;

9) Hanseníase;

10) Filariose linfática;

11) Oncocercose;

12) Esquistossomose;

13) Bouba;

14) Geohelmintíase;

15) Raiva;

16) Equinococose;

17) Fasciolíase.

As patologias acima listadas são exemplos clássicos já consagrados pela literatura científica mundial (31). No entanto, o conteúdo da Nota Técnica N.1/2011/IOC-FIOCRUZ/DIRETORIA (32) reforçou que a febre reumática, as doenças relativas à subnutrição e anemias carenciais também compõem o grupo das doenças negligenciadas. Nesta lista também podem ser adicionadas as seguintes doenças: leptospirose, outras treponematoses e escabiose (24).

A forte relação existente entre doenças infecciosas e determinantes socioeconômicos que condicionam a situação de pobreza, principalmente, das populações dos países de média e baixa renda proporcionou a adoção de novas terminologias para designar as doenças negligenciadas. Desse modo, as terminologias "doenças infecciosas relacionadas à pobreza", ou simplesmente "doenças infecciosas da pobreza" passaram a ser adotadas pela Organização Mundial da Saúde (OMS) e pela Organização Panamericana da Saúde (OPAS) para denominar o grupo de doenças que iriam compor o Plano Global para Combater as Doenças Tropicais Negligenciadas 2008-2015 (Strategic and Technical Advisory Group on Neglected Tropical Diseases) (33).

Além das terminologias acima apontadas, passou-se também a denominar as doenças negligenciadas como "doenças promotoras da pobreza", pois, chegou-se a conclusão que tais doenças além de retroalimentar as iniquidades, produziam e expunham a riscos a parcela da população submetida às condições de miséria (34).

Destaca-se que as terminologias descritas anteriormente serão utilizadas de maneira indiscriminada para designar "doenças negligenciadas" ou o seu acrônimo 
"DNs" pelo simples fato de expressar de maneira clara uma condição posta a determinadas doenças transmissíveis,

Muitas das doenças negligenciadas já foram altamente prevalentes. No entanto, ao longo do tempo foram desaparecendo em extensas partes do mundo à medida que as sociedades se desenvolveram e as condições de vida e higiene melhoraram. Hoje, embora exista o prejuízo na vida de cerca de um bilhão de pessoas, as doenças negligenciadas permanecem em grande parte ocultas, concentradas em áreas rurais remotas ou em favelas urbanas. São também, em sua maioria, silenciosas, uma vez que os indivíduos acometidos ou sob o risco têm pouca voz política (30).

No cenário prospectado em 2030, para a saúde no Brasil, segundo dados da Fundação Oswaldo Cruz (35), as doenças negligenciadas são identificadas entre as "doenças com tendência à estabilidade em seus indicadores de ocorrência".

Este grupo de doenças é constituído por aquelas que apresentam tendência à estabilidade nos indicadores de morbimortalidade ou que têm tido a sua carga reduzida, porém ainda persistindo como problema importante de saúde pública no país. Inclui a hanseníase, a tuberculose, o tracoma, a malária, a doença meningocócica, as geo-helmintíases, a cisticercose, a toxoplasmose, a febre tifoide, a sífilis e outras doenças sexualmente transmissíveis, a peste, a varicela, as micoses sistêmicas e a hidatidose [Grifo do autor]. (35, p.100)

Apesar da diminuição do número de casos ao longo do tempo das doenças que estão relacionadas à pobreza, elas ainda são consideradas como um entrave para o desenvolvimento da humanidade (26). Nesse sentido, no ano 2000, diante da relação estabelecida entre pobreza e doenças negligenciadas, o tema voltou a ganhar destaque mundial por meio dos Objetivos de Desenvolvimento do Milênio (ODM) ${ }^{3}$ declarados pelos Estados-Membros da Organização das Nações Unidas - ONU (36).

Os esforços demonstrados no controle de doenças relacionadas à pobreza constituem uma estratégia de longo alcance a favor das populações pobres. Mudou-se a lógica: no lugar da espera pelo desaparecimento gradual dessas doenças, à medida que

\footnotetext{
${ }^{3}$ Objetivos de desenvolvimento do milênio - ONU: 1) Erradicação da pobreza extrema e da fome; 2) Universalização do acesso à educação primária; 3) Promoção da igualdade entre os gêneros; 4) Redução da mortalidade infantil; 5) Melhoria da saúde materna; 6) Combate a AIDS, malária e outras doenças; 7) Promoção da sustentabilidade ambiental; 8) Desenvolvimento de parcerias para o desenvolvimento.
} 
os países tornam-se mais desenvolvidos e as condições de vida melhoram, considera-se agora que um esforço deliberado para provocar seu desaparecimento é um caminho para redução da pobreza que pode, por si só, induzir ao desenvolvimento socioeconômico (26).

Vale destacar que a Declaração dos Objetivos do Milênio além de servir como fonte de inspiração e estímulo a governos, agências, instituições e indivíduos no apoio e cuidado das populações necessitadas, também reconhece que melhorias direcionadas à saúde das populações contribuem diretamente na redução da pobreza (26).

No caso do Brasil, ainda que o país apresente o maior número de casos de doenças negligenciadas dentre os países da América Latina e Caribe, onde grande parte de milhares dos brasileiros expostos à situação de pobreza estão contaminados por uma ou mais de uma dessas doenças, verifica-se que o país tem tentado contribuir com os Objetivos do Milênio por meio da redução considerável do número de mortes causadas por doenças infecciosas relacionadas à pobreza nas últimas décadas (25).

Apesar desse avanço, verifica-se no país que doenças relacionadas à pobreza ainda são encaradas como um problema persistente de saúde pública (37), confirmado pelos alarmantes números presentes no quadro sanitário do país, como no caso das 6 mil mortes ocasionadas por ano pela doença de Chagas e pela liderança ocupada no ranking mundial para casos registrados de leishmaniose visceral com $90 \%$ dos casos mundiais (38).

Para Morel (39), a persistência das doenças promotoras da pobreza ocorre por diferentes causas ou "falhas" que são classificadas em três tipos: falha da ciência (conhecimentos insuficientes); falha de mercado (alto custo de medicamentos e vacinas); falha de saúde pública (planejamento deficiente para diagnósticos e tratamentos). Além de apontar as possíveis falhas para persistência da ocorrência das doenças relacionadas à pobreza, ele também propôs meios para resolução desses acontecimentos, tais como: falhas da ciência exigem uma reorganização do sistema nacional de pesquisa com o estabelecimento de uma ligação entre a produção do conhecimento e suas aplicações. Falhas de mercado requerem mecanismos inovadores de financiamento ou negociações. Falhas de saúde pública exigem novas estratégias de intervenção (19).

Há 149 países e territórios nos quais as doenças relacionadas à pobreza são endêmicas. Pelo menos 100 desses são endêmicos para duas ou mais doenças, e 30 países são endêmicos para seis ou mais doenças (26). Apesar desse pesado ônus, o 
Primeiro Relatório da OMS sobre doenças tropicais negligenciadas (26) ratificou que tradicionalmente não se verifica o protagonismo dessas doenças nas agendas nacionais e internacionais de saúde, mesmo diante do imenso sofrimento provocado, que na maioria das vezes permanecem ocultos e silenciosos, e frequentemente matam, mas não em números comparáveis aos de tantas outras doenças.

\subsection{DOENÇAS NEGLIGENCIADAS NO CONTEXTO DA PRODUÇÃO DO CONHECIMENTO EM SAÚDE}

O Global Forum for Health Research (40) apontou que os investimentos mundiais para produção do conhecimento em saúde são significativos e estão em processo de crescimento. Para confirmar essa ascensão, dados contidos nesse documento demonstraram que no ano de 1998 os investimentos para essa área corresponderam a US\$ 84,9 bilhões, enquanto que no ano de 2003 estes investimentos saltaram para US\$ 125, 8 bilhões. O quadro a seguir apresentado, demonstra a progressão das estimativas de dispêndios mundiais com P\&D em saúde entre os anos de 1998 e 2003.

Quadro 1 - Estimativas dos gastos mundiais com P\&D em saúde entre 1998 e 2003

\begin{tabular}{cc}
\hline Ano & Valor (US\$) \\
\hline 1998 & 84,9 bilhões \\
1999 & 92 bilhões \\
2000 & 98 bilhões \\
2001 & 105,9 bilhões \\
2002 & 115,9 bilhões \\
2003 & 125,8 bilhões \\
\hline
\end{tabular}

Fonte: Estimativas do Global Forum for Health Research baseadas em dados de relatórios oficiais de OECD e RICYT, de levantamentos nacionais, associação farmacêutica e outras publicações.

O total de gastos no Brasil com pesquisa em saúde entre os anos de 2000 e 2002 foi de US\$ 1,6 bilhões, com uma média anual de gastos de US\$ 530,6 milhões (41). O setor público foi responsável por aproximadamente US\$ 1,1 bilhões (média anual cerca de US\$379, 5 milhões), correspondendo a $71,5 \%$ do total dos gastos $(16,42,41)$. 
Dados preliminares apresentados por um observatório do financiamento à pesquisa em Saúde no Brasil (43) demonstraram que no período de 2003 a 2005, o país destinou para pesquisa em saúde o montante de $R$ \$ 2,99 bilhões, sendo $R$ \$ 2,1 bilhões oriundos do setor público, $\mathrm{R} \$ 824,6$ milhões do setor privado e $\mathrm{R} \$ 55,2$ milhões de organismos internacionais (44).

O Brasil destina para pesquisa em saúde um volume expressivo de recursos financeiros que corresponde a aproximadamente 1,5\% dos gastos nacionais em saúde e 3,3\% dos gastos públicos com saúde (45). Mesmo expressiva esta proporção ainda situa-se abaixo dos $2 \%$ dos gastos nacionais em saúde que a Commission on Health Research for Development e a OMS preconizam que os governos em países em desenvolvimento destinem na promoção da pesquisa (46).

Segundo Paraje e colaboradores (47), 90,4\% da produção científica mundial em saúde estão concentradas em 42 países de renda alta e destes, os cinco mais produtivos (EUA, Reino Unido, Japão, Alemanha e França), respondem por 72,5\% da produção total. Os 9,6\% restantes estão distribuídos entre os demais países da seguinte maneira: 1,7\% entre os 63 países de renda baixa, 5,4\% entre 54 países de renda média inferior e 2,5\% entre 31 países de renda média superior. Vale destacar os seguintes pontos acerca dos dados apresentados: 1) Os cinco países líderes do último subgrupo (China, Federação Russa, Brasil, Turquia e África do Sul) são responsáveis por 4,4\% dos 5,4\%; 2) O Brasil vem galgando posições no ranking mundial de atividades de pesquisa em saúde realizada em universidades e institutos de pesquisa.

De acordo com Guimarães (45) o país se encontra no grupo de países em desenvolvimento responsáveis pela produção de aproximadamente $6 \%$ da pesquisa em saúde em âmbito mundial.

Em 2006, o país alcançou o $15^{\circ}$ lugar dentre os países do mundo no que se refere a publicações científicas em periódicos indexados (44). Atualmente, o país já ocupa o $13^{\circ}$ lugar na produção de artigos indexados pelo Thonson Institute. O censo do ano de 2006 de grupos de pesquisa realizado pelo Conselho Nacional de Desenvolvimento Científico e Tecnológico $(\mathrm{CNPq})$ registra 6.825 grupos de pesquisa em saúde humana, esse número corresponde a $32,46 \%$ da totalidade de grupos de pesquisa existente no país que produzem 14.276 artigos em periódicos nacionais por ano e $11.910 \mathrm{em}$ periódicos internacionais (48).

Além do número de grupos de pesquisa e a sua respectiva produção, outro ponto que também chama atenção nesse cenário é a distribuição regional dos grupos de 
pesquisa. A maior parte dos grupos de pesquisa em saúde do país localizam-se nas instituições das regiões Sudeste e Sul, as mais desenvolvidas do país, consequentemente, com maior poder de captação de recursos para realização de estudos (48).

Nas últimas décadas, a comunidade científica e as instituições científicas que estavam firmemente unidas por valores, práticas e formas de organização, passaram a interagir e se integrar cada vez mais com outros setores da sociedade, desencadeando um processo de participação social na definição de agendas e na avaliação das atividades de investigação. Ou seja, a integração entre necessidades sociais e a pesquisa começam a ditar um novo no modo de produção do conhecimento (49).

Mesmo com os avanços acima apontados, a deficiência no processo de estabelecimento e de execução de prioridades para pesquisa na saúde ainda é um fato presente e reforça uma constatação apresentada no ano de 1999 pela Comission on Health Research for Development, que demonstrou a existência de uma dissociação entre carga de doenças das populações desfavorecidas e a concentração de investimento global em pesquisa em saúde nos problemas do mundo industrializado. Existe um desajuste, onde menos de $10 \%$ dos investimentos de recursos destinados para pesquisa e desenvolvimento em saúde são direcionados às doenças ou condições que atingem $90 \%$ da população mundial, determinando um desequilíbrio que foi batizado de déficit 10/90 - The 10/90 Gap (46).

Neste estudo destaca-se que as doenças negligenciadas são um clássico exemplo do desequilíbrio existente na pesquisa em saúde batizado de Gap, pois, no caso das doenças associadas à pobreza, vive-se a sombra da contradição. Enquanto milhares de pessoas necessitam urgentemente de medidas de intervenção para combater doenças relacionadas às suas precárias condições de vida, as pesquisas em saúde desenvolvidas, principalmente, pela indústria farmacêutica mundial voltam sua atenção para as doenças globais, sempre na intenção de produzir e comercializar para obter lucros.

Além do elevado custo econômico e social promovido por esse GAP, ele ainda é agravado pelo fato de que mesmo os $10 \%$ disponíveis não estão sendo utilizados em áreas nas quais poderiam assegurar maior impacto para o setor da saúde (41).

Tal fato é corroborado por Gadelha e colaboradores (50) quando afirmam a existência de uma dissociação entre necessidades locais de saúde dos países periféricos e os esforços empresariais de pesquisa e desenvolvimento (P\&D), acarretando a 
insuficiência, e às vezes, ausência, de pesquisa voltada para as doenças negligenciadas, tais como: tuberculose, Chagas, leishmaniose e outras.

Face ao exposto, verifica-se que na maioria das vezes as prioridades estabelecidas para a pesquisa em saúde são detectadas pelas necessidades do mercado e não pela demanda e necessidades existentes na realidade social (51).

O volume de conhecimento científico básico, que trata da biologia, imunologia e genética dos parasitas causadores das doenças negligenciadas apresentaram um enorme progresso nos últimos anos. Porém, possíveis intervenções provenientes da pesquisa e desenvolvimento (P\&D) para essas doenças, muitas vezes, foram colocadas em segundo plano, impedindo que indivíduos e grupos populacionais negligenciados tivessem acesso a medidas terapêuticas seguras (52).

Apesar do grande impacto causado nas condições de morbimortalidade das populações dos países periféricos, observa-se que menos de $5 \%$ do financiamento mundial destinado a pesquisa em saúde é investido com foco nas doenças infecciosas relacionadas à pobreza (53).

Malária, dengue, tuberculose, leishmaniose, hanseníase e doença de Chagas são exemplos de doenças infecciosas que apresentam poucos atrativos econômicos para o desenvolvimento de medidas terapêuticas, principalmente, por atingir as populações pobres dos países periféricos. Ou seja, o baixo interesse econômico despertado pelas doenças negligenciadas para produção de novos tratamentos apresenta uma forte relação com o público ao qual se destina (54).

Os recursos para a pesquisa em saúde tornam-se escassos, principalmente, quando são destinados para as pesquisas relacionadas com as doenças da pobreza. Nestes casos, o que se verifica é que menos de $10 \%$ dos gastos mundiais em pesquisa em saúde é destinado para uma finalidade que corresponde a $90 \%$ da carga global de doenças. Nesse sentido, os benefícios que estudos dessa natureza podem proporcionar exige que a aplicação dos investimentos seja baseada em um processo racional de definição de prioridades (55).

Em muitos países a pesquisa não considera as prioridades e objetivos do sistema de saúde. Uma abordagem sistêmica que envolva todos os atores partícipes do processo de produção do conhecimento deve ser adotada na promoção de um alinhamento das pesquisas com os objetivos e prioridades sanitárias nacionais (39).

De acordo com a organização internacional humanitária Médicos Sem Fronteiras (MSF) (56) há a necessidade de se institucionalizar mecanismos que levem os 
produtores a desenvolver pesquisas para o tratamento de doenças próprias da realidade sanitária dos países pobres, ou seja, para as doenças negligenciadas. Para que haja tal atitude, torna-se imprescindível a intervenção do Estado no fomento e na gestão da produção do conhecimento de novas medidas terapêuticas eficazes e seguros para as doenças que atingem ou ameaçam milhões de pessoas nos países em desenvolvimento (56).

Mesmo diante das adversidades até aqui apresentadas pelo autor da tese para a produção do conhecimento destinada às doenças negligenciadas, atualmente, observa-se que várias iniciativas despontam no cenário internacional e nacional da pesquisa, demonstrando, portanto, que possibilidades um tanto quanto otimistas já fazem parte da trajetória dessa temática.

Em 2007, o Instituto George para a Saúde Internacional com apoio da Fundação Bill \& Melinda Gates investiu US\$ 2,56 bilhões em pesquisas para as doenças negligenciadas. Do total de investimentos, $34 \%$ foram destinados para malária e tuberculose, e aproximadamente $5 \%$ foram destinados para pesquisas em doenças do sono, leishmaniose visceral e doença de Chagas, que juntas afetam mais de 500 milhões de pessoas (57).

No caso do Brasil, a implementação da Política Nacional de Ciência, Tecnologia e Inovação em Saúde (PNCTIS) ${ }^{4}$ e a construção da Agenda Nacional de Prioridades de Pesquisa em Saúde (ANPPS) ${ }^{5}$ promoveram uma orientação dos investimentos do Ministério da Saúde para áreas consideradas prioritárias para a pesquisa em saúde, determinadas a partir de um processo de construção coletiva que contou com a participação de diversos atores sociais (comunidade científica, tomadores de decisão dos setores da saúde, educação e ciência e tecnologia, usuários do sistema e profissionais de saúde) para assegurar a coerência entre necessidades sanitárias nacionais e prioridades de pesquisa (58).

A escassez dos recursos destinados à pesquisa tem tornado árduo o processo de definições de prioridades de pesquisa. No caso da pesquisa em saúde ${ }^{6}$, a tarefa ainda se

\footnotetext{
${ }^{4}$ PNCTIS: política pública de ciência, tecnologia e inovação em saúde destinada a orientar ações de fomento nesse campo, aprovada durante a II Conferência Nacional de Ciência, Tecnologia e Inovação em Saúde no ano de 2004.

${ }^{5}$ ANPPS: aprovada na $2^{\text {a }}$ Conferência Nacional de Ciência, Tecnologia e Inovação em Saúde. Tem como pressupostos respeitar as necessidades nacionais e locais de saúde e aumentar a indução seletiva para produção de conhecimento e bens materiais e processuais nas áreas prioritárias para o desenvolvimento de políticas sociais.

${ }^{6}$ Definida pela PNCTIS como conjunto de conhecimentos, tecnologias e inovações produzidos que resultam em melhoria da saúde da população. Assim, a pesquisa em saúde deve superar a perspectiva
} 
mostra mais complexa, pois, tem que ser estabelecida a partir de critérios racionais e transparentes para compatibilizar os interesses e visões de mundo dos diferentes atores envolvidos no processo. De acordo com o documento Processo de definição de prioridades de pesquisa em saúde: a experiência brasileira (59) "estabelecer prioridades é tão importante quanto desenvolver pesquisas".

No país, o processo de definição de prioridades de pesquisa em saúde pode ser identificado por três momentos distintos. O primeiro momento inicia-se em 2003, a partir da definição da área de C\&T como prioridade política na agenda do Ministério da Saúde, institucionalizando-se e obtendo o status no organograma a partir da Secretaria de Ciência, Tecnologia e Insumos Estratégicos (SCTIE), com a consequente expansão do seu orçamento, desenhando a partir daí um novo projeto para a produção do conhecimento em saúde no cenário nacional.

O segundo momento correspondeu ao período de 2004 e 2005, período no qual se buscou melhorar o processo de definição de prioridades de pesquisa, por meio da escuta dos atores envolvidos no processo, no caso, gestores e pesquisadores da área da saúde.

O terceiro momento foi iniciado no ano de 2005, caracterizando-se pela implementação de prioridades de pesquisa em saúde. O processo de exploração do conteúdo documental permitiu que o autor deste estudo verificasse que os momentos até aqui apresentados subsidiaram o processo de fortalecimento das ações nacionais de fomento à pesquisa em saúde, principalmente quando se trata da instituição de uma política e de uma agenda específica para área, tornando-se o primeiro exercício de definição de prioridades de pesquisa em saúde realizado no país.

Os cenários acima descritos propiciaram a formulação da Política Nacional de Ciência, Tecnologia e Inovação em Saúde (PNCTIS) e a Agenda Nacional de Prioridades de Pesquisa em Saúde (ANPPS), aprovadas na $2^{\text {a }}$ Conferência Nacional em Ciência, Tecnologia e Inovação em Saúde (59).

A primeira (PNCTIS) traz no seu conteúdo princípios e diretrizes que ordenam a sua atuação, dentre os princípios, temos os seguintes: respeito à vida e à dignidade das pessoas, superação das formas de desigualdade e discriminação, melhoria da saúde da população, busca da equidade em saúde e a participação social.

disciplinar e tomar um rumo para uma perspectiva setorial, que incluirá a totalidade das atividades de pesquisa clínica, biomédica e de saúde coletiva vinculadas às ciências da saúde, assim como as realizadas nas áreas das ciências humanas, sociais aplicadas, exatas e da terra, agrárias e engenharias e das ciências biológicas que mantenham vinculação. 
Em relação às diretrizes que orientam a PNCTIS destacam-se: o desenvolvimento da capacidade de intervir na cadeia de conhecimento, da pesquisa com aplicação imediata até a pesquisa orientada ao desenvolvimento tecnológico e inovação; a convocação à participação dos produtores, agências de financiamento e usuários da produção técnico-científica; orientação do fomento de acordo com as prioridades e a consideração da relevância social e econômica relacionada com o avanço do conhecimento ou da aplicação dos resultados à solução de problemas prioritários em saúde.

No caso da ANPPS, trata-se de um instrumento que engloba diferentes campos disciplinares em diversos níveis hierárquicos, configurando-se em 24 subagendas. Foi construído e implementado por meio de um processo político que contou com a participação de diferentes atores com as suas peculiaridades e olhares em relação à construção do processo de produção do conhecimento em saúde.

De acordo com as informações contidas no Relatório de Gestão DECIT/SCTIE/MS 2006 e no documento Processo de definição de prioridades de pesquisa em saúde: a experiência brasileira constatou-se que o debate envolvendo os diversos atores sociais em torno da agenda foi à ação mais importante na legitimação desse instrumento junto a PNCTIS (59).

Outro ponto que merece destaque é o caráter dinâmico que ANPPS apresenta. Por se tratar de um instrumento vivo de direcionamento, ele se propõe periodicamente a ser atualizado, frente às mudanças sanitárias vigentes no país, proporcionando o aumento da indução seletiva para a produção do conhecimento e bens materiais e processuais nas áreas prioritárias das políticas sociais do país $(58,59)$.

Ainda em relação à ANPPS, cabe esclarecer que o seu processo de construção foi composto pelas seguintes etapas: caracterização da situação de saúde e condições de vida da população; definição das subagendas em pesquisa; definição de linhas prioritárias de pesquisa; consulta pública; por fim, submissão à plenária da $2^{\mathrm{a}}$ Conferência Nacional de Ciência, Tecnologia e Inovação em Saúde para aprovação.

Composta por temas prioritários e relevantes às condições de saúde da população, a ANPPS tem pautado suas ações tanto para contribuir com a melhoria da equidade em saúde como para diminuir as desigualdades regionais e sociais. Além disto, as constatações advindas do cenário mundial internacional expresso pelo relatório publicado pela Commission on Health Researchand Development, em 1990, apontou a necessidade de se incluir temas como das doenças negligenciadas no centro das 
discussões das prioridades da pesquisa em saúde do país. Nesse sentido, reiterando a importância do tema, o Ministério da Saúde inseriu nas suas prioridades e passou a implementar as pesquisas relativas à área (59).

Dito isso, desde 2003, o Ministério da Saúde (MS) tem orientado grande parte dos seus recursos a linhas de pesquisa relacionadas às doenças negligenciadas. Inicialmente, foi lançado um edital temático para tuberculose (2003), seguido pelos editais de dengue (2004) e hanseníase (2005) (60). De 2003 a 2009, o MS investiu uma expressiva quantia em centenas de projetos nesta área, levando o país ao topo da lista de países que financiam pesquisas para essa finalidade (61).

A partir do processo que foi iniciado no ano de 2003 com o lançamento dos editais anteriormente citados, nos anos de 2006 e 2008 foram realizadas Oficinas para o estabelecimento de Prioridades em doenças negligenciadas (62). Essas oficinas contaram com a participação de gestores, pesquisadores e profissionais da área de saúde que a partir de dados epidemiológicos, demográficos e o impacto da doença, definiram as doenças negligenciadas que seriam prioritárias (63).

Assim, o cenário nacional da produção do conhecimento para as doenças negligenciadas passou a ganhar reforços e se tornou aquecido $(64,65)$. A preocupação e as discussões sobre a necessidade de direcionamento das pesquisas para os principais problemas sanitários do país, verificadas desde a década de oitenta (66), continua até os dias atuais como um ponto nevrálgico constante nas agendas de discussão da comunidade científica do país, no entanto, ações consequentes dessas discussões tornaram-se concretas e promoveram avanços nunca antes vistos no cenário da pesquisa em saúde do país somente a partir da primeira década de 2000.

Diante de tais fatos, uma nova etapa começou a despontar no cenário da ciência da saúde no Brasil, contudo, as autoridades sanitárias devem ficar atentas para que esse conhecimento gerado e as intervenções sanitárias resultantes desse direcionamento sejam efetivamente incorporados em políticas e ações de saúde pública (15). 


\subsection{O DIÁlOGO DO TEMA DAS DOENÇAS NEGLIGENCIADAS COM A BIOÉTICA}

Ao longo da sua trajetória, o modo de pensar e de agir da bioética vem sendo revisto e conceitos que há muito tinham sido deixados de lado voltaram a ser revisitados e incorporados como protagonistas do discurso desta disciplina que na sua essência prima pela sobrevivência da espécie humana.

Nesse sentido, há cerca de mais de 30 anos, o médico estadunidense Van Rensselaer Potter ao criar o neologismo bioética, definiu com uma área científica dedicada a busca do conhecimento e da sabedoria. Segundo ele, a sabedoria representaria o conhecimento necessário para administração do próprio conhecimento com o objetivo de se obter o bem social (67).

Da sua concepção, que compreendia a bioética como uma ponte para o futuro de aperfeiçoamento e garantia de qualidade de vida, transformando-a numa disciplina capaz de acompanhar o desenvolvimento científico, com uma vigilância ética isenta de interesses morais e a necessidade de oferecer uma contínua democratização do conhecimento científico (67), até o momento atual, a bioética enquanto pensamento filosófico busca se tornar um ente agregador materializado por meio de um diálogo contextualizado e plural que se volta para mediação de conflitos de natureza ética que na sua maioria afetam a porção excluída ou vulnerável da sociedade (68).

Com mais de 30 anos de existência, a bioética foi o campo da ética aplicada que mais apresentou progressos nas últimas décadas. A análise da sua trajetória demonstrou que três referenciais básicos passaram a sustentar seu estatuto epistemológico (8):

1) Uma estrutura com um olhar pautado obrigatoriamente na multi-intertransdisciplinaridade entre variados núcleos de conhecimento e diferentes perspectivas das questões observadas, a partir da interpretação da complexidade:

a) do conhecimento científico e tecnológico;

b) do conhecimento socialmente acumulado;

c) da própria realidade concreta em questão e da qual fazemos parte;

2) Respeito ao pluralismo moral constatado nas democracias secularizadas pósmodernas, norteadas pela busca do equilíbrio e observação dos referencias sociais 
específicos que norteiam pessoas, sociedades e nações no sentido da tolerância, sem imposições de padrões morais de umas sobre as outras;

3) A compreensão da impossibilidade de existência de paradigmas bioéticos universais, que leva à construção de um novo discurso bioético sustentado basicamente pelo diálogo, coerência e argumentação.

A partir desse novo modo de pensar a bioética é que questões que há muito se perpetuam na história da humanidade passaram a ocupar um espaço de destaque na agenda proposta para a disciplina no Século XXI. Nesse sentido, Berlinguer (7) adotou o termo bioética cotidiana para as questões que "acontecem diariamente, mas não deveriam estar mais acontecendo", a exemplo da pobreza, da exclusão social e das doenças negligenciadas. No Brasil, Garrafa (8) denominou o termo anteriormente descrito por bioética das situações persistentes.

As palavras de Berlinguer e Garrafa $(7,8)$ reforçaram a verdadeira necessidade de se pensar uma bioética que pudesse defender os determinantes sociais básicos e, portanto, persistentes e críticos sobre a vida humana, tanto nos indivíduos quanto nas coletividades.

O encontro da bioética com o coletivo, com o social, ocorreu na década de 90, tendo como protagonistas autores brasileiros e da América Latina que foram em busca de uma bioética que tratasse de questões de desigualdades sociais e equidade, justiça social, responsabilidade individual e coletiva sobre os cuidados em saúde, alocação e priorização de recursos escassos, pobreza, racismo, saúde pública e políticas sociais e sanitárias (51).

Vale destacar que a bioética enquanto nova forma de valorização da vida deve estabelecer uma forte relação com as questões sociais que impactam diretamente nas condições de saúde das populações dos países periféricos. Ela não pode ficar limitada a questões estritamente biomédicas. Questões de justiça, solidariedade, humanidade e equidade devem ser protagonistas das análises dos conflitos bioéticos, pois, por meio destes, melhores condições de vida, bem estar e direito a uma vida digna podem se tornar uma realidade (69).

Esse breve introdutório sobre a bioética e a sua vinculação com as questões de relevância social que persistem no histórico das populações, apontou a lógica adotada neste estudo para promover o diálogo entre as doenças negligenciadas e a bioética, mesmo diante das especificidades de cada área do conhecimento. Na visão do autor, três 
fatos foram fundamentais e atuaram como elementos-chave no estabelecimento do diálogo entre os dois temas.

O primeiro fato é a situação de persistência que as doenças negligenciadas ocupam dentro de um quadro de saúde, não mais restrita a uma situação local e sim global (19), como já mencionado anteriormente.

O segundo fato é que a bioética e as doenças negligenciadas, mesmo nas suas especificidades, trilham caminhos que convergem em alguns pontos. Observam-se nos seus históricos, questões associadas à determinação social e aos contextos da saúde, tornando-as assim, áreas do conhecimento de caráter transdisciplinar, complexas e que precisam ser analisadas em sua totalidade (70).

A partir do pensamento de Sotolongo (71), o autor deste estudo verificou que tanto a temática da bioética, quanto das doenças negligenciadas têm que lidar em suas reflexões teóricas e nas suas práticas com circunstâncias, situações e fenômenos referentes à vida e a sua sustentabilidade que emanam das interações entre os seres humanos, sobretudo as interações sociais. Algumas dessas interações têm incidência sobre as outras e fazem com que ocorram circunstâncias ou fenômenos inesperados, surpreendentes e paradoxais, para quais nem sempre há uma solução prevista ou pensada, configurando assim, o caráter complexo das duas áreas temáticas.

Pode-se dizer que são transdisciplinares por se tratarem de áreas do saber que superam as fronteiras que delimitam as disciplinas envolvidas no estudo dos seus objetos, nos diálogos que conduzem aos novos conhecimentos, ao enriquecimento recíproco de todos os agentes, em que o todo é maior que as partes (72). A transdiciplinaridade promove a superação das barreiras que demarcam as fronteiras das diversas disciplinas, ao promover o contínuo exercício de troca que se traduz em distinguir e não separar; associar e interligar e não reduzir ou isolar; complexificar e não simplificar (73).

As duas áreas são complexas, pois tratam de temas que envolvem uma causalidade sensível ao contexto e ao entorno dos componentes, sejam eles os componentes naturais, sociais e humanos. Ou seja, trata-se de uma causalidade que é sensível tanto ao que está acontecendo agora como também à história ou ao passado desses componentes (74).

Vale destacar que a complexidade permite distinguir as qualidades emergentes da interação entre as partes e as suas relações como o todo, projetando-se para além do clássico modelo determinista, ao captar desse ponto em diante a noção de desordem, 
imprevisibilidade, erro e caos como fomentadores da evolução e das mudanças (74). Para Morin (75), enfrentar a complexidade do real significa confrontar-se com os paradoxos da ordem/desordem, da parte/todo, do singular/geral; incorporar o acaso e o particular como componentes de análise científica, integrando a natureza singular e evolutiva do mundo à sua natureza acidental e factual.

O terceiro e último fato fundamental e determinante para o diálogo estabelecido neste tópico é que, diante da complexidade e da transdiciplinaridade que permeia as duas áreas, a bioética tem adotado uma postura mais crítica e politizada para questões éticas que envolvam os determinantes sociais da saúde e contextos sociais que em sua grande maioria apresentam-se constituídos por populações excluídas com um alto grau de vulnerabilidade social, como é o caso dos contextos que circundam as doenças e os doentes negligenciados.

Vale destacar que todos os elementos conceituais anteriormente apresentados, de acordo com Garrafa (74), quando utilizados com critérios adequados, podem contribuir para a construção de um pensamento bioético novo, amplo e comprometido com as questões éticas persistentes constatadas, em sua grande maioria, na realidade dos países periféricos.

Face ao exposto, pode-se dizer que no atual estágio que se encontra a humanidade, a tolerância para as consequências provenientes do legado das doenças negligenciadas tem se tornado algo inaceitável. O paradoxo é explícito. Convive-se com o tratamento de doenças até então incuráveis, com o avanço da engenharia genética, mas logo ali ao lado temos indivíduos que vivem em condições sub-humanas com total predisposição de serem acometidos por doenças que deveriam desfrutar apenas da condição de inexistência ou de controle por parte das autoridades sanitárias.

Diante dos fatos até aqui apresentados, verifica-se que o conflito bioético que circunda e adentra no tema das doenças negligenciadas está posto e clama por reversão da sua condição. Tal afirmação corrobora com o fato de que, por se tratar da ética aplicada que se volta às questões atinentes da vida, a bioética pode e deve ser utilizada como instrumento de mediação com poder de impulsionar o processo de reversão da condição que se coloca no histórico de muitas doenças transmissíveis, relacionadas diretamente com as condições de vida presentes principalmente nas populações dos países periféricos.

Para o autor deste estudo, o diálogo do tema das doenças negligenciadas com a bioética se fundamenta tanto pelos referenciais da bioética, que estão dispostos a 
desnudar os verdadeiros problemas de iniquidades que persistem no mundo contemporâneo, quanto por aqueles que se propõem a efetivar a saúde como um direito fundamental do ser humano, pondo em prática a definição proposta no artigo 14 da Declaração Universal sobre Bioética e Direitos Humanos da UNESCO (2).

De acordo com o referido artigo, além de definir que a promoção da saúde e do desenvolvimento social deve ser objeto central de qualquer governo democrático, considera que usufruir o mais alto padrão de saúde é um dos direitos fundamentais do ser humano e que para isso o acesso a cuidados de saúde de qualidade e a medicamentos essenciais deve ser garantido para todas as pessoas, incluindo especialmente aqueles para a saúde de mulheres e crianças, uma vez que a saúde é essencial à vida em si e deve ser considerada como bem social humano (2).

Como já foi demonstrado anteriormente pelo autor do presente estudo, o lócus de preferência das doenças negligenciadas são os contextos que foram deixados para trás pelo progresso socioeconômico, e, consequentemente, vivem à margem do desenvolvimento científico e tecnológico alcançado pela humanidade nos últimos anos. Observa-se que a relação estabelecida entre miséria e doenças negligenciadas tem agravado ainda mais o quadro de pobreza de várias populações ao redor do planeta. $\mathrm{Ou}$ seja, pode-se considerar a pobreza, simultaneamente, como ponto de partida e resultado final das doenças negligenciadas (22).

Para Pogge (76) e Luna (77) a pobreza deve ser considerada como uma espécie de violação dos direitos humanos, principalmente quando ela é causada pelos outros. No caso, os outros correspondem a muitos dos países ricos ou centrais em sua atuação perversa sobre os países pobres ou periféricos.

O denominador comum do indivíduo pobre e excluído é o desamparo, uma situação vital em que se necessita de proteção e, ainda por cima, dos elementos para obtê-la, de modo que se evite que a pobreza e a exclusão se tornem crônicas ou transformem-se em agravamento progressivo, o que tende a ocorrer quando não existe ajuda externa. A sinergia negativa entre pobreza e doença requer uma proteção que deve estar disponível e acessível como função protetora do Estado, estabelecendo-se como um direito moral que se estende mais além, de acordo com doutrina política vigente (13).

Nesta tese, o conflito bioético atrelado à temática das doenças negligenciadas, além de relevante, torna-se um fato concreto diante da sua magnitude. Tal fato é confirmado quando se constata que as doenças negligenciadas, além de acometer $80 \%$ 
da população dos países periféricos, também ocasionam milhões de óbitos por ano. Estima-se que para o enfretamento deste mal que se perpetua na história da humanidade faz-se necessário à existência de um arsenal terapêutico que corresponda a $20 \%$ da produção do mercado farmacêutico mundial (78).

No entanto, o que se verifica quando se trata de ações voltadas para o enfrentamento das doenças negligenciadas pela indústria farmacêutica mundial, é que esta, na maioria das vezes, destina grande parte do seu arsenal terapêutico para as necessidades do mercado, deixando em segundo plano as necessidades dos milhares de excluídos acometidos ou potencialmente acometidos por doenças presentes exclusivamente na realidade sanitária dos países periféricos (79).

Em um estudo sobre a realização de pesquisas voltadas para as doenças negligenciadas, que foi realizado envolvendo as principais indústrias farmacêuticas mundiais, observou-se que apenas $1 \%$ do orçamento anual de algumas dessas empresas são voltados para estudos que contemplam essas doenças (80).

Corroborando com a situação anteriormente descrita, dos milhares de medicamentos novos lançados nos últimos 25 anos, verifica-se que um percentual muito baixo (menos de 1\%) foi destinado para as doenças relacionadas à pobreza (78). Ou seja, os dados apontados demonstram e confirmam que as doenças negligenciadas não representam um mercado atraente para a indústria farmacêutica, principalmente pelo público alvo que, na maioria das vezes, não dispõe de recursos para ter acesso a tais medicamentos (81).

Cabe destacar que no período compreendido entre os anos 1975 e 2004 foram desenvolvidos um total de 1556 novos medicamentos e, desses, apenas 21 foram desenvolvidos para as doenças negligenciadas (82). Além disso, entre os anos de $2000 \mathrm{e}$ 2005, nenhuma das vinte empresas farmacêuticas com maior faturamento bruto mundial lançou no mercado um único medicamento destinado ao tratamento de doenças relacionadas à pobreza que acometem em maior escala as populações dos países periféricos (83).

Tal fato é confirmado quando Franco-Paredes e Santos-Apreciado (22) afirmam que vários indivíduos que se apresentam socialmente excluídos e que se encontram a viver uma vida com poucas opções e poucas oportunidades para evitar seu adoecimento, não recebem tratamento para evitar a incapacidade e as mortes prematuras associadas às doenças relacionadas com a pobreza. Portanto, baseado nessas necessidades, o Estado enquanto um agente promotor do bem estar social juntamente com a sociedade 
organizada deve intervir na tentativa de eliminar ou reduzir ao mínimo possível diferenças que apesar de desnecessárias, evitáveis e injustas (84), são explícitas no histórico das populações pobres e marginalizadas.

Schramm (85) também confirma tal fato quando demonstra que existe, evidentemente, condições mais específicas da assim chamada parte periférica do mundo, como a pobreza extrema, que podem tornar as pessoas reféns e vítimas de liberdades necessárias para realizar seus projetos de vida, ou seja, condições que as privam da competência para ter uma vida objetiva e subjetivamente digna. Pode-se dizer que esses indivíduos e populações podem ser considerados afetados, vulnerados (86) e excluídos do processo de globalização em curso, pois, enquadram-se nas características básicas daqueles que são e estão predispostos a desenvolver algum tipo de doença negligenciada.

Desta forma, o autor do presente estudo reforça que a bioética pode ser pensada como uma práxis capaz de explicitar e debater conflitos morais na intenção de proteger indivíduos e coletividades contra ameaças que podem prejudicar de maneira irreversível suas existências, inclusive, recomendando estratégias para o enfrentamento das iniquidades.

Além disso, por meio do seu discurso a bioética deve reforçar que a assistência à saúde não pode ser comparada a uma mercadoria que pode ser comprada e vendida de maneira inadvertida (87), pois, na medida em que tais fatos tendem a acontecer, eles levam à exclusão, ao distanciamento e ao isolamento daqueles grupos populacionais que não tiveram acesso aos benefícios proporcionados pelo desenvolvimento (88).

De acordo com Farmer e Campos (89), os avanços da ciência no campo da saúde ocorrem de maneira desigual, de acordo com cada contexto social, fazendo com que os frutos deste avanço não estejam disponíveis para muitos dos que mais precisam. Ainda de acordo com estes autores, o direito à saúde e à participação nos avanços científicos são explicitamente díspares quando se observa os países centrais e os periféricos.

Na visão de Garrafa (90) é indispensável que uma nova bioética, mais dinâmica e mais politizada, construa e coloque à disposição das localidades mais necessitadas de bens e consumo mínimos para a sobrevivência humana um conjunto de ferramentas concretas da teoria e do método científico que possibilitem a obtenção da devida dignidade que por muitas vezes a muitos foi negada. Nesse sentido, o acesso universalizado à saúde torna-se uma pauta na nova agenda bioética do século XXI, visto 
como direito, cidadania, sendo responsabilidade dos Estados proverem o mínimo necessário para que as pessoas vivam com dignidade (90).

Aos olhos do mundo as doenças negligenciadas continuam imprimindo a sua marca e fazendo cada vez mais vítimas por meio da desfiguração, do estigma, da incapacidade e da mortalidade prematura (22). Os grupos mais suscetíveis tanto na frequência como na magnitude das lesões são invariavelmente os grupos sociais em desvantagens socioeconômicas (91).

Basta observar que em virtude de doenças como a oncocercose e o tracoma indivíduos desenvolvem cegueira; que a lepra e a filariose linfática tornam indivíduos deformados e limitados na sua produtividade e em suas vidas sociais; deformidades e amputações ainda acontecem para evitar a morte de indivíduos acometidos por úlcera de Buruli; tripanossomíase humana africana (doença do sono) debilita gravemente antes de provocar a morte; a hidrofobia que provoca encefalite aguda e é sempre fatal; a leishmaniose deixa cicatrizes profundas e permanentes ou destrói totalmente as membranas mucosas do nariz, da boca e da garganta e, em sua forma mais grave, ataca os órgãos internos, fazendo com que, se não for tratada, ocorra rapidamente à morte; a doença de Chagas pode levar adultos jovens a desenvolver problemas cardíacos, ocupando leitos de hospital ao invés de postos no mercado de trabalho; a esquistossomose severa funciona como um empecilho para a frequência à escola, além de contribuir para a desnutrição e prejudicar o desenvolvimento cognitivo das crianças (1).

Assim, o corpo enquanto um espelho para o flagelo das doenças negligenciadas deve ser reconhecido como parâmetro de intervenção ética que não se limita a dimensão fisiológica. Nele identifica-se e incorpora-se a dimensão social, a articulação das dimensões físicas e psíquicas que se manifestam de maneira integrada nas relações sociais e nas relações como o meio. Ao considerar o corpo físico como a estrutura de suporte da vida social, pois sem ele a vida social não se concretiza, o conceito de corporeidade e a consequente manutenção da existência concreta das pessoas, passam a ser um marco de intervenção ética (92).

Inúmeras marcas que se apresentam nos corpos e nas vidas dos indivíduos, tornam-se claros exemplos de quanto determinados indivíduos e coletividades estão subjugados a uma condição de negligência. Outro fato que salta aos olhos e deve ser levado ao debate é a impossibilidade da dissociação da doença na sua dimensão biológica com a dimensão social que a cerca, pois na maioria dos casos ocorrem de 
maneira concomitante. Para Porto e Garrafa (93) os atores sociais produzem e reproduzem a dinâmica da sociedade nos seus corpos e suas vidas, reforçando assim a ideia trazida anteriormente nesta tese.

Uma ampla abordagem da doença deve-se fazer presente, pois, a partir desta, a compreensão do ser humano como simultaneamente biológico, social, cultural e simbólico torna-se mais concreta. As condições de vida de indivíduos e da coletividade determinam as suas condições de saúde, que por sua vez devem ser estudadas numa perspectiva ampla, levando em consideração não só os elementos biológicos, mas também elementos sociais, culturais e simbólicos $(94,95)$.

Nesse sentido, o autor deste estudo considera que a bioética enquanto área do conhecimento transdisciplinar, complexa, vinculada às questões atinentes à vida, a saúde e ao meio ambiente tem a capacidade de proporcionar maior clareza e a transparência dos pressupostos que movem os saberes e as práticas em saúde. Ou seja, por meio da sua mediação, do seu debate ético, almeja-se a possibilidade da promoção da ética do conhecimento que, no caso das doenças negligenciadas, torna-se uma peçachave para reversão da sua condição.

$\mathrm{Na}$ atualidade, ao se discutir transplantes, implantes e projeto genoma, que prolongam a vida, é necessário atentar que também persiste a necessidade de encontrar solução para doenças relacionadas à pobreza como no caso da malária, da dengue, da hanseníase e de tantas outras que ainda ceifam vidas precocemente em grande parte do mundo e se mantêm epidêmicas para as pessoas mais vulneráveis e para os povos mais pobres (96).

Para isso, a bioética deve estimular o diálogo com esses problemas a partir de princípios como os da justiça, da equidade e da solidariedade, haja vista a necessidade da sensibilização com o sofrimento alheio para que se possam compartilhar recursos de maneira legítima enfatizando a necessidade de proporcionar condições com menores iniquidades, promovendo assim o acesso a bens e serviços, sem os quais é impossível vislumbrar um futuro mais justo (96). É compreendendo criticamente a realidade que se pode interpretar o passado e projetar um futuro digno para todos (70). 


\section{OBJETIVOS}

\section{OBJETIVO GERAL}

Analisar quantitativamente e qualitativamente a produção do conhecimento em doenças negligenciadas no Brasil, sob a perspectiva da bioética, considerando os dispositivos normativos relativos ao tema e a atuação dos pesquisadores da área.

\section{OBJETIVOS ESPECÍFICOS}

1. Promover o diálogo do tema das doenças negligenciadas com a bioética;

2. Conhecer a produção do conhecimento em doenças negligenciadas decorrente dos dispositivos normativos dos anos 2006 e 2008;

3. Analisar o perfil dos pesquisadores contemplados pelos dispositivos normativos no período selecionado, considerando: sexo, formação, tipo e natureza da instituição as quais estão vinculados e região do país de localização das suas instituições;

4. Investigar a atuação desses pesquisadores. 


\section{MÉTODOS}

\subsection{NATUREZA DO ESTUDO}

Trata-se de um estudo com abordagem quanti-qualitativa. Para Jick (97) pesquisas que utilizam como abordagem os métodos quantitativos e qualitativos devem observar que estes atuam de maneira complementar, e não como rivais. Minayo e Sanchez (98) reforçam que do ponto de vista metodológico, não há contradição como também não há continuidade. São de naturezas diferentes. Enquanto o primeiro atua no nível de realidade, o segundo trabalha com valores, crenças, representações, hábitos, atitudes e opiniões.

Enquanto as pesquisas quantitativas estabelecem suas práticas e seus objetivos a partir dos dados, indicadores e tendências observáveis, que utilizam do ponto de vista social, grandes aglomerados de dados, classificando-os e tornando-os evidentes por meio de variáveis (98), as pesquisas qualitativas procuram entender o processo pelo qual as pessoas constroem significados e descrevem o que são estes, tendo o significado como ideia-chave (99).

Ainda na visão do autor anteriormente mencionado (99), o trabalho qualitativo implica em entender, interpretar e compreender os sentidos e as significações que uma pessoa dá aos fenômenos em foco, através de técnicas de observação ampla e entrevistas com profundidade, em que são valorizados o contato pessoal e os elementos do setting em que se encontra o sujeito.

O foco principal da pesquisa qualitativa é, portanto, o sentido que adquire a ação da sociedade na vida e os comportamentos dos indivíduos, assim como o sentido da ação individual quando ela se traduz em ação coletiva. Por excelência, o objeto da pesquisa qualitativa é a ação interpretada, ao mesmo tempo, pelo pesquisador e pelos sujeitos da pesquisa; de onde a importância da linguagem e das conceituações que devem dar conta tanto do objeto "vivido", como do objeto "analisado" (100). 
Do ponto de vista epistemológico nenhuma das duas abordagens é mais científica do que a outra (100). Flick (101) reforça esta afirmação quando relata que nenhum dos métodos combinados é visto como superior ou preliminar. Quer os métodos sejam ou não utilizados de modo simultâneo, ou empregados um após o outro, este é um aspecto de menor relevância se comparado à noção de serem observados em igualdade quanto ao papel que desempenham junto ao estudo.

A escolha do método de pesquisa está intrinsecamente relacionada às características do fenômeno a ser estudado. Nesse sentido, a escolha da abordagem vai ao encontro dos objetivos desta investigação, que busca analisar, sob a perspectiva da bioética, a produção do conhecimento em doenças negligenciadas no país considerando os dispositivos normativos (2006 - 2008) e a atuação dos pesquisadores responsáveis por essa produção.

\subsection{DESENHO DO ESTUDO}

O desenho do presente estudo foi constituído a partir da triangulação de dados quantitativos e qualitativos. Para Bryman (102) a lógica da triangulação significa a verificação de resultados qualitativos em comparação com resultados quantitativos. Os resultados quando combinados, complementam-se, proporcionando uma análise em maior profundidade acerca de um determinado tema de estudo. Para o referido autor, a combinação dos métodos permite a visualização de aspectos estruturais e processuais sobre o objeto pesquisado.

De acordo com Creswell \& Clarck (103) existem variações de desenhos de estudo quando se trata de triangulação de dados. No caso desta tese, utilizou-se o Modelo de Triangulação dos Dados (103).

Trata-se de um modelo tradicional de triangulação dos dados que consiste na coleta e análise separada dos dados quantitativos e qualitativos sobre um mesmo fenômeno. Os resultados obtidos são analisados separadamente, mas interpretados de maneira global pelo pesquisador para obter conclusões válidas e bem fundamentadas. A 
seguir, o autor demonstra graficamente como foi realizado o estudo (Figura 1 - Modelo de Triangulação dos dados).

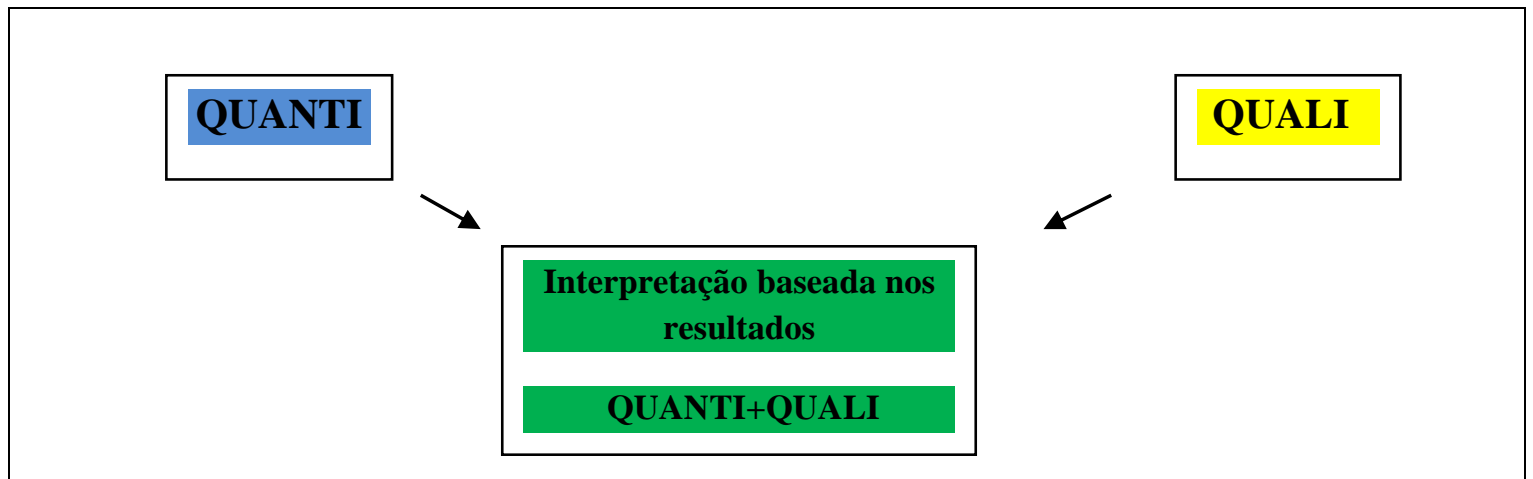

Figura 1 - Modelo de Triangulação dos Dados

Fonte: Creswell \& Clark, 2007, p.63

Vale destacar que os procedimentos metodológicos utilizados na etapa da análise documental levaram em consideração dados qualitativos e quantitativos para analisar os dispositivos normativos das pesquisas em doenças negligenciadas publicados no Brasil nos anos de 2006 e 2008, conhecer a produção do conhecimento proveniente desses dispositivos e construir o perfil dos pesquisadores responsáveis por essa produção.

$\mathrm{Na}$ etapa da análise do discurso, tais procedimentos serviram para investigar a atuação desses pesquisadores antes e depois de serem contemplados pelos referidos dispositivos normativos de apoio à pesquisa. No caso do presente estudo, utilizou-se um recorte temporal que considerou o período de 2003 a 2011. Ou seja, três anos antes e três anos depois da publicação de cada edital.

\subsection{PROCEDIMENTOS METODOLÓGICOS}

\subsubsection{Levantamento bibliográfico:}

O levantamento bibliográfico iniciou-se em janeiro de 2012 e foi finalizado em dezembro de 2014. A busca na literatura científica e técnica da área "Ciências da Saúde em Geral" da Biblioteca Virtual em Saúde (BVS), cuja captação reúne as seguintes bases: LILACS, IBECS, MEDLINE, Biblioteca Cochrane e SciELO utilizando os 
seguintes descritores: doenças negligenciadas, doenças tropicais negligenciadas, prioridades de pesquisa, pesquisa e desenvolvimento em saúde, bioética e ética em pesquisa em português, e neglected diseases, neglected tropical diseases, research priorities, health research and development, bioethics e research ethics em inglês.

\title{
4.3.2 Análise documental:
}

\author{
Documentos são artefatos padronizados na medida em que ocorrem \\ tipicamente em determinados formatos como: notas, relatórios de caso, \\ contratos, rascunhos, certidões de óbitos, diários, estatísticas, certidões, \\ sentenças, cartas ou pareceres de especialistas. (104, p.284)
}

Nesta etapa, o autor da tese utilizou a análise documental para saber como se deu a produção do conhecimento em doenças negligenciadas nos anos de 2006 e 2008, a partir dos referenciais normativos de apoio estabelecidos pelo país para a pesquisa em saúde e da atuação dos pesquisadores responsáveis pela produção do conhecimento em doenças negligenciadas.

De acordo com Triviños (105) a análise documental constitui um importante instrumento de produção das informações qualitativas; nela o pesquisador deverá orientar sua atenção não só para o conteúdo manifesto, mas tentar descobrir o seu conteúdo latente, ou seja, as características estruturais e históricas do fenômeno social estudado.

Ao optar pela análise de documentos, o pesquisador deve considerar quem produziu os documentos, com que objetivo, quem os utiliza em seu contexto natural e a forma de seleção de uma amostra de documentos individuais. $\mathrm{O}$ pesquisador deve atentar também que não se deve manter apenas o foco no conteúdo dos documentos sem levar em conta o contexto, a utilização e a função do documento (101).

De acordo com Scott (106) os documentos são constituídos por uma combinação de duas dimensões: a autoria (pessoais e oficiais) e o acesso aos documentos (privados e públicos). No caso do presente estudo foram utilizados documentos oficiais e públicos para compor o corpus de análise. 
A composição do corpus de análise desta etapa da tese se deu a partir da relação dos documentos com o processo de indução da produção do conhecimento em doenças negligenciadas no período compreendido entre os anos de 2006 e 2008, com exceção dos currículos dos pesquisadores, cuja base de dados utilizada foi a do ano de 2013.

Destaca-se que na seleção dos documentos do presente estudo foram levados em consideração os seguintes critérios propostos por Scott (106): autenticidade, credibilidade, representatividade e significação. No caso do primeiro critério, ele foi utilizado para verificar se os documentos eleitos para o estudo eram completos ou resumidos; para o segundo critério levou-se em consideração para verificar a exatidão e a confiabilidade dos documentos escolhidos, o terceiro critério foi utilizado para analisar se os documentos continham as informações que os documentos do seu tipo devem conter e, por fim, o critério da significação serviu para verificar se os documentos selecionados eram claros e compreensíveis. Abaixo, são descritos cada um dos corpus de análise utilizados nesta etapa da tese (Quadros 2; 3;4):

Quadro 2 - Corpus de análise documental relativo à visão do Estado sobre o problema das DNs

\begin{tabular}{|c|c|c|}
\hline $\begin{array}{c}\text { Ano de } \\
\text { Publicação }\end{array}$ & $\begin{array}{c}\text { Documentos relativos à visão do Estado } \\
\text { sobre o problema das DNs }\end{array}$ & Fonte \\
\hline $2006 ; 2008$ & Relatórios de Gestão & DECIT/SCTIE/MS \\
\hline 2006 & $\begin{array}{c}\text { Processo de definição de prioridades de } \\
\text { pesquisa em saúde: a experiência brasileira - } \\
\text { Relatório DECIT }\end{array}$ & DECIT/SCTIE/MS \\
\hline 2008 & $\begin{array}{l}\text { Pesquisa em Saúde no Brasil - Informe } \\
\text { Técnico Institucional MS/SCTIE/MS }\end{array}$ & $\begin{array}{c}\text { Revista de Saúde } \\
\text { Pública }\end{array}$ \\
\hline 2008 & $\begin{array}{l}\text { Oficina de Prioridades - Boletim } \\
\text { eletrônico/edição especial }\end{array}$ & MS \\
\hline $2010^{*}$ & $\begin{array}{c}\text { Doenças Negligenciadas: estratégias do } \\
\text { Ministério da Saúde - Informe Técnico } \\
\text { Institucional MS/SCTIE/MS }\end{array}$ & $\begin{array}{c}\text { Revista de Saúde } \\
\text { Pública }\end{array}$ \\
\hline
\end{tabular}

*Boletim publicado no ano de 2010 com conteúdo referente às ações ocorridas nos anos de 2006 e 2008

Fonte: elaborado pelo autor 
Quadro 3 - Corpus de análise documental para normativas de apoio à produção do conhecimento em Saúde/DNs

\begin{tabular}{|c|c|c|}
\hline $\begin{array}{c}\text { Ano de } \\
\text { Publicação }\end{array}$ & $\begin{array}{c}\text { Normativas de apoio à produção do } \\
\text { conhecimento em Saúde/DNs }\end{array}$ & Fonte \\
\hline 2006 & $\begin{array}{c}\text { Edital MCT/CNPq/MS - SCTIE - DECIT n }{ }^{\circ} \\
\text { 025/2006 - Seleção pública de propostas para } \\
\text { apoio às atividades de pesquisa direcionadas } \\
\text { ao estudo das Doenças Negligenciadas }\end{array}$ & MS/CNPq \\
\hline 2008 & $\begin{array}{r}\text { Edital MCT/CNPq/CT - } \\
\text { Seleção pública de propostas para apoio às } \\
\text { atividades de pesquisa direcionadas ao estudo } \\
\text { das Doenças Negligenciadas: dengue, doença } \\
\text { de Chagas, esquistossomose, hanseníase, } \\
\text { leishmaniose, malária e tuberculose }\end{array}$ & \\
\hline
\end{tabular}

Fonte: elaborado pelo autor

Quadro 4-Corpus de análise documental relativo aos pesquisadores

\begin{tabular}{|c|c|c|}
\hline $\begin{array}{c}\text { Ano de } \\
\text { Publicação }\end{array}$ & Documentos relativos aos pesquisadores & Fonte \\
\hline 2013 & $\begin{array}{c}\text { Currículos Lattes dos pesquisadores } \\
\text { contemplados nos editais de apoio a pesquisa } \\
\text { em DNs (2006-2008) }\end{array}$ & Plataforma Lattes \\
& \begin{tabular}{c} 
CNPq \\
\hline
\end{tabular} & \\
\hline
\end{tabular}

Fonte: elaborado pelo autor

Os dados quantitativos constituíram-se de fontes secundárias disponíveis nos bancos de dados do sítio eletrônico pesquisa em saúde (www.pesquisasaude.saude.gov.br). Nesta fase do estudo, os dados foram conferidos e lançados no programa Microsoft Excel 2010 para que se procedesse ao cálculo das frequências e dos percentuais.

Nesta etapa foi construída a caracterização dos projetos de pesquisa a partir dos projetos aprovados pelos editais públicos de apoio ao estudo das doenças negligenciadas que ocorreram nos anos de 2006 e 2008, considerando: quantidade, tipo e natureza dos 
projetos. Também foi realizada a análise do perfil dos pesquisadores responsáveis pela coordenação dos projetos, considerando: gênero, formação, tipo e natureza da instituição as quais estão vinculados e região do país de localização das instituições.

\subsubsection{Análise do Discurso:}

Na sua etimologia, a palavra discurso contém em si a ideia de percurso, de correr por, de movimento. O objeto da análise do discurso é o discurso, ou seja, ela toma por interesse o estudo da língua funcionando para a produção de sentidos. Tal fato permite que outras unidades além da fala sejam analisadas, no caso, o texto (107).

Por meio da linguagem, o homem transforma a realidade em que vive e a si mesmo. O homem constrói a existência humana, ou seja, confere-lhe sentido. E é essa capacidade do homem de atribuir, incessantemente, sentidos que promove seu constante devir, e o das coisas, que interessa à análise de discurso (108, p. 16).

A análise do discurso tem por finalidade trabalhar o conteúdo de textos, ou seja, com a materialidade linguística por meio das condições empíricas do texto, estabelecendo categorias para sua interpretação. Este tipo de análise procura compreender o pensamento do sujeito através do conteúdo expresso no texto, numa concepção transparente de palavra (109).

Tal técnica visa detectar por meio dos indicadores uma série de significações que estão associados. Ou seja, ela objetiva garantir a descoberta do verdadeiro significado, pois se propõe a trazer do esconderijo do texto os significados. Ela tem como proposta a ultrapassagem da incerteza e o enriquecimento da leitura. A análise do discurso por meio de técnicas precisas e objetivas pretende garantir a descoberta do verdadeiro significado (110).

A análise do discurso leva em conta o homem e a língua em suas concretudes, não enquanto sistemas abstratos. Ou seja, considera processos e as condições por meio dos quais se produz a linguagem. Assim sendo, insere o homem e a linguagem à sua exterioridade, à sua 
Trabalha-se com o sentido e não com o conteúdo do texto, um sentido que não é traduzido, mas produzido; afirma-se que o corpus da análise do discurso é constituído da seguinte forma: ideologia + história + linguagem (109).

Entende-se por ideologia como um sistema lógico e coerente de ideias, valores, normas e regras que indicam e prescrevem aos componentes da sociedade o que devem pensar, o que devem valorizar, o que devem sentir, o que devem fazer e como devem fazer (111).

Assim, a análise do discurso tenta compreender como a ideologia se materializa no discurso e como o discurso se materializa na língua, para entender como o sujeito, atravessado pela ideologia de seu tempo, de seu lugar social, lança mão da língua para demonstrar seus significados. Nesse sentido, pode-se dizer que todos os discursos são ideológicos e materializam-se por meio da linguagem (108).

O discurso materializa o contato entre o ideológico e o linguístico: por um lado, representa, no interior da língua, os efeitos das contradições ideológicas e, inversamente, manifesta a existência da materialidade linguística no interior ideológico (112, p. 134).

Trabalhar com análise do discurso é ter capacidade para desvendar significados escondidos por meio de técnicas seguras de trabalho. De acordo com Rocha e Deusdará (110), o pesquisador que se propõe a trabalhar com este tipo de análise tem que ter uma observação cuidadosa, pois, a significação profunda que se pretende chegar com este tipo de análise surgirá apenas depois de tal ato diante do texto a ser trabalhado. Além disso, deve ser também um exímio observador, pois, muitas vezes terá o trabalho de um “espião" para desvendar a "subversão" escondida.

Partindo-se do princípio que esse tipo de análise toma por objeto de trabalho o sentido, sendo o discurso heterogêneo marcado pela história e ideologia, a análise do discurso entende que, não necessariamente, irá desvendar nada novo, apenas fará uma nova interpretação ou uma nova leitura. Vale destacar que a análise do discurso não tem a pretensão de dizer o que é certo, porque isso não está em julgamento, ela apenas demonstra o funcionamento do discurso (109). Deve-se ficar atento, pois o sentido não é absoluto nem definitivo, mas relativo e provisório (112). 
Face ao exposto, os pressupostos da técnica de análise vão ao encontro da proposta da tese, principalmente pelo olhar da ideologia, da história e da linguagem que se quer captar de um grupo determinado a estudar um tema que se encontra enquadrado na condição de negligência por muitos.

Nesta etapa do estudo, portanto, investigou-se a atuação dos pesquisadores brasileiros contemplados pelos já referidos editais por meio dos seus artigos científicos publicados três anos antes até três anos depois da publicação de cada um dos editais de apoio à pesquisa. Portanto, para o edital publicado em 2006 a série temporal foi composta pelas publicações do período de 2003 a 2009; para o edital de 2008 o espaço temporal vai de 2005 a 2011.

É notório no meio acadêmico/científico que a métrica das instituições que fomentam as pesquisas e avaliam a produção docente tem como critério principal a produção científica baseada no número de artigos produzidos, fazendo com que grande parte da comunidade científica mantenha atualizados esses dados nos seus currículos. Apesar do autor do presente estudo reconhecer que a produção do conhecimento vai além daquela registrada pelos artigos científicos, pois também está presente nas atividades de ensino e extensão, optou-se pelo uso dos artigos científicos por se tratar de um meio fidedigno e capaz de demonstrar a atuação do grupo analisado.

Cabe esclarecer que se tentou buscar a atuação dos pesquisadores além dos artigos científicos mediante a consulta ao currículo Lattes. No entanto, verificou-se que as atividades de extensão, a produção de patentes, os relatórios técnicos e as atividades de assessorias encontravam-se registradas de maneira incipiente. Nesse sentido, pode-se questionar se este fato ocorre devido à baixa valorização dessas atividades na avaliação da produção acadêmica pelos órgãos de fomento ou mesmo pela descontinuidade do registro das informações nos currículos da Plataforma Lattes.

Dessa forma, selecionou-se o material para análise a partir dos dados contidos nos currículos alojados na Plataforma Lattes - CNPq, considerando título dos artigos, resumos e palavras-chaves. A partir do material captado foram elaborados quatro corpus, dois para a produção na língua portuguesa (2006 e 2008) e dois para a produção na língua inglesa (2006 e 2008), sendo em seguida analisados pelo software ALCESTE (Análise Lexical de Co-ocorrências em Enunciados Simples de um Texto). Os quadros 5 e 6, apresentados na página seguinte, descrevem o material utilizado em cada um dos corpus textual que serviu como referencial de análise para consecução dos resultados. 
Para compreensão da organização do discurso e interpretação dos dados, utilizou-se o software ALCESTE, criado na França por Max Reinert, em 1986. Desenvolvido e distribuído pela sociedade IMAGE. Este programa é uma ferramenta utilizada para análise lexical a fim de sintetizar e organizar as informações provenientes de dados textuais. Essa análise lexical, de forma geral, caracteriza-se por identificar as informações essenciais e quantificar, a partir da coocorrência das palavras, para extrair as estruturas significativas mais fortes do corpus textual (113).

Quadro 5-Corpus textual 2006

\begin{tabular}{|c|c|c|}
\hline Material utilizado & Fonte & Período \\
\hline $\begin{array}{c}\text { Artigos científicos publicados em } \\
\text { português, registrados nos } \\
\text { Currículos Lattes dos } \\
\text { pesquisadores contemplados }\end{array}$ & Plataforma Lattes CNPq & 2003 a 2009 \\
\hline $\begin{array}{c}\text { Artigos científicos publicados em } \\
\text { inglês, registrados nos Currículos } \\
\text { Lattes dos pesquisadores } \\
\text { contemplados }\end{array}$ & Plataforma Lattes CNPq & \\
\hline
\end{tabular}

Fonte: elaborado pelo autor

Quadro 6 - Corpus textual 2008

\begin{tabular}{|c|c|c|}
\hline Material utilizado & Fonte & Período \\
\hline $\begin{array}{c}\text { Artigos científicos publicados em } \\
\text { português registrados nos } \\
\text { Currículos Lattes dos }\end{array}$ & Plataforma Lattes CNPq & 2005 a 2011 \\
pesquisadores contemplados & & \\
\hline $\begin{array}{c}\text { Artigos científicos publicados em } \\
\text { inglês registrados nos Currículos } \\
\text { Lattes dos pesquisadores } \\
\text { contemplados }\end{array}$ & Plataforma Lattes CNPq & 2005 a 2011 \\
\hline
\end{tabular}

Fonte: elaborado pelo autor

No caso do software ALCESTE, a análise ocorreu a partir do material textual relativo a cada período, organizado em um documento de texto, o corpus, denominado 
também de Unidade de Contexto Inicial (UCI). A partir da UCI, o programa fez a primeira fragmentação e classificação do texto em Unidades de Contexto Elementar (UCE), que são segmentos de textos, com cerca de três linhas, dimensionados pelo próprio programa em função do tamanho do corpus, em geral, respeitando-se a pontuação.

Outra operação essencial realizada pelo software foi à redução das palavras a sua forma mais simples, ou seja, em radicais. Assim, foi pelas formas reduzidas (raízes dos vocábulos) que se teve capacidade de verificar a coocorrência das formas reduzidas (radicais) e agrupar as UCE com uma característica comum - selecionadas conforme a coocorrência das palavras comuns.

A partir desse cenário, com base na frequência das palavras e no cálculo do chiquadrado $\left(X^{2}\right)$ das palavras e UCE, o programa organizou o texto em classes lexicais que puderam ser apreendidas, posteriormente, configurando eixos temáticos ou categorias. Esta análise foi chamada de Classificação Hierárquica Descendente (CHD) e se apresentou por meio de gráfico, semelhante a uma árvore, conhecido como dendograma, que estabeleceu a relação entre as classes (de 0 a 1 , sendo 0 referente à "relação nula" e 1 à "relação importante/forte") e o tamanho, em percentil, de cada uma delas em comparação ao corpus total. Essas informações possibilitaram ao pesquisador o conhecimento de diversos temas abordados no interior de um texto e, assim, a compreensão das diferentes formas que os sujeitos de pesquisa concebem o objeto investigado.

De acordo com Kronberg e Wagner (113), a utilização do ALCESTE proporciona a análise de textos produzidos por diferentes indivíduos, fazendo com que os pontos de vistas que são coletivamente partilhados em determinado tempo sejam compreendidos. O pressuposto do ALCESTE é que pontos diferentes de referência produzem diferentes modos de falar, isto é, a utilização de um vocabulário específico é visto como uma fonte para constatar maneiras de pensar sobre um objeto. Portanto, o ALCESTE permite a distinção de classes de palavras que representam diferentes formas de discurso a respeito do objeto estudado. É importante mencionar que tal compreensão se dá a luz dos pressupostos teóricos e do conhecimento do pesquisador acerca do objeto estudado.

Deve-se levar em consideração que a interpretação do discurso é um gesto, ou seja, é um ato simbólico. A interpretação é o vestígio do possível. É o lugar onde se encontra a ideologia que é materializada pela história. Ela sempre ocorrerá em algum 
lugar da história e da sociedade. $\mathrm{O}$ ato de interpretar é assumido, sendo um gesto simbólico que dá sentido fazendo a significação. Não há sentido sem interpretação, portanto, deverá sempre haver uma interpretação para tornar o sentido visível por meio do discurso transmitido pelo sujeito (114).

Cabe lembrar que o analista é um intérprete, que faz também uma leitura discursiva influenciada por aquilo que lhe afeta, pela posição, suas crenças, suas experiências e vivências; portanto, a interpretação nunca será absoluta e única, pois também fará a produção dos seus sentidos (109). Além disso, toda interpretação sempre será passível de equívoco, pois embora pareça ser clara, na realidade existem várias e diferentes definições, sendo que os sentidos não são tão evidentes como parecem ser (114). Portanto, a interpretação deverá levar sempre em consideração o texto e o contexto.

\subsection{PROCESSAMENTO, ANÁLISE E APRESENTAÇÃO DOS RESULTADOS}

Após a análise quantitativa e qualitativa das informações disponíveis no banco de dados do sítio eletrônico pesquisa em saúde (www.pesquisasaude.saude.gov.br), dos documentos oficiais e públicos e das informações obtidas pela análise dos currículos Lattes, identificou-se os aspectos convergentes, divergentes e singulares, para em seguida, apresentá-los por meio de quadros, tabelas, figuras e fragmentos de falas.

Desta forma, a operacionalização da análise englobou as etapas de descrição, sistematização, comparação e interpretação dos aspectos considerados significativos em todo material coletado, promovendo a articulação do referencial teórico com os achados analíticos obtidos ao longo da pesquisa. 


\subsection{ASPECTOS ÉTICOS}

O estudo foi submetido para análise do Comitê de Ética em Pesquisa da Faculdade de Ciências da Saúde da Universidade de Brasília (CEP FS-UnB) no mês de setembro de 2012 e aprovado no mês de outubro de 2012 sob registro de aprovação número 142/12.

O autor do estudo destaca que foram observados todos os aspectos técnicos e éticos para a construção deste estudo. Assim, o estudo respeitou os princípios éticos para pesquisas que envolvem seres humanos de acordo com a Resolução 466/12 do Conselho Nacional de Saúde/CNS de 12 de dezembro de 2012. Para os pesquisadores que foram analisados pelo do estudo foi conservado o anonimato e utilizado um processo de codificação.

Os benefícios individuais e coletivos provenientes do estudo referem-se à geração de conhecimento direcionado para área da saúde. Vale destacar que após a defesa de tese, o trabalho será disponibilizado na Biblioteca da Universidade de Brasília, devendo também ser divulgado por meio de artigos científicos, os quais não farão qualquer menção aos nomes dos sujeitos analisados, mantendo-se o anonimato necessário para garantia desse tipo de estudo. Por fim, destaco que os resultados obtidos pelo presente estudo também serão compartilhados como os participantes e tomadores de decisão. 


\section{RESULTADOS}

O capítulo a seguir apresentado foi estruturado de acordo com os objetivos específicos do estudo. Para tanto, o conteúdo desenvolvido foi sistematizado a partir dos tópicos a seguir descritos. Ressalta-se que o primeiro objetivo específico proposto por este estudo encontra-se respondido tanto no terceiro tópico do seu Marco Teórico como, também, no formato de artigo. Este foi aprovado pela Revista de Bioética do Conselho Federal de Medicina e encontra-se presente no Apêndice A desta tese.

\subsection{DISPOSITIVOS NORMATIVOS DAS PESQUISAS}

O cenário que foi estabelecido no país a partir da instituição da Política Nacional de Ciência e Tecnologia e Inovação (PNCTI) e da agenda (ANPPS) fez com que diversas ações fossem promovidas no intuito de ajustar as prioridades de saúde com as prioridades de pesquisas nacionais.

A partir de tais fatos, foi programada uma chamada pública dedicada às doenças negligenciadas no ano de 2006, com intenção de contribuir com a correção do GAP 10/90 e com a redução de casos dessas doenças no país. Com o desencadeamento do processo foi realizada ainda nesse ano, a primeira oficina de prioridades em doenças negligenciadas e lançado o edital MCT/CNPq/MS - SCTIE - DECIT n 025/2006 (60).

O desenvolvimento desse processo teve por objetivo a coordenação da massa crítica dos pesquisadores que desenvolvem estudos sobre o tema e a continuidade das ações de fomento pesquisas na área das doenças negligenciadas, consideradas como "prioridade das prioridades", promovendo assim o encontro de uma prioridade sanitária com a ciência e a tecnologia (63).

No ano de 2008, nova oficina de prioridades foi realizada, tendo como produto um novo edital de apoio às atividades de pesquisa científica, tecnológica e de inovação que foi o EDITAL MCT/CNPq/CT - SAÚDE/MS/SCTIE/DECIT N 034/2008. (60). 
Inicialmente, para o edital foram selecionadas 10 doenças definidas pelo Programa Especial de Pesquisa e Treinamento em Doenças Tropicais da OMS (UNICEF/UNDP/World Bank/Who/Special Programme for Research and Training in Tropical Disease) como negligenciadas, e a partir deste grupo, selecionaram-se sete doenças como prioritárias para P\&D em saúde no país. As sete doenças selecionadas e os seus critérios de seleção para os editais foram as seguintes:

- Esquistossomose - considerada um dos grandes problemas de Saúde Pública no Brasil, atingindo principalmente as Regiões Nordeste e Sudeste;

- Leishmaniose tegumentar e visceral - no Brasil cerca de 30 mil casos de formas tegumentares e 3500 casos de calazar;

- Doença de Chagas - priorizada em função da existência de surtos em diversas regiões do país, em especial a Região Amazônica, com cerca de 100 novos casos comprovados por ano;

- Dengue - eleita pela sua relevância social e pela necessidade de evolução de conhecimento;

- Malária - priorizada por apresentar pontos deficitários nas suas ações de controle e lacunas de conhecimento sobre a doença;

- Tuberculose - devido à elevada taxa de abandono do tratamento da doença no Brasil, o que resulta em risco de ocorrência de formas resistentes da doença e de persistência da cadeia de transmissão, desencadeando grave problema de controle da doença no país;

- Hanseníase - priorizada também por apresentar necessidade de avanço no conhecimento sobre os determinantes da situação epidemiológica das doenças.

Apesar da proposta de superação das desigualdades regionais e socioeconômicas no campo da pesquisa científica contida nos editais de 2006 e 2008, verificou-se que a parcela mínima de $30 \%$ (trinta por cento) do valor global de cada edital destinada a projetos desenvolvidos por pesquisadores vinculados a instituições de pesquisa sediadas nas regiões Norte, Nordeste e Centro-Oeste, caso houvesse projetos qualificados, não ocorreu.

Observou-se que para os dois editais que foram disponibilizados ao público alvo, no caso, pesquisadores vinculados a instituições nacionais de pesquisa, com linhas de pesquisa que contemplavam estudos de natureza básica e aplicada continuaram 
concentrados sob a coordenação de profissionais e de instituições da região Sudeste do país.

Abaixo, segue tabela para demonstrar os valores investidos por editais para pesquisas em doenças negligenciadas no país no período de 2003 a 2008.

Tabela 1 - Grandes editais temáticos na área de doenças negligenciadas e recursos destinados entre os anos 2003 e 2008

\begin{tabular}{lcc}
\hline Ano & Edital & Recursos (R\$) \\
\hline 2003 & Tuberculose & 9,8 milhões \\
2004 & Dengue & 945 milhões \\
2005 & Hanseníase & 2,8 milhões \\
$\mathbf{2 0 0 6}$ & Doenças negligenciadas & $\mathbf{2 2}$ milhões \\
$\mathbf{2 0 0 8}$ & Doenças negligenciadas & $\mathbf{1 7}$ milhões \\
\hline
\end{tabular}

Fonte: Decit/MS

A exploração dos documentos permitiu ao autor do presente estudo um aprofundamento sobre o processo de construção do conteúdo dos dispositivos normativos de apoio ao combate das doenças negligenciadas, no caso, os editais de 2006 e 2008. Assim, constatou-se que cada edital foi elaborado por um grupo formado por gestores da área da saúde e pelos pesquisadores que mais produziram entre os anos de 2000 e 2006 sobre as doenças selecionadas que compuseram os editais. Vale destacar que os pesquisadores que comandaram todo o processo de discussão e elaboração dos dispositivos normativos analisados por esta tese foram, predominantemente, provenientes das instituições públicas de ensino e pesquisa localizadas na região Sudeste do país.

Face ao exposto, constatou-se que a intervenção e o protagonismo exercido pelo Estado no campo da pesquisa em saúde, com destaque para as ações comandadas pelo Ministério da Saúde, vêm ocorrendo de maneira orientada e estratégica. O esforço nacional na implementação das ações vinculadas à PNCTIS e a ANPPS, por meio de ações de incentivo a produção do conhecimento, de fato, demonstra que o país tem tomado para si a responsabilidade de prevenir, controlar e erradicar do seu mapa de saúde o flagelo provocado por determinadas doenças infecciosas que apesar do seu 
status de negligência não se encontram esquecidas para grande parte das autoridades sanitárias e da comunidade científica nacional.

\subsection{AS PESQUISAS}

Para o enfrentamento da situação de negligência que cerca determinadas doenças e doentes, o país vem promovendo ações de apoio à pesquisa na área da saúde, como no caso dos editais publicados nos anos de 2006 e 2008. Ao longo do período estudado foram contemplados pelos editais um total de 140 projetos de pesquisas. Do universo observado, 82 projetos foram contemplados no ano de 2006 e 58 projetos no ano de 2008. Segue abaixo um quadro demonstrativo do histórico de fomento à pesquisa em doenças negligenciadas promovido pelo Ministério da Saúde entre os anos de 2002 e 2008 (Quadro 7):

Quadro 7 - Histórico do fomento à pesquisa em doenças negligenciadas pelo Ministério da Saúde (2002 a 2008)

\begin{tabular}{|c|c|c|}
\hline Edital & $\mathbf{N}^{\circ}$ de projetos & Investimento (R\$) \\
\hline Tuberculose & 06 & 9.8 milhões \\
\hline Dengue & 29 & 945 mil \\
\hline Hanseníase & 38 & 2,8 milhões \\
\hline $\begin{array}{c}\text { Doenças Negligenciadas } \\
\mathbf{2 0 0 6}\end{array}$ & $\mathbf{8 2}$ & $\mathbf{2 2}$ milhões \\
\hline $\begin{array}{c}\text { Doenças Negligenciadas } \\
\mathbf{2 0 0 8}\end{array}$ & $\mathbf{5 8}$ & $\mathbf{1 7}$ milhões \\
\hline Total & $\mathbf{2 1 3}$ & $\mathbf{5 2 , 5}$ milhões \\
\hline
\end{tabular}

Fonte: DECIT/MS 
Para o ano de 2006 o autor obteve os seguintes resultados relativos aos tipos de pesquisas realizadas em doenças negligenciadas (Gráfico 1):

- $\quad$ Pesquisa biomédica - $35(42,8 \%)$;

- $\quad$ Pesquisa em saúde coletiva - $16(19,4 \%)$;

- Desenvolvimento tecnológico - 13 (15,9\%);

- $\quad$ Pesquisa clínica - $12(14,7 \%)$;

- $\quad$ Pesquisas em fase de classificação - $3(3,6 \%)$.

- $\quad$ Outras ações de C\&T $2(2,4 \%)$;

- $\quad$ Pesquisa em ciências sociais e humanas aplicadas à saúde - $1(1,2 \%)$;

No ano de 2008 foram verificados os seguintes resultados para os tipos de pesquisa (Gráfico 2):

- $\quad$ Pesquisas clínica - $22(37,9 \%)$;

- $\quad$ Pesquisas em fase de classificação - $10(17,2 \%)$.

- $\quad$ Pesquisas em saúde coletiva - $9(15,5 \%)$;

- Desenvolvimento tecnológico - $9(15,5 \%)$;

- $\quad$ Pesquisas biomédicas - $7(12,1 \%)$;

- $\quad$ Pesquisas das ciências sociais e humanas aplicadas à saúde - $1(1,7 \%)$

Verificou-se que no edital de 2008 não foram contemplada pesquisas classificadas como outras ações em C\&T (Gráfico 2).

Em relação à natureza das pesquisas foram obtidos os seguintes resultados:

No ano de 2006 ocorreu o seguinte desempenho quando se tratou da natureza da pesquisa:

- $34(41,4 \%)$ pesquisas aplicadas/estratégicas;

- $\quad 33(40,2 \%)$ pesquisas básicas;

- $10(12,2 \%)$ pesquisas tecnológicas

- $3(3,6 \%)$ pesquisas consideradas como não classificadas;

- $\quad 2(2,4 \%)$ pesquisas consideradas como ações de CT; 
Para o ano de 2008, o comportamento se deu da seguinte forma:

- $\quad 48(82,7 \%)$ pesquisas aplicadas/estratégicas;

- $10(17,3 \%)$ pesquisas consideradas como não classificadas.

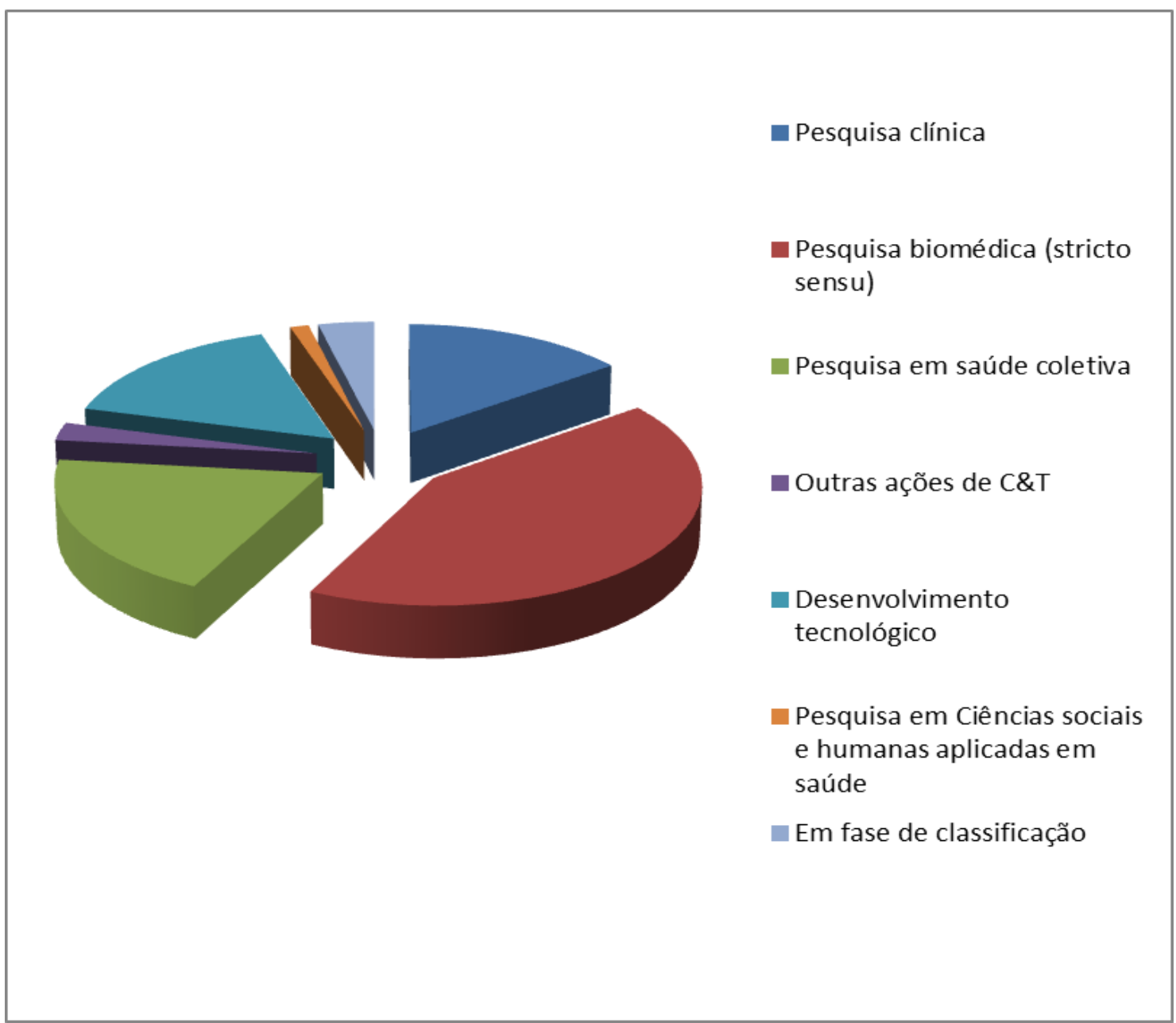

Gráfico 1 - Distribuição dos tipos de pesquisas realizadas pelo edital de apoio às atividades de pesquisa científica, tecnológica e inovação para as doenças negligenciadas no ano de 2006

Fonte: MS/SCTIE/DECIT

Dentre os resultados observados, o incremento obtido pelo número de pesquisas clínicas em relação às pesquisas biomédicas merece ser destacado. Em 2006, as pesquisas biomédicas $(42,8 \%)$ foram aprovadas em maior quantidade. Tal fato não se repetiu no edital de 2008, pois as pesquisas clínicas ganharam destaque sendo as mais contempladas pelo edital $(37,9 \%)$, tanto em relação às pesquisas biomédicas quanto aos outros tipos de pesquisa. 
Outro fato que merece destaque é o decréscimo do número de pesquisas biomédicas no ano de 2008. No ano de 2006, o maior número de pesquisas contempladas foi classificado como pesquisas biomédicas $(42,7 \%)$, no entanto, no ano de 2008, apenas $7(12,1 \%)$ pesquisas dessa natureza foram contempladas pelo edital. As pesquisas em fase de classificação também chamaram atenção, pois, no primeiro edital elas representavam um percentual de 3,6\% do total da classificação das pesquisas, enquanto que no segundo edital tal percentual passou para 17,2\%, ou seja, quase cinco vezes o valor do primeiro.

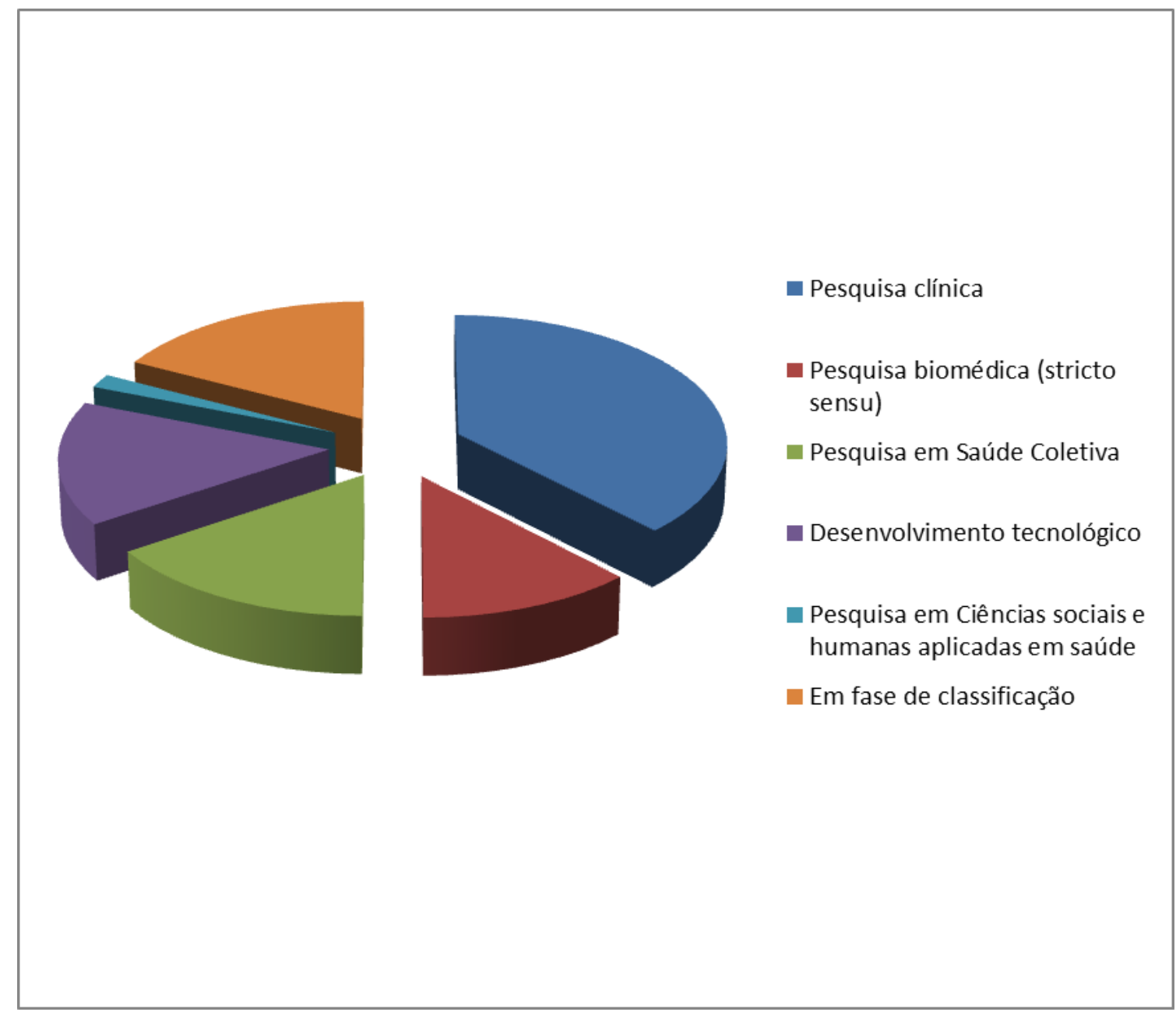

Gráfico 2 - Distribuição dos tipos de pesquisas realizadas pelo edital de apoio às atividades de pesquisa científica, tecnológica e inovação para as doenças negligenciadas no ano de 2008

Fonte: MS/SCTIE/DECIT 


\subsection{OS PESQUISADORES}

Os pesquisadores identificados como responsáveis pela produção do conhecimento em doenças negligenciadas associadas às ações de apoio às pesquisas provenientes dos dispositivos normativos anteriormente apontados para os períodos estudados são profissionais com título de doutor, em sua grande maioria, vinculados a instituições nacionais com capacidade de desenvolvimento de pesquisas científicas.

Como já foi descrito anteriormente, os editais contemplaram 140 projetos de pesquisa. No entanto, o número total verificado de pesquisadores responsáveis pelos projetos foi de 130. Desta forma, 10 pesquisadores tiveram projetos aprovados nos editais dos anos de 2006 e 2008 (Figura 2). Vale destacar que estes pesquisadores submeteram projetos diferentes para cada um dos editais.

No ano de 2006, 47(58\%) dos pesquisadores responsáveis pelos projetos eram do sexo masculino e $35(42 \%)$ do sexo feminino, gerando um total de 82 (100\%) pesquisadores para esse ano. No ano de 2008, o sexo masculino apresentou 29(50\%) contemplados e o sexo feminino também apresentou 29(50\%) contempladas, com um total de 58 pesquisadores (Gráfico 1).

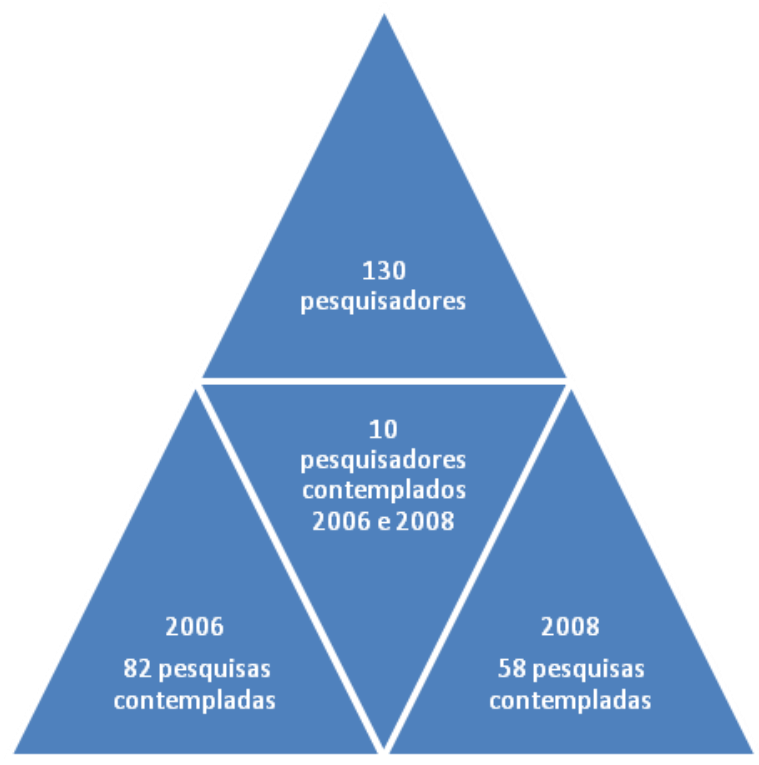

Figura 2 - Pesquisadores contemplados nos anos de 2006 e 2008 por editais de apoio às atividades de pesquisa direcionadas ao estudo das doenças negligenciadas Fonte: MS/SCTIE/DECIT 


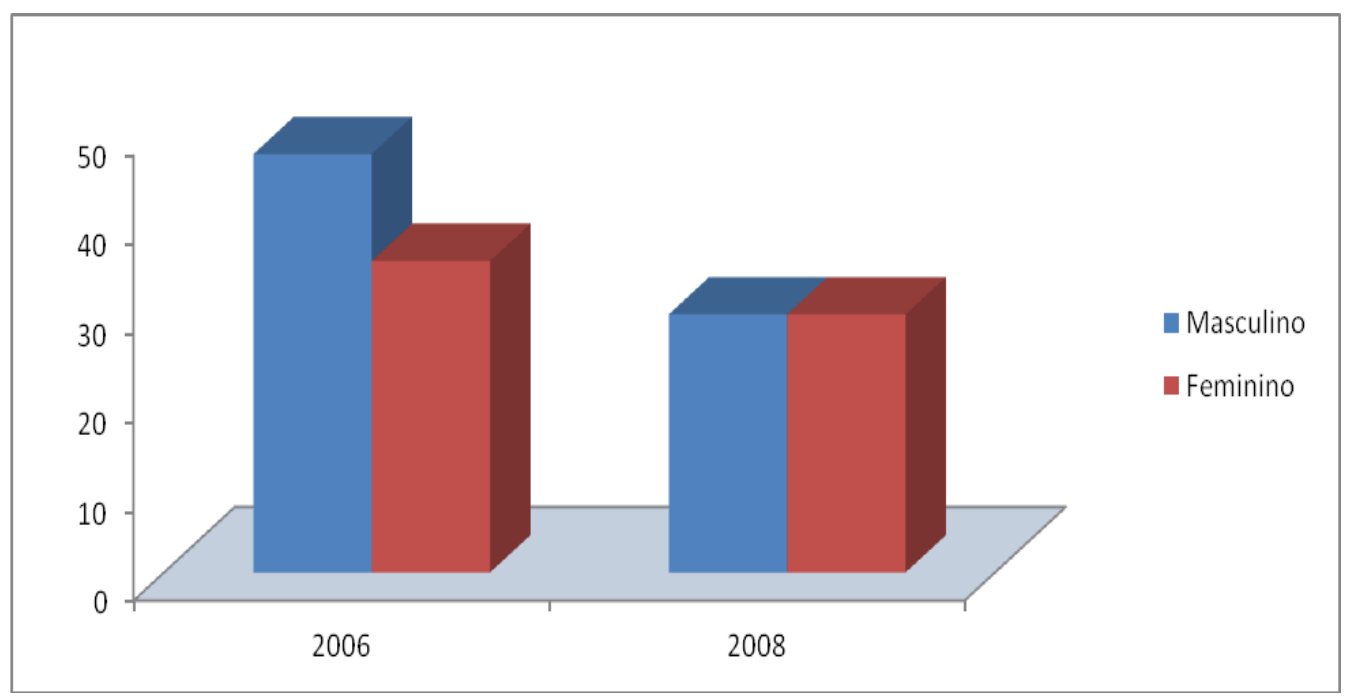

Gráfico 3 - Distribuição dos pesquisadores por sexo nos anos de 2006 e 2008 Fonte: MS/SCTIE/DECIT

Em relação à formação dos pesquisadores, no ano de 2006 foram observados os seguintes resultados:

- $\quad 67(82 \%)$ pesquisadores eram provenientes das ciências da saúde;

- $14(17 \%)$ pesquisadores das ciências exatas;

- $1(1 \%)$ pesquisador não apresentou registro do seu currículo na Plataforma Lattes para verificação (Gráfico 2).

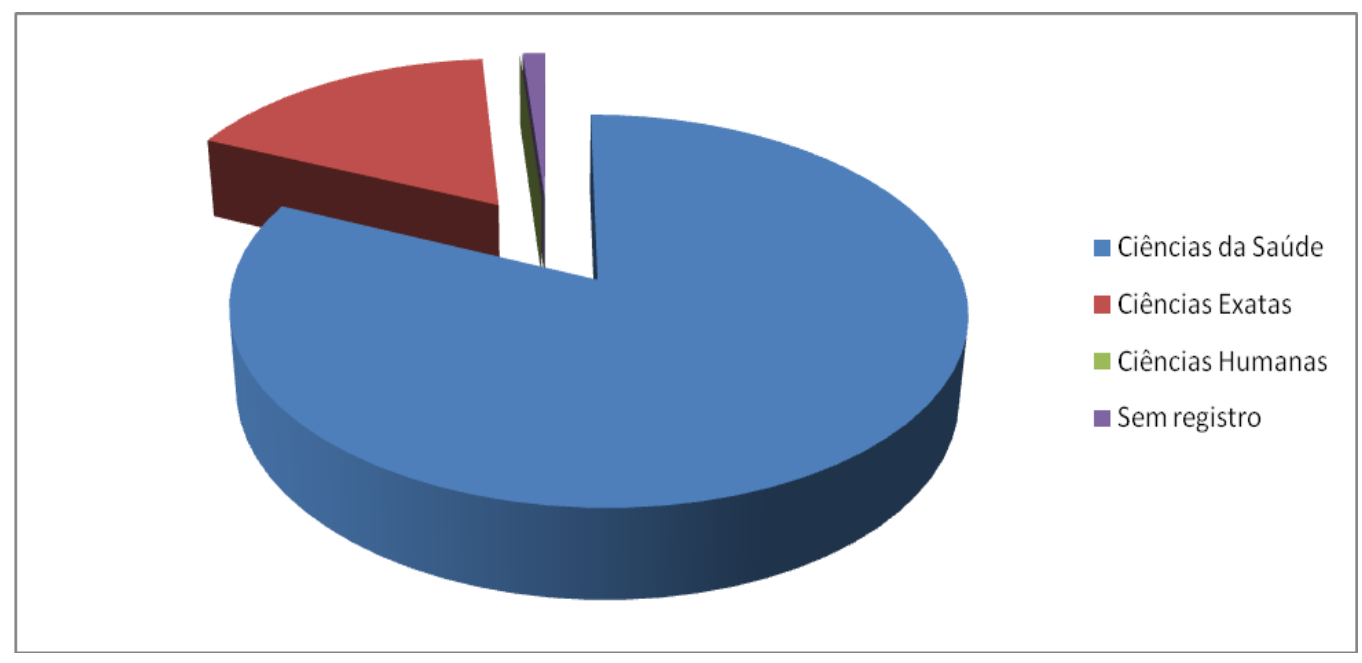

Gráfico 4 - Distribuição dos pesquisadores por área de formação no ano de 2006 Fonte: MS/SCTIE/DECIT

Para o ano de 2008 foram observados os seguintes resultados: 
- $\quad 48(83 \%)$ dos pesquisadores tinham formação nas ciências da saúde,

- $8(14 \%)$ pesquisadores na área das ciências exatas

- $\quad 2(3 \%)$ pesquisadores não tinham seu currículo registrado na Plataforma Lattes.

$\mathrm{O}$ autor destaca que em ambos editais não foram encontrados pesquisadores contemplados com formação na área das ciências humanas (Gráfico 3).

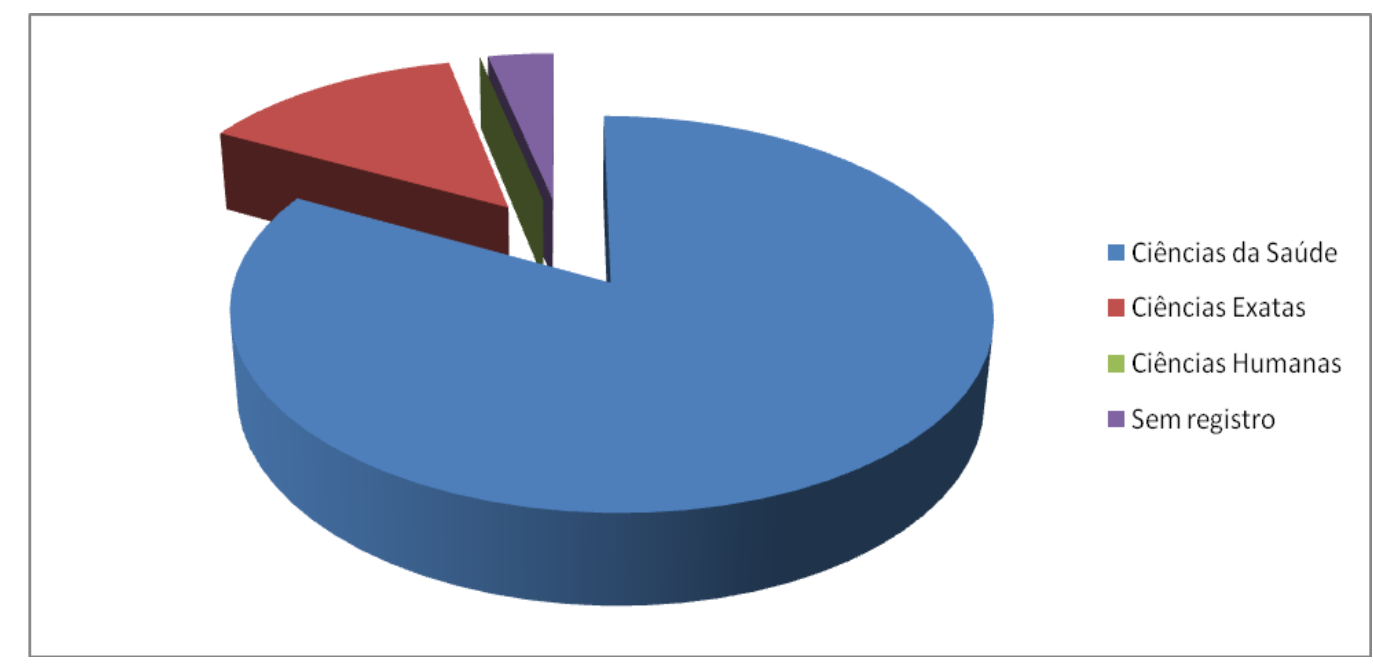

Gráfico 5 - Distribuição dos pesquisadores por área de formação no ano de 2008 Fonte: MS/SCTIE/DECIT

Em relação à formação, do universo de 130 pesquisadores responsáveis, 126 (97\%) apresentaram o título de doutor, 1(1\%) de especialista e 3(2\%) não constavam o currículo na Plataforma Lattes para verificação.

O autor deste estudo verificou os seguintes tipos de instituições com projetos aprovados pelos editais: Universidades (IES), Institutos de Pesquisa, Hospitais de Ensino, Serviços de Saúde e Organizações sem fins lucrativos (ONG, OSCIP, etc).

No ano de 2006, 50(61\%) Universidades foram contempladas, 31(38\%) Institutos de Pesquisa e 1(1\%) Serviço de Saúde. Dessas instituições, a maioria estava concentrada na região Sudeste do país (66\%) (Tabela 2).

Em 2008 foram contempladas as seguintes instituições: 39(67\%) Universidades, 16(27,5\%) Institutos de Pesquisa, 2 (3,5\%) Hospitais de Ensino e 1(2\%) Organizações sem fins lucrativos. Novamente a concentração de instituições contempladas foi na 
região Sudeste (65,5\%), seguida pela região Nordeste do país (17\%) (Tabela 3). Por fim, em relação à natureza da instituição, observou-se que a maioria das instituições com projetos aprovados eram de natureza pública (95\% e 98\%).

Tabela 2 - Distribuição das instituições contempladas no Edital de apoio à pesquisa para doenças negligenciadas por regiões do país no ano de 2006

\begin{tabular}{l|ccccccc}
\hline \multirow{2}{*}{\multicolumn{1}{c|}{ Tipo de Instituição }} & \multicolumn{5}{c}{ Região } \\
\cline { 2 - 7 } & SE & NE & CO & S & N & Total \\
\hline Instituto de Pesquisa & 23 & 2 & 1 & 2 & 3 & 31 \\
Ensino Superior & 30 & 12 & 0 & 7 & 1 & 50 \\
Hospital de ensino & 0 & 0 & 0 & 0 & 0 & 0 \\
Serviço de Saúde & 1 & 0 & 0 & 0 & 0 & 1 \\
Outras organizações sem fins lucrativos (ONG, OSCIP etc.) & 0 & 0 & 0 & 0 & 0 & 0 \\
\hline Total & $\mathbf{5 4}$ & $\mathbf{1 5}$ & $\mathbf{1}$ & $\mathbf{9}$ & $\mathbf{3}$ & $\mathbf{8 2}$ \\
\hline
\end{tabular}

Fonte: MS/SCTIE/DECIT

Tabela 3 - Distribuição das instituições contempladas no Edital de fomento à pesquisa para doenças negligenciadas por regiões do país no ano de 2008

\begin{tabular}{l|cccccc}
\hline \multirow{2}{*}{\multicolumn{1}{c|}{ Tipo de Instituição }} & \multicolumn{5}{c}{ Região } \\
\cline { 2 - 8 } & SE & NE & CO & S & N & Total \\
\hline Instituto de Pesquisa & 15 & 1 & 0 & 0 & 0 & 16 \\
Ensino Superior & 20 & 9 & 2 & 4 & 4 & 39 \\
Hospital de ensino & 2 & 0 & 0 & 0 & 0 & 2 \\
Outras organizações sem fins lucrativos (ONG, OSCIP etc.) & 1 & 0 & 0 & 0 & 0 & 1 \\
\hline Total & $\mathbf{3 8}$ & $\mathbf{1 0}$ & $\mathbf{2}$ & $\mathbf{4}$ & $\mathbf{4}$ & $\mathbf{5 8}$ \\
\hline
\end{tabular}




\subsection{A ATUAÇÃO DOS PESQUISADORES}

Para o conjunto de artigos científicos que compuseram o corpus 2006 e 2008 em português e inglês respectivamente, o ALCESTE classificou as Unidades de Contexto Elementar (UCE) da seguinte forma:

- Corpus 2006 português - 51\% das UCE;

- Corpus 2008 português - 77\% das UCE;

- Corpus 2006 inglês - 80\% das UCE;

- Corpus 2008 inglês $-85 \%$ das UCE.

Dessa forma, o percentual obtido em cada corpus para a sua respectiva UCE representou o conteúdo dos dados que foram considerados para esta análise. Entre os anos de 2006 e 2008, observou-se que o percentual obtido por cada UCE aumentou, possivelmente, em decorrência do crescimento no número de artigos científicos publicados ao longo da série temporal analisada por este estudo (2003-2011).

Cada corpus analisado teve suas UCE organizadas em classes do seguinte modo:

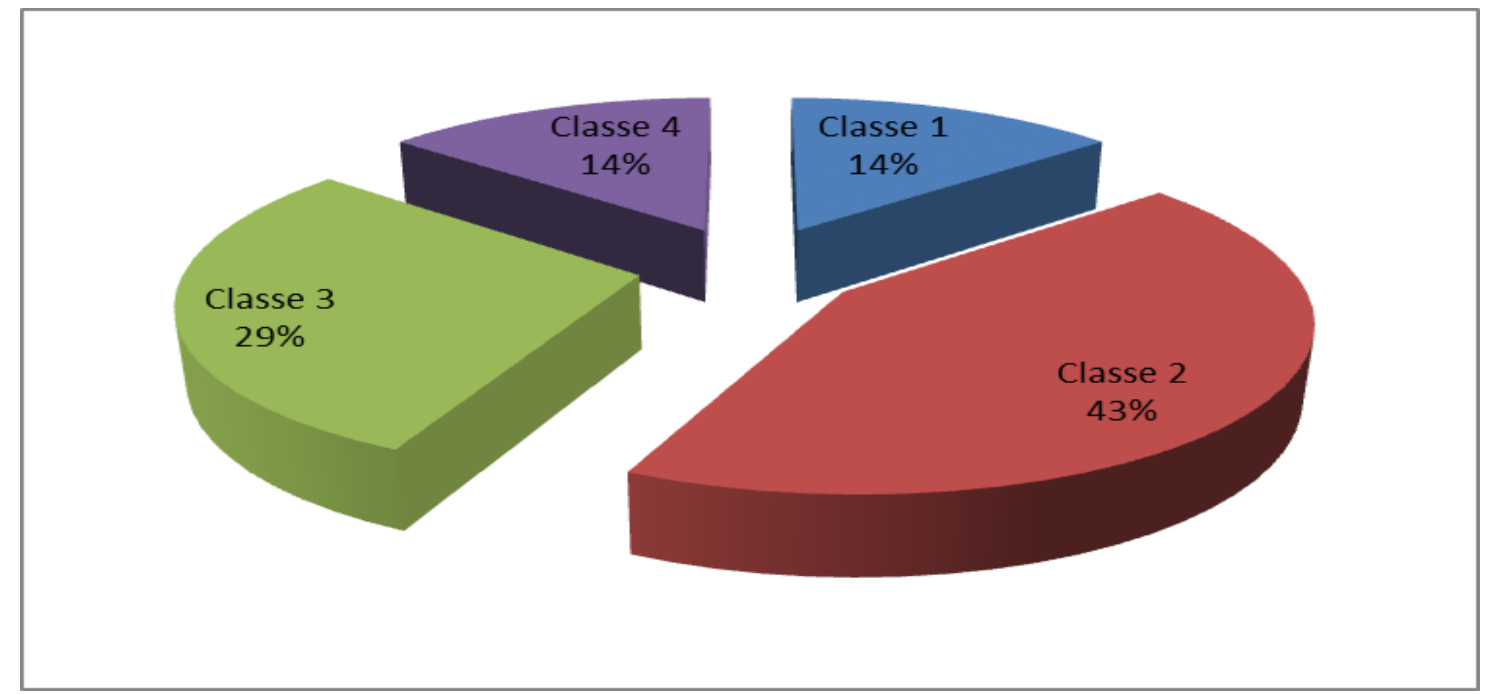

Gráfico 6 - Número e repartição percentual das UCE por classes do corpus 2006 português Fonte: Relatório da produção científica em português do ano de 2006 gerado pelo ALCESTE 


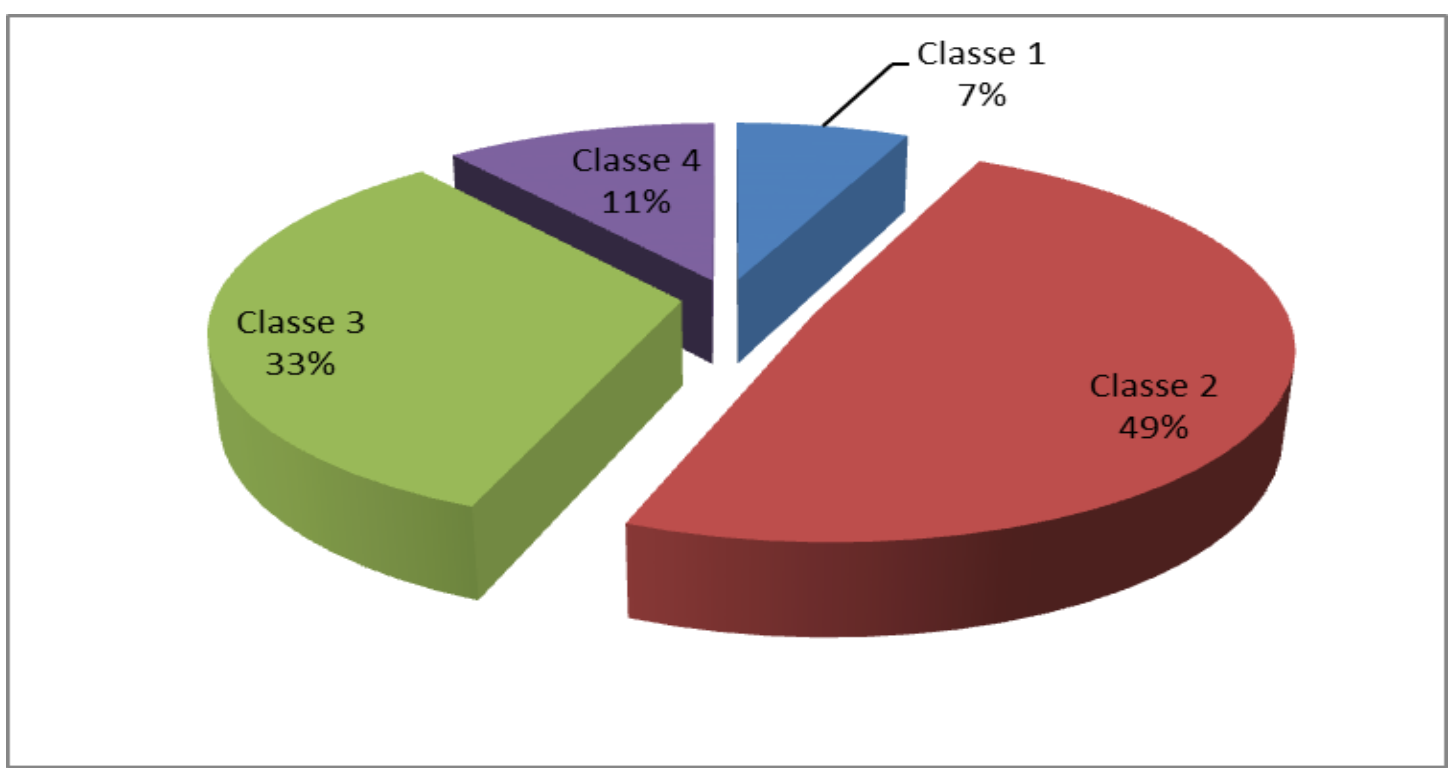

Gráfico 7 - Número e repartição percentual das UCE por classes do corpus 2008 português Fonte: Relatório da produção científica em português do ano de 2006 gerado pelo ALCESTE

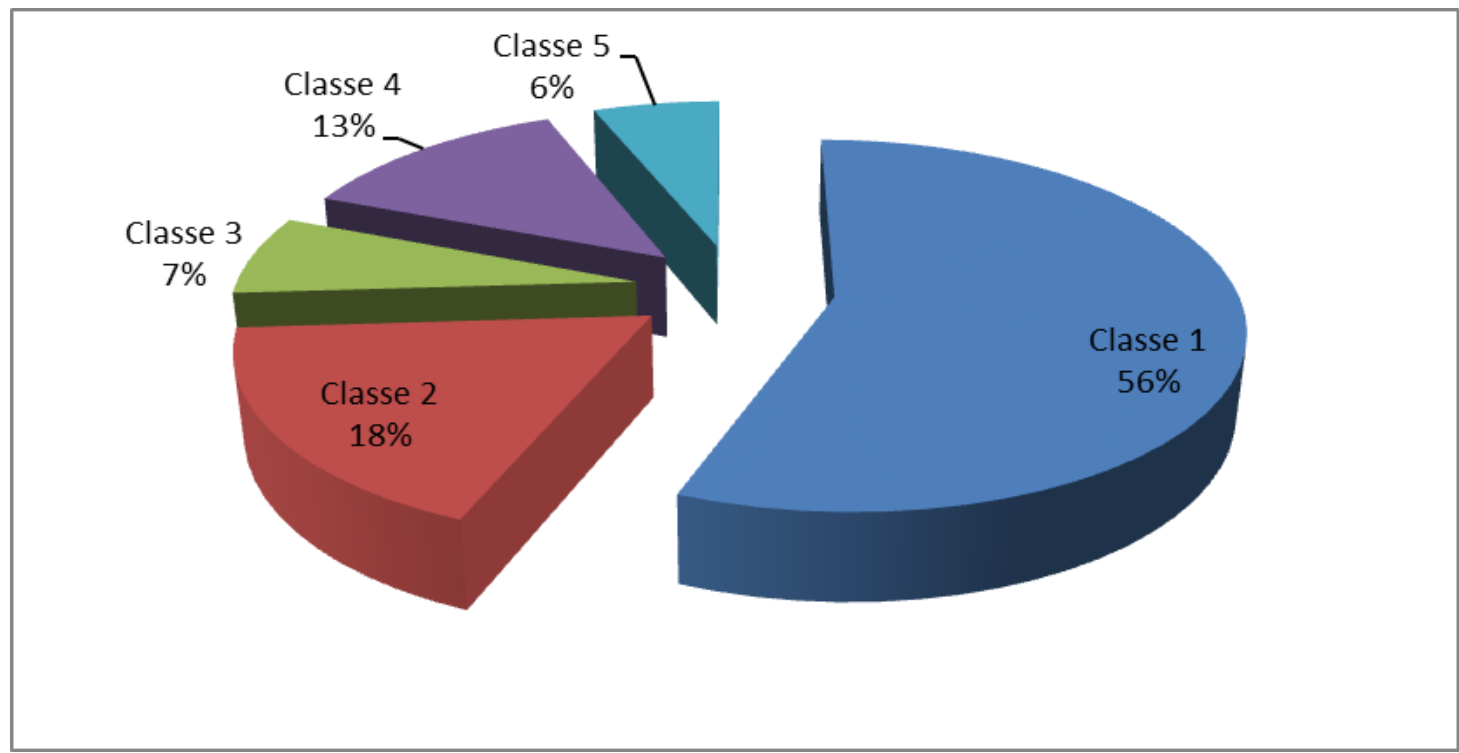

Gráfico 8 - Número e repartição percentual das UCE por classes do corpus 2006 inglês Fonte: Relatório da produção científica em português do ano de 2006 gerado pelo ALCESTE 

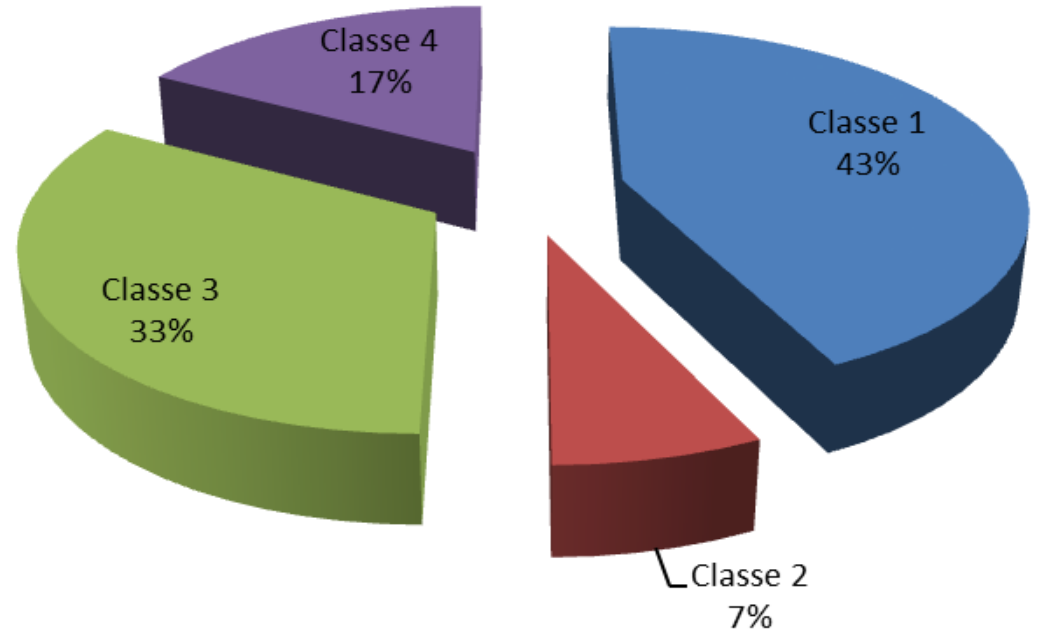

Gráfico 9 - Número e repartição percentual das UCE por classes do corpus inglês 2008 Fonte: Relatório da produção científica em português do ano de 2006 gerado pelo ALCESTE

Os gráficos trazidos anteriormente (Gráfico 6; Gráfico 7; Gráfico 8; Gráfico 9) representam a composição de cada corpus analisado pela tese. Assim, para melhor compreender a atuação dos pesquisadores diante da temática das doenças negligenciadas, as classes foram interpretadas e organizadas a partir da relação estabelecida pelos seus conteúdos. Ou seja, pela interpretação da lista de palavras, das UCE que lhes são específicas; pelas relações de proximidade/distanciamento das palavras com o tema tratado por cada classe e pelas representações ao corpus que compõem, chegou-se ao sentido pretendido para cada classe, que agrupadas formaram uma categoria. Vale destacar que a interpretação das palavras ou das suas formas reduzidas contribuiu tanto para a sugestão dos assuntos específicos tratados por cada uma das classes verificadas em cada corpus, quanto no processo de surgimento das categorias que elas compõem.

Por decisão do autor da tese, foram consideradas apenas as classes com o percentual igual ou maior a $14 \%$ para compor as categorias que emergiram no transcorrer da análise de cada corpus. Tal decisão foi embasada pela presença do número elevado de classes em cada corpus analisado e pela repetição de sentidos que as classes não consideradas poderiam trazer ao estudo. Mesmo assim, ainda ocorreram repetições de sentido em decorrência da semelhança do conteúdo em português e inglês que foram interpretados. Abaixo, a Figura 7 retrata as categorias que emergiram após a interpretação de cada classe. 


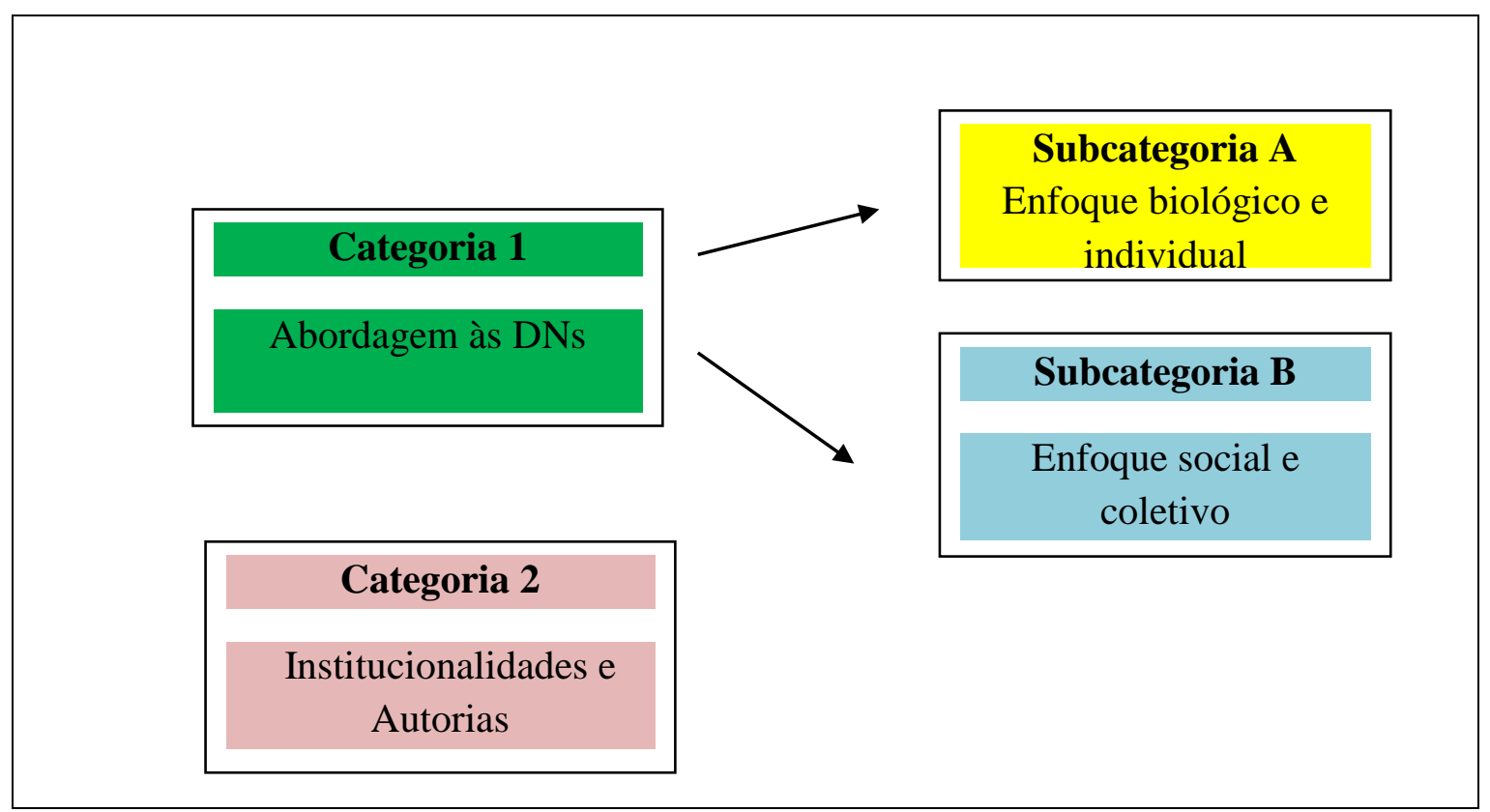

Figura 3 - Categorias que emergiram após análise das classes

Fonte: elaborado pelo autor

\section{Categoria 1 - Abordagem às doenças negligenciadas}

A primeira categoria foi denominada de "Abordagem às DNs" (Figura 7). A sua composição se deu pela relação de 10 classes cujos conteúdos foram capazes de expressar o sentido dos discursos que influenciaram, ao longo do período analisado (2003-2011) por esta tese, a atuação de um grupo específico de pesquisadores relativa ao tema das doenças negligenciadas. Como pode ser observado, a Categoria 1 (Figura 7) foi desdobrada em duas linhas de abordagem, denominadas de "Enfoque biológico e individual" (subcategoria A) e "Enfoque social e coletivo" (subcategoria B).

\section{Subcategoria A - Enfoque biológico e individual}

Nesta subcategoria, a atuação foi incentivada pela investigação de ações e fenômenos biológicos. Ou seja, a visão que se destacou neste grupo é biologicamente centrada, proveniente dos estudos teóricos, experimentais ou das investigações desenvolvidas nos serviços especializados ou nos laboratórios de pesquisas que envolvem um grande aparato tecnológico; sua linguagem, na maioria das vezes, é técnica e restrita aos integrantes da comunidade científica que compartilham dos mesmos saberes e de práticas semelhantes. 
Esta subcategoria foi composta por classes presentes no corpus da língua portuguesa e da língua inglesa dos anos de 2006 e 2008. Para facilitar a leitura dos resultados que a seguir serão apresentados, o Quadro 8 demonstra a composição da subcategoria A.

Quadro 8 - Composição da subcategoria A

\begin{tabular}{|c|c|c|c|}
\hline Corpus & Classe & \% & $\begin{array}{c}\text { Denominação da } \\
\text { Classe }\end{array}$ \\
\hline Português 2006 & 2 & 43 & Biomédica \\
\hline Português 2008 & 2 & 49 & Clínica \\
\hline Inglês 2006 & 1 & 56 & Biomédica \\
& 2 & 18 & Clínica \\
\hline Inglês 2008 & 1 & 43 & Biomédica \\
& 4 & 17 & Desenv. Tecnológico \\
\hline
\end{tabular}

Fonte: Elaborado pelo autor

Para o corpus 2006 português, o enfoque biológico (subcategoria A) representou $43 \%$ do corpus analisado, tendo apenas uma classe com significados relativos ao enfoque. Ou seja, $43 \%$ de todo conteúdo dos dados analisados do corpus está relacionado com o tema abordado pela subcategoria em questão. A subcategoria é composta pela classe 2 que aborda no seu conteúdo temas que dizem respeito a uma atuação dos pesquisadores influenciada pelas pesquisas biomédicas.

A Tabela $4^{7}$ demonstra as palavras que foram significativas para esta classe. Vale destacar que, para melhor compreensão, as formas reduzidas foram apresentadas como palavras em todas as tabelas desta etapa dos resultados.

Conforme observado na Tabela 4, as palavras com maior presença significativa são substantivos. Isto quer dizer que palavras consideradas com conteúdo expressaram o sentido do discurso desta classe.

\footnotetext{
${ }^{7}$ Todas as tabelas mencionadas neste tópico encontram-se localizadas no Apêndice B desta tese.
} 
Para uma compreensão mais completa acerca do discurso defendido pela classe 2, verificou-se a relação de proximidade e de distância do conteúdo das palavras ausentes (Tabela 5).

Pode-se verificar que as palavras trazidas na Tabela 5 demonstraram distanciamento da classe em questão, principalmente, por estarem relacionadas a termos utilizados nos estudos da área da saúde coletiva. Verificou-se, portanto, que o sentido enunciado pela classe diz respeito a uma atuação cuja abordagem ocorre por um "enfoque biológico por meio das pesquisas biomédicas" (classe 2).

Ainda sobre as presenças significativas vistas na classe, a Tabela 6 traz as variáveis que também contribuíram na formação do sentido do discurso da classe. Destaca-se que o pesquisador (*Sujeito) foi considerado como a única variável significativa do presente estudo.

Sobre a presença de variáveis significativas, de acordo com a Tabela 6 o *Sujeito 02, procedente da região Sudeste, possuiu o conteúdo do seu discurso mais associado à presente classe, seguidos pelos *Sujeitos 72 e 35, ambos também procedentes da região Sudeste do Brasil. Tendo em vista a região de origem dos sujeitos, pode-se dizer que o discurso desta classe no período de tempo interpretado foi liderado pelos pesquisadores que, na sua grande maioria, estão localizados nas instituições do Sudeste do país. Ainda em relação aos três sujeitos mais significativos para a classe, verifica-se que a produção científica deles para o período analisado é expressiva e proveniente das pesquisas biomédicas.

Face ao exposto, indica-se que o olhar biomédico foi uma grande influência para a atuação dos pesquisadores contemplados pelos editais de apoio ao combate das doenças negligenciadas ao longo deste período.

Em relação ao corpus 2008 português, 49\% dos dados analisados deste corpus são relacionados ao tema da subcategoria A. A sua classe 2 também compõe a subcategoria em questão. A Tabela 7 demonstra as palavras significativas para esta classe:

A interpretação das palavras com presença significativa proporcionou a identificação de conteúdos que conferiram sentido ao discurso da classe. Observa-se que a palavra "paciente" teve maior valor do chi-quadrado $\left(X^{2}=0.28\right)$ para a classe 2 , ou seja, com maior significado para a classe. Tal fato sugere que esta classe encontrou nas práticas clínicas, cujo objetivo maior é a atenção individualizada ao paciente, o sentido da sua atuação. Outras palavras também mereceram o devido destaque em relação ao 
valor do chi-quadrado, são elas: "resposta", "clínica" e "sintoma". Estas palavras quando associadas ao seu contexto e interpretadas sugerem que a classe 2 do corpus 2008 português indicam uma forte relação com as pesquisas clínicas. Portanto, esta classe foi nomeada de "enfoque biológico por meio das pesquisas clínicas" (classe 2).

As ausências significativas também se apresentaram como dados relevantes que auxiliaram na interpretação desta classe. A Tabela 8, lista as principais ausências significativas que foram necessárias para interpretação do discurso presente na classe:

Percebe-se que as palavras da Tabela 8 apresentam uma relação de distância do sentido proferido pela classe em questão. A palavra "saúde" foi novamente a que mais se distanciou do conteúdo da classe $\left(X^{2}=-0,32\right)$, demonstrando uma situação de oposição ao enfoque proposto pela subcategoria. Dessa forma, pode-se dizer que a visão desta classe é procedente da doença e dos fenômenos biológicos que a cercam.

Palavras como "coletiva", "município", "política” e "epidemiológica" demonstraram por meio dos seus conteúdos que não estão associadas ao sentido observado na classe. No caso desta classe, as ausências a possibilitaram a confirmação da existência de uma atuação norteada por um discurso que nasce dos profissionais voltados as práticas clínicas, determinadas a tratar doenças de modo individualizado. Desta forma, as palavras acima listadas distanciam-se do tema tratado pela classe, pois, quando interpretadas expressam significados relativos a uma abordagem as doenças negligenciadas por meio de um enfoque social.

As variáveis significativas também estiveram presentes e foram fundamentais para análise da classe (Tabela 9).

No que diz respeito às variáveis significativas (Tabela 9), o *Sujeito 05 foi o que teve o conteúdo da fala mais próximo do tema abordado pela classe 2. Os *Sujeitos 08 , 21, 56, 06 e 02 também tiveram falas com o conteúdo muito próximo da abordagem da classe. Apesar dos discursos mais significativos terem sido dos pesquisadores da região Sudeste do país, começou-se a observar que os discursos dos pesquisadores provenientes das regiões Sul, Centro-Oeste e Nordeste também passaram a contribuir na formação do sentido desta classe.

Diante dos dados até aqui apresentados, pode-se apontar que a interpretação do conteúdo das palavras juntamente com análise das variáveis relacionadas à classe 2 do corpus 2008 português ajudaram na compreensão da atuação dos pesquisadores em prol das doenças negligenciadas. Na intenção de promover um melhor entendimento das 
palavras, a seguir serão descritas as UCE caracterizadas como as mais representativas para esta classe.

“...Foram estudados 39 indivíduos do sexo masculino que foram divididos em quatro grupos: indivíduos normais; indivíduos portadores e portadores de doença de Chagas de forma indeterminada..." (*Suj. 08; UCE n 237 );

“...Não foi administrada qualquer medicação venosa ou via oral. Os valores de dor nos dois grupos estudados foram comparados pelo teste não paramétrico de Man Whitney U...” (*Suj. 05; UCE 151);

“...Pacientes do grupo TCI/TC apresentaram manifestações clínicas de ambas as doenças e a resposta concomitante aparentemente não interferiu nos sintomas clínicos...” (*Suj. 56; UCE 1031);

“...Quantificar o percentual de contratilidade dos diversos segmentos miocárdicos em portadores de doença de Chagas através da medida do strain miocárdico e verificar diferenças na função contrátil radial e longitudinal ventricular...”(*Suj. 08; UCE 236);

“...O teste imunoenzimático de Elisa realizado com amostras de plasma de 45 pacientes com tuberculose pulmonar e 172 contatos, 96 prova tuberculínica negativa e 76 positiva foi conduzido para avaliação da resposta imune humoral..." (*Suj. 02; UCE $30)$.

Os trechos acima descritos contextualizam as palavras significativas e confirmam que o significado desta classe foi influenciado pelo discurso dos pesquisadores que focam suas atividades nos estudos clínicos. Outro fato que também pode ser observado nesta classe é a mudança no cenário das pesquisas em doenças negligenciadas no país. No corpus anteriormente descrito, verificou-se o predomínio das pesquisas biomédicas, neste, percebe-se que há um predomínio das pesquisas clínicas. O Quadro 9 sintetiza os meios de obtenção do sentido do discurso dos corpus português 2006 e 2006 até aqui apresentados. 
Quadro 9 - Síntese da obtenção do sentido dos corpus português 2006 e 2008 para a subcategoria A

\begin{tabular}{|c|c|c|c|c|c|c|}
\hline Corpus & Classe & $\%$ & $\begin{array}{c}\text { Denominação } \\
\text { da Classe }\end{array}$ & $\begin{array}{c}\text { Palavras } \\
\text { Significativas }\end{array}$ & $\begin{array}{c}\text { Ausências } \\
\text { Significativas }\end{array}$ & $\begin{array}{c}\text { Variáveis } \\
\text { Significativas }\end{array}$ \\
\hline $\begin{array}{l}\text { Português } \\
2006\end{array}$ & 2 & 43 & $\begin{array}{l}\text { Enfoque } \\
\text { biológico por } \\
\text { meio da } \\
\text { pesquisa } \\
\text { biomédica }\end{array}$ & $\begin{array}{c}\text { Especialidades; } \\
\text { Amostra; } \\
\text { Teste; } \\
\text { Parâmetro; } \\
\text { Exame }\end{array}$ & $\begin{array}{c}\text { Saúde; } \\
\text { Município; } \\
\text { Epidemiologia; } \\
\text { Contexto; } \\
\text { Sociais }\end{array}$ & $\begin{array}{c}\text { Sujeito 02; } \\
\text { Sujeito } 72 ; \\
\text { Sujeito } 35 \\
\text { Procedentes } \\
\text { da Região } \\
\text { Sudeste }\end{array}$ \\
\hline $\begin{array}{c}\text { Português } \\
2008\end{array}$ & 2 & 49 & $\begin{array}{l}\text { Enfoque } \\
\text { biológico por } \\
\text { meio da } \\
\text { pesquisa } \\
\text { clínica }\end{array}$ & $\begin{array}{l}\text { Paciente; } \\
\text { Resposta; } \\
\text { Clínica; } \\
\text { Sintoma; } \\
\text { Diagnóstico }\end{array}$ & $\begin{array}{c}\text { Saúde; } \\
\text { Coletiva; } \\
\text { Município; } \\
\text { Política; } \\
\text { Social; } \\
\text { Comunidade }\end{array}$ & $\begin{array}{c}\text { Sujeito } \\
\text { 05;Sujeito 08; } \\
\text { Sujeito 21; } \\
\text { Contribuição } \\
\text { do S, CO e } \\
\text { NE }\end{array}$ \\
\hline
\end{tabular}

Fonte: elaborado pelo autor

O corpus 2006 inglês também contribui para esta subcategoria, sendo representado pelas classes 1 e 2, com os percentuais de $56 \%$ e $18 \%$ respectivamente.

Em relação à classe 1, ela apresentou uma íntima relação com a classe 2 do corpus 2006 português. A Tabela 10 demonstra quais as palavras que apresentaram maior frequência e consequentemente tiveram os conteúdos mais significativos para formação do discurso da classe em questão.

As palavras listadas acima confirmam pelo valor dos seus khi-quadrados uma próxima relação da visão biológica enunciada pela subcategoria. Logo abaixo, demonstram-se algumas UCE significativas para a classe com capacidade de expressar e confirmar o sentido enunciado pela classe. Ressalta-se que os fragmentos apresentados foram traduzidos para facilitar o entendimento acerca do conteúdo interpretado.

“...Esta revisão descreve o conhecimento atual sobre a organização das estruturas e organelas mais significativas encontradas no protozoário Trypanosoma cruzi, como o citoesqueleto, cinetoplasto, complexo mitocondrial, glicossomo..." (*Suj. 82; UCE 7802); 
“...Análise de parasitas realizada por microscopia eletrônica de transmissão demonstrou alterações morfológicas graves no formato da célula, na mitocôndria e no núcleo, enquanto cinetoplasto, reservossomo e compartimentos pré lysossomal...” (*Suj. 71; UCE 6990);

“...Investigamos os mediadores de ativação dos leucócitos no coração de camundongos infectados. Sabe-se que óxido nítrico não modula a resposta inflamatória durante a infecção pelo Trypanossoma cruzi..." (*Suj.62; UCE 3081);

“...No entanto, camundongos co-infectados tiveram proliferação por mycobacterias. Nossos resultados sugerem que t. infecção canis não conduz necessariamente a uma maior suscetibilidade à tuberculose pulmonar...”(*Suj. 05; 3988).

Pela interpretação das UCE verificou-se que o conhecimento produzido pelos pesquisadores desta classe foi proveniente das pesquisas biomédicas que relacionavam temas da biologia celular e da imunologia com doenças negligenciadas. Portanto, a interpretação das palavras juntamente com as suas UCE denominou a classe de “enfoque biológico por meio das pesquisas biomédicas" (classe 1).

A Tabela 11 traz os pesquisadores (*Sujeitos) cujos discursos contribuíram para formação do sentido verificado a classe. Dois fatos chamaram atenção em relação a estes pesquisadores. O primeiro diz respeito ao volume de publicações científicas em inglês procedentes de pesquisas que são enquadradas como biomédicas. O segundo diz respeito à ligação deles com as áreas da biologia celular, imunologia e bioquímica. Em se tratando das regiões de origem dos pesquisadores com discurso mais significativo para classe, observou-se que novamente o Sudeste ocupou a liderança.

Em se tratando da classe 2, observou-se que ela tem um sentido análogo ao já observado na classe 2 do corpus 2008 português. O sentido verificado nas suas palavras significativas indicou a existência de uma forte ligação dos métodos de diagnósticos como elementos subsidiários das práticas clínicas demonstradas na produção científica desta classe. A Tabela 12 retrata palavras significativas que contribuíram na obtenção do sentido da classe.

Nesta classe, as ausências significativas surgiram de palavras que também foram significativas para a obtenção do sentido de classes que fazem parte desta subcategoria. 
Apesar do significado associado ao enfoque biológico verificado nas palavras ausentes, percebeu-se que elas estão mais próximas das classes, cujo enfoque ocorre por meio das pesquisas biomédicas. Palavras como "célula", "cobaias", "proteína" e "membrana" foram as que tiveram os menores valores de chi-quadrado, portanto, as que mais se afastaram do tema tratado por esta classe. Pela proximidade e pelo distanciamento verificado nas palavras desta classe, pode-se denominá-la também de "enfoque biológico por meio das pesquisas clínicas".

Em relação aos sujeitos que tiveram discursos significativos para a classe, verificou-se que a maioria dos sujeitos tem vinculados a sua atuação a realização de pesquisas clínicas que utilizam amplamente métodos diagnósticos para consecução dos resultados. Para esta classe, o discurso mais significativo foi procedente da região Sul do país, apesar do maior quantitativo ser procedente da região Sudeste do Brasil.

Abaixo, são trazidas algumas UCE significativas para contextualizar e confirmar o sentido adotado para a classe.

“...Os testes ADA, para medir atividade, IGA-ELISA, para medir dois antígenos do Mycobacterium tuberculosis combinados, e o de reação em cadeia da polimerase, PCR para detecção de DNA do Mycobacterium tuberculosis foram realizado..." (*Suj. 52; UCE 4880);

“...Para melhorar a qualidade do teste de Mitsuda foi utilizada na sua fabricação uma ferramenta para detectar a composição micobacteriológica de lepromas de pacientes com hanseníase...”(*Suj. 46; UCE 4544);

“...Concluímos que o PCR é o método de escolha para indivíduos com baixa concentração de parasitas e, portanto, poderia representar uma ferramenta complementar capaz de resgatar com segurança..." (*Suj. 14; UCE 1376).

As classes 1 e 4 do corpus 2008 inglês também contribuíram na formação do sentido enunciado por esta subcategoria. Em relação à classe 1, verificou-se que ela apresentou um conteúdo relacionado com a classe 2 do corpus 2006 português e com a classe 1 do corpus 2006 inglês. Nesta classe, o percentual de conteúdo analisado foi de 43\%. Seu sentido surgiu, principalmente, das suas palavras e dos seus sujeitos significativos. Dessa forma, ela também foi nomeada de "enfoque biológico por meio da 
pesquisa biomédica". A Tabela 13 traz algumas das palavras que foram fundamentais para a obtenção do sentido da classe.

Ainda em relação aos sujeitos significativos, observou-se que os discursos mais significativos para a classe também foram procedentes dos pesquisadores do Sudeste e do Nordeste do país. Abaixo, são descritas algumas UCE para demonstrar o sentido verificado na classe.

“...Detectamos uma geração significativa de interferon gamma por esplenócitos de cobaias vacinados em resposta ao antígeno i. chagasi e a proteína rlack. No entanto, nós não observamos uma redução na carga parasitária no fígado nem no baço...” (*Suj. 30; UCE 4168);

“...Neste trabalho foi demonstrado que a imunização de camundongos com antígenos do i.". amazonensis resulta em aumento da susceptibilidade a leishmaniose tegumentar..."(*Suj. 9; UCE 2636);

“...Utilizando a técnica do PCR iniciador degenerado nós clonamos um fragmento homólogo para este gene do Anopheles aquasalis caril, um vetor neotropical da malária. Além disso baseada nesta primeira sequência, um novo iniciador..." (*Suj. 25; UCE 3657).

A classe 4 do corpus 2008 inglês foi formada por 17\% do total do conteúdo analisado em todo corpus textual. Esta classe tratou de temas relacionados às pesquisas das doenças negligenciadas que tem por finalidade desenvolver novos produtos ou novos processos ou melhorar os já existentes. O desenvolvimento tecnológico foi o foco principal dos pesquisadores que compõem esta classe. Portanto, ela foi denominada de “enfoque biológico por meio das pesquisas de desenvolvimento tecnológico" (classe 4).

As Instituições do Sudeste, Sul e Nordeste do Brasil foram as que mais contribuíram com seus discursos para esta classe. A presença desta classe indicou que, apesar de não predominante, ela foi marcante e indicou um possível avanço na pesquisa nacional ao demonstrar a sua capacidade de desenvolver ou aprimorar produtos em prol da saúde da população.

A Tabela 14 aponta as palavras que contribuíram para a formação do discurso e consequentemente o sentido proferido pela classe. 
As ausências significativas verificadas na classe apontaram que as palavras que mais se afastaram do seu tema foram àquelas associadas às pesquisas clínicas e às pesquisas em saúde coletiva. A Tabela 15, lista as principais palavras ausentes que contribuíram para captação do sentido do discurso surgido da classe.

Finalmente, demonstram-se algumas UCE para contextualizar o conteúdo que foi interpretado e proporcionou o sentido para a classe.

“...Este complexo inorgânico representa uma nova classe de compostos capazes de levar ao desenvolvimento de agentes anti-tuberculínicos, visando a inibição de um alvo validado. Assim, descrevemos os desenvolvimentos recentes..." (*Suj. 14; UCE 1940);

“...Tem sido proposto como um alvo para a busca racional de novos fármacos leishmanicidas. Neste trabalho, descrevemos a avaliação da atividade inibitória sobre a enzima I. tarentolae aprt de 46 extratos de Meliaceae e Rutaceae..." (*Suj. 44; UCE 6193);

“...A atividade antimalárica de derivados hidroxyethylpiperazine, sintetizado a partir da reação de, $2 \mathrm{~s}, 3 \mathrm{~s}$, boc fenilalanina epóxido com benzylpiperazines com bons rendimentos..." (*Suj. 4; UCE 398).

“...Tem um grande potencial para se tornar uma nova molécula de chumbo que através da inibição desta enzima chave poderá haver o desenvolvimento de novas drogas contra a doença de Chagas...” (*Suj. 37; UCE 5001).

A seguir, o Quadro 10 traz a síntese da obtenção do sentido dos corpus na língua inglesa dos anos de 2006 e 2008. 
Quadro 10 - Síntese da obtenção do sentido dos corpus inglês 2006 e 2008 para a subcategoria A

\begin{tabular}{|c|c|c|c|c|c|c|}
\hline Corpus & Classe & $\%$ & $\begin{array}{c}\text { Denominação da } \\
\text { Classe }\end{array}$ & $\begin{array}{c}\text { Palavras } \\
\text { Significativas }\end{array}$ & $\begin{array}{c}\text { Ausências } \\
\text { Significativas }\end{array}$ & $\begin{array}{c}\text { Variáveis } \\
\text { Significativas }\end{array}$ \\
\hline \multirow{2}{*}{ Inglês 2006} & 1 & 56 & $\begin{array}{c}\text { Enfoque biológico por } \\
\text { meio da pesquisa } \\
\text { biomédica }\end{array}$ & $\begin{array}{l}\text { Resposta; Imune; } \\
\text { Membrana; } \\
\text { Mitocôndria; } \\
\text { Organela }\end{array}$ & & $\begin{array}{l}\text { Sujeito 82; Sujeito } \\
\text { 05; Sujeito 71; } \\
\text { Sujeito } 62 \\
\text { Biologia celular, } \\
\text { imunologia e } \\
\text { bioquímica } \\
\text { Sudeste; }\end{array}$ \\
\hline & 2 & 18 & $\begin{array}{c}\text { Enfoque biológico por } \\
\text { meio da pesquisa } \\
\text { clínica }\end{array}$ & $\begin{array}{l}\text { PCR; Amostras; } \\
\text { Paciente; Clínica; } \\
\text { Diagnóstico }\end{array}$ & $\begin{array}{l}\text { Células; } \\
\text { Cobaias; } \\
\text { Proteína; } \\
\text { Membrana }\end{array}$ & $\begin{array}{l}\text { Sujeitos mais } \\
\text { significativos da } \\
\text { região Sul. No } \\
\text { entanto, os da região } \\
\text { Sudeste foram dm } \\
\text { maior quantidade; }\end{array}$ \\
\hline \multirow{2}{*}{ Inglês 2008} & 1 & 43 & $\begin{array}{c}\text { Enfoque biológico por } \\
\text { meio da pesquisa } \\
\text { biomédica }\end{array}$ & $\begin{array}{l}\text { Células; Cobaia; } \\
\text { Imune; } \\
\text { Macrófago; } \\
\text { Proteína }\end{array}$ & & $\begin{array}{c}\text { Sujeitos da região } \\
\text { Sudeste e Nordeste } \\
\text { do país; }\end{array}$ \\
\hline & 4 & 17 & $\begin{array}{l}\text { Enfoque biológico por } \\
\text { meio da pesquisa de } \\
\text { des. Tecnológico }\end{array}$ & $\begin{array}{c}\text { Composto; } \\
\text { Síntese; Enzima; } \\
\text { Química }\end{array}$ & $\begin{array}{c}\text { Paciente; } \\
\text { Risco; Saúde; } \\
\text { População; } \\
\text { Epidemiologia }\end{array}$ & $\begin{array}{l}\text { Sujeitos da região } \\
\text { Sudeste, Sul e } \\
\text { Nordeste. }\end{array}$ \\
\hline
\end{tabular}

Fonte: Elaborado pelo autor

\section{Subcategoria B - Enfoque social e coletivo}

Na subcategoria B, a visão que se destaca é aquela capaz de interpretar ações e intervir nos fenômenos humanos e sociais que afetam as condições de saúde das populações. Portanto, a alteração das condições de saúde que são investigadas nas coletividades torna-se a questão chave para a formação do sentido desta subcategoria. Diante disso, indica-se que esta subcategoria é formada pelas classes, cujos conteúdos dos discursos convergem para formar sentidos que são inerentes a área da saúde coletiva. O Quadro 11 representa a composição da subcategoria B: 
Quadro 11 - Composição da subcategoria B

\begin{tabular}{|c|c|c|c|}
\hline Corpus & Classe & $\%$ & $\begin{array}{c}\text { Denominação da } \\
\text { Classe }\end{array}$ \\
\hline Português 2006 & 3 & 29 & $\begin{array}{c}\text { Saúde Coletiva } \\
\text { Pesquisas } \\
\text { Epidemiológicas }\end{array}$ \\
\hline Português 2008 & 3 & 33 & $\begin{array}{c}\text { Saúde Coletiva } \\
\text { Inglês 2008 }\end{array}$ \\
\hline
\end{tabular}

Fonte: Elaborado pelo autor

A primeira classe que compôs esta subcategoria foi a classe 3 do corpus 2006 português. Ela contribuiu com $29 \%$ do conteúdo dos dados analisados do referido corpus. A partir da análise do conteúdo das palavras significativas presentes, das palavras significativas ausentes, das variáveis significativas e do conteúdo das UCE construiu-se o sentido do discurso presente nesta classe e nas demais classes que compõem a subcategoria B.

A Tabela 16 apresenta as palavras com os maiores valores do chi-quadrado, portanto, as mais significativas para formação do discurso. Observou-se que por se tratar de palavras que possuíam conteúdo elas foram imprescindíveis para a formação do sentido do discurso da classe e consequentemente influenciaram na atuação dos pesquisadores presentes nesta classe.

Um aspecto interessante trazido pelas palavras de maior frequência neste discurso é o destaque dado ao vocábulo "saúde" $\left(X^{2}=0.29\right)$. Vale salientar que, até então, ele tinha apenas aparecido na lista das ausências significativas das classes que compuseram o enfoque biológico, representando apenas o oposto da doença. No caso desta classe, pode-se dizer que é dele que surge o verdadeiro sentido enunciado pela classe. Portanto, a associação deste vocábulo com as demais palavras significativas da classe proporcionou a denominação de "enfoque social por meio das pesquisas em saúde coletiva" (classe 3 ).

Em relação às ausências significativas, a Tabela 17 traz palavras que reforçam o conteúdo abordado pela classe 3 . 
Por meio das palavras ausentes (Tabela 18) observou-se um distanciamento do conteúdo verificado nos estudos da saúde coletiva e uma aproximação aos estudos biomédicos, clínicos e de desenvolvimento tecnológico. Estas ausências reforçam ainda mais que a atuação dos pesquisadores desta classe foi influenciada pelo discurso daqueles que consideram acontecimentos humanos e sociais como fatores preditores das condições de saúde das populações.

As variáveis significativas também estiveram presentes nesta classe. Elas representaram os pesquisadores (*Sujeitos) com as suas singularidades. A Tabela 18 traz as variáveis que foram significativas para esta classe.

Observou-se que o *Sujeito 74 obteve o maior valor para o chi-quadrado $\left(X^{2}=\right.$ 0.29). Analisando este sujeito diante do seu contexto de atuação, verificou-se que dentre todos os sujeitos que foram significativos, ele apresentou o discurso mais associado ao conteúdo da classe 3, seguidos pelos *Sujeitos 37, 27, 73 e 55. Vale salientar que a produção científica de todos os sujeitos desta classe foi procedente das pesquisas na área da saúde coletiva. Os pesquisadores das instituições das regiões Sudeste e Nordeste foram os mais significativos. As demais regiões do país não estiveram presentes nesta classe.

Para melhor compreender o contexto das palavras e o significado das falas dos sujeitos que compõem esta classe, logo abaixo serão demonstradas as UCE mais significativas para a classe:

“...A integração das atividades de controle da tuberculose na atenção básica será possível mediante organização do sistema de saúde, seguindo os princípios da atenção primária e elaboração/implementação de uma política...” (*Suj. 74; UCE 1593);

“...Com a continuidade para as questões da educação, do saneamento e da geração de emprego e renda, poderiam provocar transformações de impacto na condição das populações..." (*Suj. 37; UCE 814);

“..O assessoramento as diversas instancias do SUS; a elaboração de documentos de referência e a análise da viabilidade da integração das propostas da iniciativa do programa nacional do controle da tuberculose..." (*Suj. 74; 1547); 
“...A maioria dos doentes enfrentava dificuldades de ordem econômica e social, e grande parte dos gerentes desconheciam os recursos aplicados às ações em tuberculose..." (*Suj. 74; UCE 1549).

As UCE trazidas acima ratificam que o discurso desta classe além de encontrar força nos estudos da saúde coletiva, surge e se mobiliza a partir da visão de um grupo específico de pesquisadores da área da saúde que valorizam e procuram estabelecer relações das doenças negligenciadas com os contextos socioeconômicos e os determinantes que a elas estão associadas. Portanto, o sentido verificado nesta classe indica a existência de um distanciamento das demais classes que compõem a subcategoria denominada no presente estudo de "enfoque biológico" (subcategoria A).

Ainda no corpus 2006 português, verificou-se que mais uma classe contribuiu para a formação do discurso relacionado à subcategoria B. Trata-se da classe 4, que explica $14 \%$ do conteúdo total analisado pelo corpus.

A Tabela 19 traz as palavras que foram significativas para obtenção do sentido do discurso que influenciou a atuação dos componentes desta classe no período estudado pela presente tese.

Pelas palavras trazidas na tabela 19 , nota-se que os vocábulos com os maiores valores de chi-quadrado indicam que os conteúdos das palavras significativas remetem ao sentido de uma atuação influenciada pelas pesquisas epidemiológicas, que por sua vez, voltaram seu foco para a tuberculose. Dessa forma, a classe 4 foi nomeada de "enfoque social por meio das pesquisas epidemiológicas".

Nesta classe também fora observadas variáveis significativas, no caso, os pesquisadores (*Sujeitos). A Tabela 20 demonstra em ordem decrescente do valor do chi-quadrado os sujeitos que tiveram falas que se aproximaram do assunto tratado pela classe. Ou seja, foram significativos para a classe.

Dentre todos os sujeitos que foram significativos para a classe 4, o discurso do *Sujeito 23 foi o que mais contribui para formação do discurso da classe, seguido pelos * Sujeitos 01 e 78. Destaca-se que dois fatos os conectam. O primeiro fato é que todos os três sujeitos mais significativos da classe 4 são oriundos de instituições de referência localizadas na região Sudeste do país. O segundo é que eles possuem uma expressiva produção de estudos epidemiológicos, sendo a maioria, para a investigação da tuberculose. 
Apesar da menor participação, a região Nordeste também contribuiu na formação do discurso e consequentemente influenciou também na atuação dos pesquisadores analisados no período.

Para uma melhor compreensão das palavras nos seus contextos e o consequente entendimento do sentido do discurso que foi estabelecido pela classe 4, apresenta-se a seguir as UCE mais significativas selecionadas pela ALCESTE.

“...O objetivo deste trabalho foi traçar o perfil epidemiológico de casos notificados de tuberculose entre os moradores de abrigos em Vitória e Vila Velha no período de 2000 a 2006...” (*Suj. 23; UCE 440);

“...Descrever os fatores associados ao abandono da quimioprofilaxia da tuberculose no município de Vitória/ES por parte dos maiores de 15 anos atendidos em programas de referência de controle da doença: Um estudo e coorte histórica..." (*Suj. 23; UCE 363);

“...Descrever o perfil de uso de medicamentos entre crianças residentes em áreas pobres e fatores associados..." (*Suj. 55; UCE 1094)

“...A tuberculose é uma doença ligada à pobreza, má distribuição de renda, urbanização, epidemia da síndrome da imunodeficiência adquirida e multirresistente..." (*Suj. 78; UCE 1690).

A análise discursiva das UCE trazidas acima reforça a interpretação do conteúdo das palavras e das variáveis e indica que ela está relacionada com a atuação dos pesquisadores que, no caso da classe 4 , ocorreu por meio da realização das pesquisas epidemiológicas, com destaque para aquelas cujo objeto de estudo foi a tuberculose. Deve-se atentar que apesar das pesquisas epidemiológicas pertencerem ao universo das pesquisas em saúde coletiva, fez-se necessário classificar de maneira específica para expressar o sentido contido no discurso da classe. Por meio do Quadro 12 o autor deste estudo sintetiza o caminho da obtenção do sentido do corpus português 2006. 
Quadro 12 - Síntese da obtenção do sentido do corpus português 2006 para a subcategoria B

\begin{tabular}{|c|c|c|c|c|c|c|}
\hline Corpus & Classe & $\%$ & $\begin{array}{c}\text { Denominação da } \\
\text { Classe }\end{array}$ & $\begin{array}{c}\text { Palavras } \\
\text { Significativas }\end{array}$ & $\begin{array}{c}\text { Ausências } \\
\text { Significativas }\end{array}$ & $\begin{array}{c}\text { Variáveis } \\
\text { Significativas }\end{array}$ \\
\hline & 3 & 29 & $\begin{array}{l}\text { Enfoque social por } \\
\text { meio das pesquisas } \\
\text { em saúde coletiva }\end{array}$ & $\begin{array}{l}\text { Saúde; Vida; } \\
\text { Atenção; } \\
\text { População; } \\
\text { Sociais }\end{array}$ & $\begin{array}{c}\text { Especialidades; } \\
\text { Proteína; } \\
\text { Sorológico; } \\
\text { Sangue }\end{array}$ & $\begin{array}{l}\text { Sujeitos da região } \\
\text { Sudeste e } \\
\text { Nordeste do país; }\end{array}$ \\
\hline $\begin{array}{l}\text { Português } \\
2006\end{array}$ & 4 & 14 & $\begin{array}{c}\text { Enfoque social por } \\
\text { meio das pesquisas } \\
\text { epidemiológicas }\end{array}$ & $\begin{array}{l}\text { Pneumologia; } \\
\text { Tuberculose; } \\
\text { Notificados; } \\
\text { Epidemiologia }\end{array}$ & & $\begin{array}{c}\text { Sujeitos mais } \\
\text { significativos } \\
\text { oriundos da região } \\
\text { Sudeste; } \\
\text { Investigação da } \\
\text { tuberculose }\end{array}$ \\
\hline
\end{tabular}

Fonte: elaborado pelo autor

O corpus 2008 português também contribuiu com uma classe para formação do discurso da subcategoria B. Neste caso, a classe 3 compõe com 33\% do conteúdo total analisado pelo corpus a referida subcategoria.

A Tabela 21 demonstra as palavras que foram significativas para formação do discurso que influenciou a atuação dos pesquisadores ao longo da série temporal da presente tese.

Como podem ser observadas, as palavras "saúde", "necessidade", "coletiva", "vulnerabilidade", "política" e "social" foram as protagonistas na concepção do sentido da classe. Ou seja, foram as palavras mais significativas e de maior frequência no discurso dos componentes desta classe.

A palavra "saúde" obteve novamente o maior valor do chi-quadrado $\left(X^{2}=0.43\right)$. Este fato além de indicar oposição às classes que compõem o enfoque proposto pela subcategoria A, reforça o sentido proposto pela subcategoria B. Pela relação que se observa das palavras, pode-se também indicar que elas trazem a abordagem coletiva da saúde.

O conteúdo das palavras significativas visto nesta classe indica que o discurso que surge dos seus componentes apresenta uma forte relação com o discurso oriundo dos estudos da saúde coletiva. Portanto, esta classe foi nomeada também de "enfoque 
social por meio das pesquisas em saúde coletiva" (classe 3). Vale destacar que o sentido observado nesta classe é semelhante ao da classe 3 do corpus 2006 português, sendo assim, a denominação ocorreu de maneira igual ao dessa classe.

As ausências significativas também foram relevantes para consecução do sentido que se conferiu a classe. A Tabela 22 traz as principais ausências da classe 3.

No caso das ausências significativas, a palavra que mais apresentou distanciamento do conteúdo abordado pela classe foi o vocábulo "paciente" $\left(X^{2}=-\right.$ 0.17), seguido pelos vocábulos "teste", "resposta" e "clínica". Todas as palavras demonstradas na Tabela 22 se aproximam do significado e demonstraram relação com classes presentes na subcategoria A. Este distanciamento, demonstrado pelas palavras ausentes, reforça ainda mais que o significado inerente a classe 3 apresenta uma forte relação com a dimensão coletiva e social da saúde.

Para finalizar a interpretação da classe, apresenta-se a seguir as UCE que foram mais significativas e capazes de contextualizar o conteúdo das palavras que deram o sentido a classe. Ressalta-se que as UCE que apresentaram a maior capacidade de retratar o discurso que influenciou a atuação dos pesquisadores da classe também são provenientes do discurso da região Sudeste do Brasil. Dessa forma, constata-se que os discursos das classes com conteúdo em português que mais contribuíram para formação do enfoque coletivo (subcategoria B) são originários, em sua grande maioria, da região Sudeste, seguido pelos discursos da região Nordeste do Brasil.

“...Tem como finalidade ampliar a compreensão de agravos de saúde, com base neste conceito, além de possibilitar a proposição de intervenções para o seu enfrentamento, que extrapolem o âmbito individual...” (*Suj. 39; UCE 756)

“...Nesse sentido, os profissionais de saúde devem receber treinamento sobre técnicas para identificar, avaliar e prevenir as deficiências físicas na hanseníase e, também adquirir conhecimento sobre o preenchimento correto dos dados...” (*Suj. 35; UCE 694);

“...É desafio posto pela saúde coletiva, propiciar tecnologias, dispositivos e instrumentos que apoiem a construção de práticas qualificadas, para responder as necessidades dos grupos sociais...” (*Suj. 58; UCE 1036). 
O corpus 2008 inglês também contribuiu na composição desta subcategoria. A sua contribuição foi com a classe 3 , que representou $33 \%$ do conteúdo total dos dados analisados pelo corpus.

A Tabela 23 traz as palavras que foram mais significativas para interpretação do discurso da classe. Destaca-se que o conteúdo interpretado deste corpus foi traduzido para o português para tornar mais fácil a sua compreensão.

Verifica-se que a palavra "prevalência" surgiu como a mais significativa para a classe $\left(X^{2}=0.28\right)$, seguida das palavras "saúde", "comunidade", "urbano", "rural" e "epidemiologia". Relacionando-se estas palavras com a das outras classes, verificou-se que o sentido desta classe apresentou conexão com o enfoque estabelecido para esta subcategoria. As palavras com conteúdo significativo quando associadas aos seus contextos expressaram um sentido relativo às pesquisas epidemiológicas realizadas, em sua maioria, pela saúde coletiva.

A verificação dos sujeitos significativos que se apresentaram para classe juntamente com as UCE, proporcionou a confirmação do sentido que havia surgido a partir da interpretação das palavras significativas. Portanto, a convergência dos três componentes proporcionou que ela fosse denominada de "enfoque social por meio das pesquisas epidemiológicas" (Classe 3). Vale destacar que o sentido desta classe por se apresentar análogo ao da classe 4 do corpus 2006 português, apresentou o mesmo nome.

A Tabela 24 demonstra a seguir os sujeitos que contribuíram para a formação do discurso estabelecido pela classe.

Em relação aos sujeitos significativos, verificou-se que todos apresentaram uma forte ligação com a área do conhecimento da saúde coletiva, mais especificamente com a epidemiologia. Vale mencionar que os *Sujeitos 42 e 24 apresentaram nas suas trajetórias profissionais uma vasta e expressiva produção científica associada à epidemiologia e a saúde coletiva. Com isso, verificou-se quanto o discurso deles foi fundamental para a formação do sentido atinente a classe.

Em relação à origem dos sujeitos significativos, o maior número destes foi proveniente das instituições situadas na região Sudeste do Brasil. No entanto, os discursos que apresentaram os maiores valores do chi-quadrado, tornando-os os mais significativos, foram provenientes das instituições situadas na região do Nordeste do país. Tal fato leva a crer que apesar da predominância dos discursos advindos da região Sudeste, observa-se que neste corpus o discurso dos pesquisadores da região Nordeste 
foi o mais significativo para classe e capaz de influenciar na atuação desempenhada pelos pesquisadores desta série temporal.

Por fim, para que haja uma ratificação do sentido aferido à classe, a seguir são apresentadas as UCE mais significativas, destacando que elas foram traduzidas para a língua portuguesa para proporcionar uma melhor compreensão.

“...Nosso objetivo foi investigar fatores de risco associados com a incidência e a prevalência da diarreia em crianças de até 3 anos. No total, 926 crianças foram acompanhadas em casa duas vezes por semana a partir de Outubro de 2000 a Janeiro..." (*Suj. 42; UCE 5777);

“...Estudo epidemiológico de corte transversal que incluiu 590 crianças de 1 a 5 anos de idade. Os dados foram coletados a partir das famílias das crianças selecionadas por meio de entrevistas domiciliares com os pais ou responsáveis..." (*Suj. 42; UCE 5788);

“....Notável mudança no padrão epidemiológico da infecção tem sido observada dentro das cidades, portanto, a investigação de transmissão de dengue em pequenas áreas é importante para a formulação de estratégias de controle...” (*Suj. 58; UCE 7518);

“...Foi realizado um estudo de base populacional em 78 municípios do Tocantins, na região Centro-Oeste do Brasil, aplicando-se questionários estruturados aos pacientes contaminados pela hanseníase para avaliação dos fatores de risco..." (*Suj. 24; UCE 3199).

O Quadro 13 faz a síntese da obtenção do sentido dos corpus português e inglês no ano de 2008 para a subcategoria B. 
Quadro 13 - Síntese da obtenção do sentido dos corpus português 2008 e inglês 2008 para a subcategoria B

\begin{tabular}{|c|c|c|c|c|c|c|}
\hline Corpus & Classe & $\%$ & $\begin{array}{c}\text { Denominação da } \\
\text { Classe }\end{array}$ & $\begin{array}{c}\text { Palavras } \\
\text { Significativas }\end{array}$ & $\begin{array}{c}\text { Ausências } \\
\text { Significativas }\end{array}$ & $\begin{array}{c}\text { Variáveis } \\
\text { Significativas }\end{array}$ \\
\hline $\begin{array}{c}\text { Português } \\
2008\end{array}$ & 3 & 33 & $\begin{array}{l}\text { Enfoque social por } \\
\text { meio das pesquisas em } \\
\text { saúde coletiva }\end{array}$ & $\begin{array}{c}\text { Saúde; } \\
\text { Necessidade; } \\
\text { Coletiva; Política; } \\
\text { Social }\end{array}$ & $\begin{array}{c}\text { Paciente; Teste; } \\
\text { Resposta; Clínica; } \\
\text { Cirúrgico; } \\
\text { Experimento }\end{array}$ & $\begin{array}{l}\text { Procedentes da } \\
\text { Região Sudeste }\end{array}$ \\
\hline Inglês 2008 & 3 & 33 & $\begin{array}{l}\text { Enfoque social por } \\
\text { meio das pesquisas } \\
\text { epidemiológicas }\end{array}$ & $\begin{array}{l}\text { Prevalência; Saúde; } \\
\text { Comunidade; } \\
\text { Epidemiologia; } \\
\text { Intervenção; } \\
\text { Sanitária }\end{array}$ & & $\begin{array}{l}\text { Sujeito 42;Sujeito } \\
\text { 24; Produção } \\
\text { científica associada } \\
\text { à epidemiologia e a } \\
\text { saúde coletiva; } \\
\text { Maior número do } \\
\text { SE; Mais } \\
\text { significativos NE. }\end{array}$ \\
\hline
\end{tabular}

Fonte: elaborado pelo autor

\section{Categoria 2 - Institucionalidades e Autorias}

O discurso que influenciou e vai configurar a atuação da categoria denominada de "Institucionalidades e Autorias" (categoria 2) é proveniente dos grandes grupos de pesquisa coordenados por expoentes da área do ensino e da pesquisa em saúde, vinculados a universidades e centros de pesquisa de excelência que estão situados, em sua grande maioria, na região Sudeste do país. Os pesquisadores que foram significativos para esta categoria, geralmente, têm seus nomes vinculados à coordenação de estudos multicêntricos, além de possuírem uma expressiva produção científica. Pesquisas clínicas, biomédicas e da saúde coletiva compõem a categoria 2 (figura 3 ).

Nesta categoria, apenas o corpus 2006 português contribui com uma classe (classe 1). Foi a única classe que demonstrou relação de proximidade com a categoria e apresentou um percentual de $14 \%$ do conteúdo total analisado pelo corpus. A interpretação do conteúdo das suas palavras e da representação dos seus sujeitos proporcionou a denominação de "autores expoentes" (classe 1). 
A Tabela 25 demonstra as variáveis que contribuíram para formação do sentido do discurso desta classe. Considerou-se como variável significativa os pesquisadores (*Sujeito) juntamente com as suas singularidades profissionais e institucionais.

De acordo o com a Tabela 25, o *Sujeito 76 apresentou o maior valor do chiquadrado para esta classe $\left(X^{2}=0.32\right)$, indicando que o conteúdo do seu discurso foi fundamental para o delineamento do sentido da classe. Os demais sujeitos apontados na tabela, apesar de não terem apresentado o mesmo valor do chi-quadrado, também contribuíram com o conteúdo dos seus discursos para concepção do sentido que influenciou a atuação da classe.

Observou-se que todos os sujeitos significativos eram procedentes da região Sudeste do Brasil e estavam vinculados a instituições públicas de ensino e pesquisa de referência para doenças negligenciadas no país. Vale ressaltar que os pesquisadores desta classe continham nos seus históricos profissionais a ocupação de cargos de chefia e/ou coordenação das instituições das quais eram procedentes, além de se enquadrarem na categoria de titular ou eméritos da sua profissão. Outro fato que merece destaque é a expressiva participação destes pesquisadores como coordenadores de grupos de pesquisas responsáveis, na maioria das vezes, pela realização de projetos multicêntricos.

Deve-se levar em consideração que a classe denominada de "autores expoentes" não se restringe apenas a pesquisadores que comungam do mesmo discurso ou que deles são próximos. Verifica-se que há uma sugestiva oposição nos seus discursos, pois, apesar de surgirem da área da saúde, cada um é originário de uma perspectiva de atuação diferente. A posição ocupada pelos seus sujeitos significativos, perante a comunidade científica, agrega e dá sentido aos seus pontos de vista. A observação a partir dos valores decrescentes do chi-quadrado das variáveis significativas desta classe sugere que as pesquisas biomédicas seguidas das pesquisas em saúde coletiva comandaram o sentido do discurso que influenciou a atuação desta classe.

A procedência de instituições da região Sudeste do país, a ocupação de cargos de liderança e a vasta produção científica, apesar de designar expoência para um determinado grupo de pesquisadores, não foi suficiente para comandar o discurso que influenciou a atuação presente nos corpus do estudo. O que se observou é que o sentido dos discursos provenientes das outras categorias, principalmente da categoria cujo enfoque é o biológico, além de contribuírem mais, eles foram os que mais demonstraram influência sobre a atuação do grupo de pesquisadores brasileiros que foram contemplados pelos editais públicos de fomento à pesquisa destinado ao 
enfrentamento das doenças negligenciadas. O Quadro 14 sintetiza a obtenção do sentido obtido no corpus 2006 português.

Quadro 14 - Síntese da obtenção do sentido do corpus português 2006 para a categoria Institucionalidades e Autorias

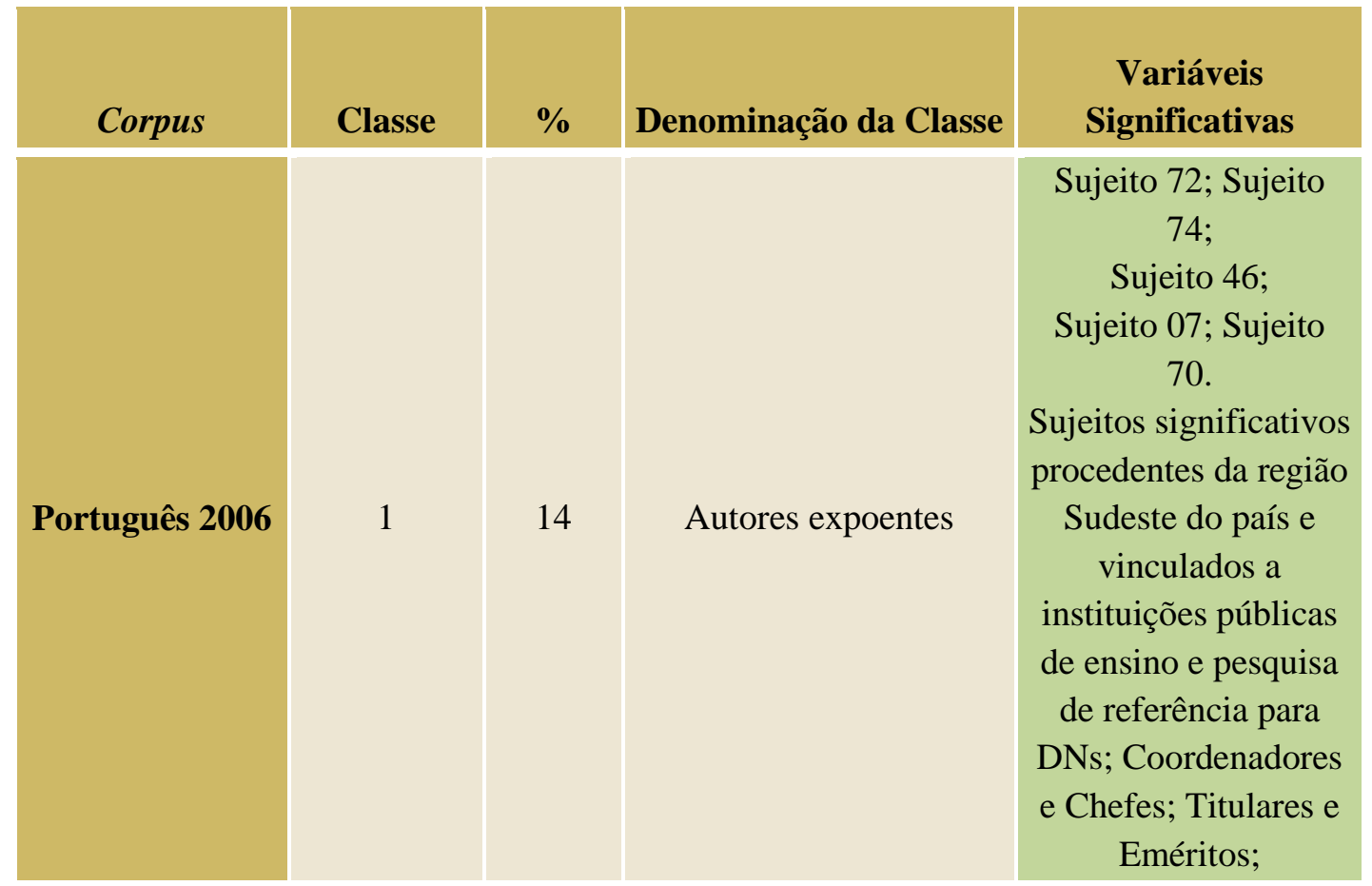

Fonte: elaborado pelo autor

Para finalizar, o autor deste estudo traz abaixo uma figura (Figura 3) para ilustrar as relações estabelecidas entre as categorias com as classes que compõem o corpus 2006 português, com destaque para a relação da categoria nomeada de "institucionalidades e Autorias" (Categoria 2) com a classe nomeada "autores expoentes" (classe 1). 

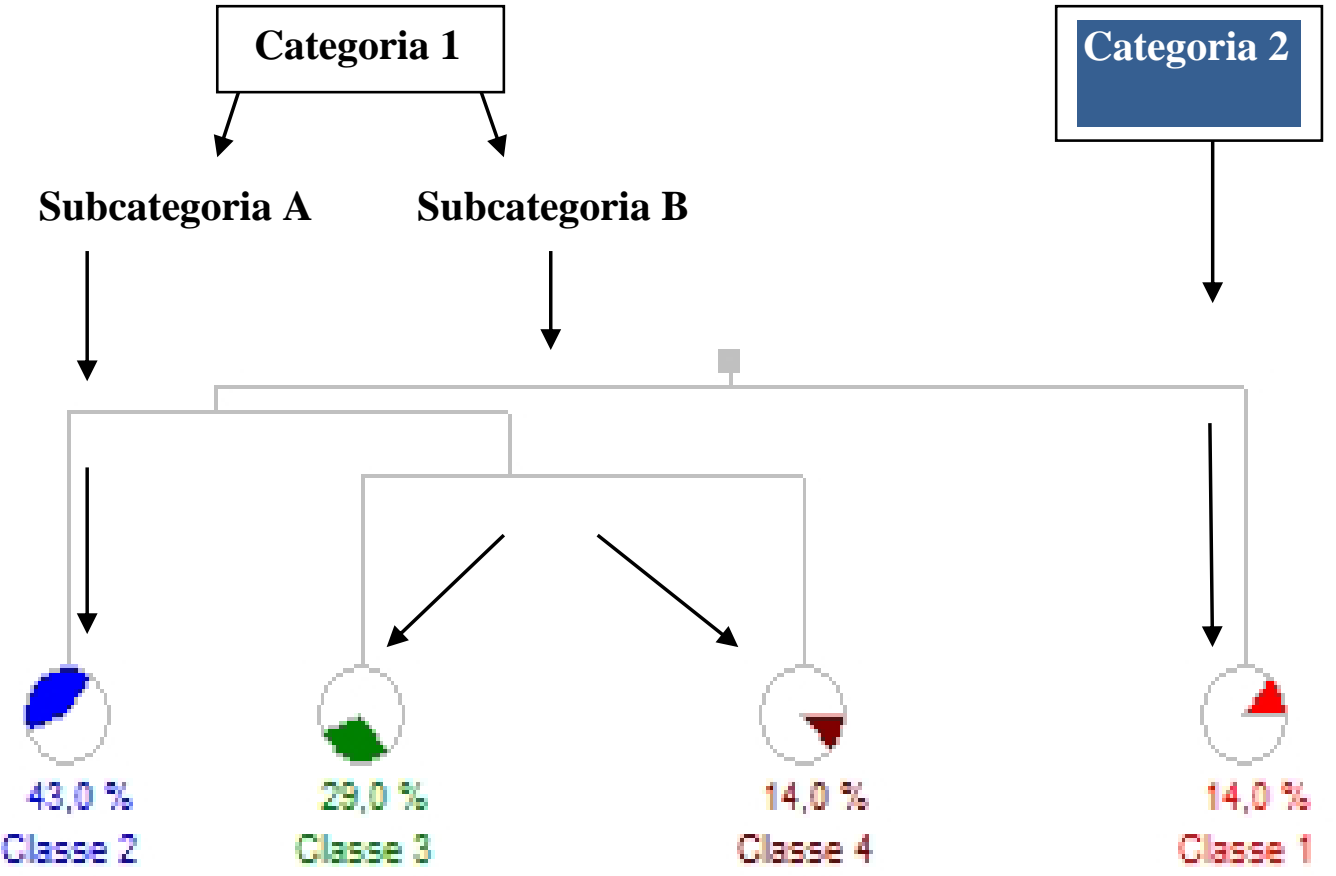

Figura 4 - Relação das classes do corpus 2006 português

Fonte: Relatório ALCESTE 


\section{DISCUSSÃO}

O modo de produção do conhecimento na área da saúde do país atravessa um período de transformações significativas, aonde as verdadeiras necessidades da sociedade deixam de ser latentes para se tornarem explícitas e assumirem o lugar de destaque que lhe é devido dentre as ações de responsabilidade do Estado. Nesse sentido, o tema das doenças negligenciadas, cujas consequências são consagradas pela literatura científica mundial, foi incorporado na agenda de pesquisa em saúde instituída para o país, tornando-se uma "prioridade das prioridades" (63). Dessa forma, a responsabilidade de enfrentamento tomada pelo país relativa ao tema, ratificou para o autor deste estudo que, apesar de negligenciadas, elas não estão esquecidas.

Como consequência, a atitude tomada pelo Estado brasileiro para enfrentamento de tal problema demonstrou-se como uma forte aliada na reversão de uma lacuna existente no campo da pesquisa e desenvolvimento em saúde, usualmente denominada de 10/90 GAP, que pode ser descrita como um desequilíbrio aonde $10 \%$ de todo financiamento mundial da pesquisa científica em saúde vai para doenças ou condições que afetam $90 \%$ da população mundial.

Ao que se vê, um cenário favorável para a produção do conhecimento em doenças negligenciadas despontou a partir da implementação de uma política pública voltada para a ciência, tecnologia e inovação no país, cuja consequência foi o arrefecimento de um tema que não pode mais ficar relegado ao segundo plano devido a sua magnitude global e sua relevância social.

Dessa maneira, o país foi responsável por um processo que priorizou o diálogo entre gestores e componentes da comunidade científica, respeitando os seus contextos e suas visões acerca de um tema que historicamente tem se mostrado negligenciado, entretanto, demonstra não estar esquecido pela ciência (115), corroborando com o que já foi afirmado anteriormente pelo autor deste estudo. Vale destacar que a participação dos gestores num processo dessa natureza foi fundamental, sobretudo, pela capacidade deste público trazer para pauta das investigações científicas problemas de saúde que são atinentes aos seus cotidianos (116).

As profundas transformações observadas no modo nacional de produção do conhecimento e a relação que foi estabelecida entre ciência e sociedade, que são 
justamente aquelas que concedem uma maior integração entre necessidades sociais e pesquisa científica outrora afirmada por Pellegrini (49), refletiram na totalidade do processo de apoio à pesquisa em saúde em andamento no país.

Com isso, por meio da implementação de uma política nacional de apoio à pesquisa e inovação em saúde - PNCTIS, da criação de novas ferramentas e métodos adequados para identificar prioridades de pesquisa e do aumento de recursos destinados ao incentivo da produção do conhecimento científico, observou-se que, apesar de não estarmos no mesmo patamar dos países de alta renda, existe o empenho para que as deficiências presentes na situação da pesquisa do país sejam superadas e, cada vez mais, o estímulo à produção do conhecimento acerca de temas que refletem diretamente nas condições de desenvolvimento de uma nação, como no caso do tema das doenças negligenciadas, ganhe mais espaço nas agendas de pesquisa e tornem-se prioritários.

Para o autor deste estudo, um compromisso ético começa a ser assumido por parte do Estado e da comunidade científica para superar um problema que quase sempre se apresenta associada à porção pobre e excluída da sociedade. Assim, as consequências ocasionadas pelo flagelo das doenças negligenciadas e o conflito ético que é reforçado pelo descompasso e pelo desinteresse do mercado em investir em ações de pesquisa e de desenvolvimento para tais doenças, impulsionaram o encorajamento das autoridades nacionais na promoção de medidas públicas voltadas ao enfrentamento dessas doenças.

Dessa forma, o Estado passou a desempenhar o que Schramm (118) considera como seu papel legítimo. Ou seja, o enfrentamento das doenças negligenciadas avocado por parte do Estado brasileiro, demonstrou que a proteção e o amparo dos cidadãos do seu território que não tem condições objetivas e subjetivas necessárias para ter uma qualidade de vida que possa ser considerada adequada, tornou-se um fato real e moralmente justificado que foi assumido pelas áreas da saúde e da ciência e tecnologia do país.

Constatou-se que o Estado brasileiro nada mais fez do que tomar para si uma responsabilidade, pois, de acordo com Semplici (87) é inevitável à consideração do Estado como o principal destinatário da responsabilidade para com a saúde e o bem estar de indivíduos e das coletividades que estão sob sua responsabilidade.

Para o autor da tese, a atitude tomada pelo país, além de moralmente justificada, ratificou o que anos mais tarde foi propugnado pelo conteúdo de documentos internacionais, a exemplo dos conteúdos abaixo descritos que são respectivamente do 
Relatório de Responsabilidade Social e Saúde (4) e da Declaração da América Latina e Caribe para a Sexta edição do Fórum Mundial da Ciência (6).

No caso do primeiro documento, ele afirma que a pesquisa deve ser vista como um investimento e não como uma despesa. Quando se trata do conhecimento produzido pelas pesquisas em saúde, pode-se afirmar que se trata de algo essencial capaz de elucidar a natureza e o contexto dos problemas, para desenvolver e implementar intervenções que salvem vidas, para buscar melhorias dos determinantes sociais da saúde e proporcionar celeridade na consecução dos Objetivos de desenvolvimento propostos para o Milênio pela ONU (36).

O segundo documento traz proposições já vigentes no país, a exemplo da viabilização de oportunidades de pesquisa para doenças tropicais, também denominadas de negligenciadas, da correção das assimetrias de oportunidades no campo do acesso as pesquisas científicas, da promoção da inclusão social, do bem estar e da redução de pobreza, confirmando assim, que o país já se antecipava e avançava em matéria de ciência, tecnologia e inovação.

Como já foi explicitado por esta tese, o processo de apoio à pesquisa em doenças negligenciadas culminou com a publicação de dois grandes editais nos anos de 2006 e 2008, envolveu sete doenças como prioridades e demonstrou que, além do caráter vanguardista, uma intervenção necessária foi desempenhada pelo Estado no cenário da pesquisa nacional em saúde.

As evidencias apontam que as ações governamentais voltadas para a pesquisa de doenças enquadradas no status de negligência são uma prática no país que podem ser exemplificadas pelos editais publicados para a tuberculose (2003), para a dengue (2004) e para hanseníase (2005) (58).

No entanto, o presente estudo constatou que nenhuma ação de apoio à pesquisa foi tão expressiva quanto às que foram promovidas nos anos de 2006 e 2008. Nenhum edital, até então, tinha contemplado tantas linhas de pesquisa para um número tão expressivo de doenças (trouxe sete doenças como prioridade no seu conteúdo). De acordo com o DECIT (62) o edital temático das doenças negligenciadas foi considerado como a mais importante iniciativa do ano de 2006, tanto pela relevância do tema quanto ao aporte de recursos destinado para o edital.

$\mathrm{O}$ incremento de investimento realizado, principalmente pelo Ministério da Saúde, ao longo de seis anos (2003 - 2008) gerou os seguintes resultados: publicação de 140 estudos sobre dengue; 175 com foco em hanseníase, 300 a respeito de tuberculose, 
775 sobre leishmaniose e 922 a respeito da abordagem da doença de Chagas. Além desses avanços proporcionados pela pesquisa científica, em 2008 o Ministério da Saúde divulgou uma lista de 80 itens de suprimentos considerados estratégicos para o Sistema único de Saúde (SUS). Dentre estes, medicamentos, equipamentos e materiais destinados à prevenção e ao tratamento da malária, tuberculose, hanseníase e doença de Chagas (118).

Nesse sentido, verifica-se que em termos de financiamento público, o Brasil está em sexto lugar no ranking dos países que mais investem no segmento das doenças negligenciadas, e o primeiro, se considerarmos apenas os países de média e baixa renda onde essas doenças são endêmicas (57). Atualmente, fatos apontam e confirmam que as medidas adotadas pelo país relativas à pesquisa em doenças negligenciadas refletem na sua liderança mundial em pesquisas sobre o tema (119), demonstrando, inclusive, a supressão do abismo científico instituído no país entre a área das doenças negligenciadas com outras áreas da saúde (120).

O que se verifica é que o país é destaque mundial na produção de medicamentos para assistência a doenças negligenciadas, por meio de parcerias entre laboratórios públicos e privados. O investimento em laboratórios públicos produtores saltou de $\mathrm{R} \$$ 8,8 milhões em 2000 para mais de R 54 milhões em 2011 (121).

De acordo com as autoridades sanitárias do país, os cortes promovidos pelo Governo Federal para as áreas de Ciência, Tecnologia e Inovação não impediram o crescente investimento em pesquisas na área das doenças negligenciadas, pelo contrário, nunca o Brasil investiu tanto em algumas doenças sob o status da negligência (119).

Destaca-se que além de investir de modo expressivo em pesquisas sobre o tema, o país também passou a investir na produção de insumos utilizados no combate e no tratamento de determinadas doenças negligenciadas, a exemplo do medicamento Benzonidazol utilizado no combate da doença de Chagas e dos medicamentos para tuberculose (119).

De fato, as evidências científicas confirmam que a vinculação de programas de combate a doenças, como nos casos dos bem sucedidos programas de controle da varíola, oncocercose e doença de Chagas $(122 ; 123)$ devem, em parte, seu sucesso ao fato de terem incluído como parte das suas ações atividades de pesquisa, reforçando a ideia que a produção do conhecimento científico torna-se um forte componente para superação das iniquidades na medida em que integram as verdadeiras necessidades da sociedade à agenda de pesquisa vigente no país. 
Nesse sentido, Sanders e colaboradores (124) reforçam que as ações de saúde, como no caso das pesquisas, devem ter seu ordenamento baseado tanto na crescente dívida existente entre localidades ricas e pobres, como também no espaço existente entre a disponibilidade do conhecimento científico e sua efetiva aplicação para solucionar problemas de saúde que acometem principalmente as populações expostas à pobreza.

Desta forma, pode-se considerar que o processo de priorização das doenças negligenciadas, que culminou com os editais de 2006 e 2008, foi uma espécie de divisor de águas para a produção do conhecimento desta área no país. Por isso, esses editais devem ser considerados como um marco legítimo na historia da pesquisa em saúde do Brasil, reforçando ainda mais a existência de compromisso ético com o tema. Portanto, o que se observa é que o tema não se encontra numa vala comum, relegado ao esquecimento, pelo contrário, observa-se que o país tem demonstrado esforço por meio de várias ações, inclusive as não atinentes ao setor da saúde, para reversão da sua condição de líder no ranking de número de casos das doenças negligenciadas das Américas (115).

Apesar do longo caminho que se tem a percorrer, constata-se que autoridades sanitárias e comunidade científica do país demonstram-se moralmente comprometidos com o tema já que estão trabalhando de maneira sinérgica para descobrir ou aprimorar medidas já existentes capazes de contribuir na reversão de uma condição que persiste para doenças e doentes.

A louvável tentativa do país em estabelecer uma nova ordem no campo da pesquisa em saúde, além de considerar as necessidades prementes na realidade dos coletivos socialmente excluídos, considerou também as diferenças regionais presentes nas cinco regiões do país aonde as pesquisas seriam produzidas. Como consequência foi prescrita uma medida pelos editais na intenção de abrandar tais diferenças e incentivar o acesso dos estudos provenientes das regiões menos estruturadas e com altos índices de doenças negligenciadas.

De acordo com Albuquerque (125), esse movimento começou a ocorrer, principalmente, pela crescente preocupação com a questão regional que se torna explícito pela grande desigualdade em relação à capacidade produtiva, à formação de pesquisadores, ao financiamento, ao planejamento e à gestão de ciência, tecnologia e inovação no Brasil. Ainda de acordo com a autora, as desigualdades que historicamente persistem no país, funcionam como um importante entrave para o fortalecimento da 
produção do conhecimento, pois, muitas vezes dificultam a aproximação dos interesses, competências e necessidades regionais das diretrizes que constam nas políticas da área de ciência, tecnologia e inovação vigentes no país.

Realmente, um incentivo pautado no combate das iniquidades regionais da pesquisa foi instituído para todas as regiões do país, inclusive, para as regiões com maior prevalência das doenças negligenciadas e com menor capacidade para pesquisa, como é o caso das regiões geográficas do Norte, Nordeste e Centro-Oeste $(120 ; 126)$.

Na visão de Morel e colaboradores (120), esse tipo de incentivo funciona para estimular a produção do conhecimento em regiões que as iniquidades regionais no campo da pesquisa em saúde são visíveis e inversamente proporcionais à prevalência de muitas doenças.

No entanto, o que se constatou foi que a maioria das pesquisas contempladas com recursos públicos tratava-se dos estudos realizados por instituições de pesquisas da região mais desenvolvida, com melhor estrutura e que não se enquadra na maior prevalência de casos de doenças negligenciadas no país (126), no caso, a região Sudeste, ratificando o que outrora já foi afirmado por Noronha e colaboradores (48).

De fato, a realidade apontada por este estudo não foge aos padrões da situação da produção do conhecimento vigente no país. Quando se analisa a produção relativa ao tema das doenças negligenciadas, verifica-se que esta ainda se concentra, principalmente, nas instituições situadas no Rio de Janeiro e São Paulo, estados da região Sudeste $(127 ; 48 ; 126)$, seguidas pela produção das regiões Nordeste, Norte e Centro-Oeste.

Os dados analisados pelo autor deste estudo confirmam que o apoio público à produção científica nacional acerca do tema das doenças negligenciadas além de ascendente é um dos mais expressivos da área da saúde (120). Entretanto, nem todos os grupos de pesquisas conseguem desfrutar de tal apoio. Percebe-se que os grupos de pesquisa mais estruturados, localizados na sua grande maioria em instituições de pesquisas situadas na região Sudeste, detêm o maior poder de captação dos recursos públicos para o desenvolvimento dos seus estudos.

Apesar da tentativa de fortalecimento da capacidade de pesquisa pelo apoio público das regiões com maiores necessidades, como no caso do Norte, Nordeste e Centro-Oeste, verifica-se ainda que o crescimento da produção científica voltada às doenças negligenciadas nestas regiões é aquém da que ocorre na região de maior desenvolvimento e capacidade de captação de recursos do país. 
O que se verifica entra as regiões é uma divisão "bastante desigual e ainda pouco articulada" (125, p.182), permanecendo algumas dificuldades de cooperação interinstitucional para formação de redes nacionais e regionais de pesquisa que integrem as de maior densidade tecnológica e produtividade com as regiões de menor densidade e menos produtivas (128).

A despeito das investidas do Estado, constata-se que uma repartição injusta e ineficaz dos recursos destinados à área ainda é algo que, além de moralmente conflitante, deixa o Norte, Nordeste e Centro-Oeste do país, que são regiões que apresentam alta prevalência de doenças negligenciadas $(120 ; 126)$, num certo descompasso do processo vigente no país de incentivo a produção conhecimento da área.

Apesar da tentativa de se estabelecer um parâmetro que considere a equidade como ponto de partida para divisão dos projetos em doenças negligenciadas por região do país, poucas modificações foram observadas no cenário da pesquisa acerca deste tema. Com isso, verificou-se o descumprimento do critério de equidade estabelecido pelas normativas. A quantidade de projetos contemplados das regiões Norte, Nordeste e Centro-Oeste, além de não representarem nem a metade dos projetos contemplados pela região Sudeste, não chegou ao patamar estabelecido pelas normativas vigentes para a pesquisa em saúde no país.

O que se pôde observar foi que instituições que ocupam lugar de destaque no ranking de produção do conhecimento foram as mesmas contempladas pelos dois editais, concentradas em sua grande maioria nos estados de São Paulo e Rio de Janeiro. Deste modo, há uma sugestão que as mesmas instituições perpetuam o seu poder e suas subjetividades, ferem o que se considera por equidade nas ações de saúde e confirma a máxima de quem tem o conhecimento, detém o poder.

$\mathrm{O}$ autor desta tese defende que o poder das instituições e de muitos de seus pesquisadores, que ao longo dos anos vem se perpetuando, necessita urgentemente ser revisto. Para o caso específico visualizado por este estudo, em vez de pensar o poder como "poder sobre os outros", deve-se pensá-lo como "poder com os outros" (129, p.31). Ou seja, a lógica da independência, da cooperação e, sobretudo, da partilha de recursos deve ser estimulada para que instituições e pesquisadores que se encontram em regiões menos desenvolvidas, porém, não menos capazes, possam desfrutar das possibilidades nacionais de estímulo à produção do conhecimento. 
Para o autor deste estudo, critérios para aprovação dos projetos de pesquisas devem ser estabelecidos pela equidade e não pela igualdade de condições das instituições responsáveis pelos estudos. De acordo com Garrafa e Porto (130), igualdade é a consequência que se deseja para a equidade, sendo esta apenas o marco inicial para aquela. Ou seja, por meio do reconhecimento das diferenças e a supressão das necessidades diversas dos sujeitos sociais é que torna possível o alcance da igualdade. Para os autores anteriormente citados, quando se observa a igualdade de forma exclusivamente horizontalizada, que tende a anular as diferenças, está se ignorando as desigualdades concretas e aviltantes que marcam hoje a vida da maior parte das populações mundiais. A igualdade é a conclusão da justiça social, referencial dos direitos humanos mais elementares, cujo objetivo futuro é o reconhecimento da cidadania.

Desta forma, critérios de equidade devem prevalecer nesses tipos de editais, pois, além de respeitar as diferenças regionais, pode ser um caminho para que se atinja a igualdade de acesso das partes envolvidas. Sendo assim, Nunes (131) afirma que a eleição dos mais necessitados é central na elaboração de qualquer metodologia que pretenda alocar ou alterar alocação de recursos, que no primeiro momento, para ser mais equitativa, a alocação deve ocorrer pela seleção de necessidades.

Portanto, uma ação que pretende ser guiada pela equidade tem que reconhecer as "necessidades diversas em sujeitos também diferentes para atingir objetivos iguais" (130, p.38), pois, só assim, quando concebida à luz desta afirmação, parâmetros éticos estarão presentes e poderão proporcionar satisfação não apenas aos mais fortes e, sim, as necessidades de todos os envolvidos.

Na visão do autor deste estudo, apesar da distribuição não equitativa dos projetos por regiões, espera-se que o incentivo do Estado à produção do conhecimento voltada ao combate das doenças negligenciadas esteja atuando como uma ação cujas consequências possam possibilitar a promoção de bem estar para um maior número de pessoas, tornando-se moralmente justificável, mas que não deve deixar de ser questionada, apesar dos seus desdobramentos favorecerem, principalmente, indivíduos e os coletivos que são socialmente excluídos.

Nesse sentido, é indispensável, portanto, que além de serem criados mecanismos destinados ao combate das iniquidades regionais no campo da produção do conhecimento da área, eles devem, efetivamente, ser colocados em prática. Para isso, a bioética pode e deve ser utilizada como um instrumento com capacidade de mediar 
conflitos dessa natureza, pois, é notório que questões que envolvem iniquidades e assimetrias de poder são pontos recorrentes da agenda de atuação desta disciplina no século XXI $(90 ; 129 ; 130)$. De acordo com Porto (132), a partir do momento que a bioética identifique um conflito, quer seja por evidência ou por suspeita, ela deve se posicionar para estimular um processo reflexivo capaz de definir e aplicar parâmetros éticos que poderão conduzir efetivamente a transformação de uma realidade.

Deve ficar claro que, entre outras razões, o surgimento da bioética se deu, sobretudo, para dar reforço ao lado mais frágil de qualquer inter-relação historicamente determinada. Para isso, ela sempre será uma mediadora da relação privilegiados/incluídos e desprivilegiados/excluídos na tentativa de evitar que se estabeleça a ausência da ética, impedindo que os que estão em situação de desprivilegio/exclusão tornem-se verdadeiros "excluídos morais” (130).

É interessante observar que o processo de produção do conhecimento estimulado pelos editais de 2006 e 2008 foi exercido, na sua grande maioria, pelas instituições universitárias, consideradas o lócus privilegiado de construção científica e de desenvolvimento tecnológico, não só no Brasil, mas em todo mundo (133), foi corroborado pelas evidências apontadas por Iozi (134) ao afirmar que as atividades de pesquisa no Brasil ocorrem em instituições universitárias e em instituições de pesquisa específicas da área da saúde, com uma incipiente participação das unidades de serviço, com exceção dos hospitais de ensino, e das empresas privadas do setor.

Seguindo esta tendência, as universidades e centros de pesquisas da região Sudeste do país mantiveram-se como o locus preferencial da produção do conhecimento em doenças negligenciadas no país ao longo da série temporal analisada por este estudo. Leta e colaboradores (135) já haviam demonstrado esta dinâmica ao afirmar que a produção de pesquisa do país estaria concentrada nas universidades e em alguns centros de pesquisa da região mais desenvolvida do país.

Desta forma, os fatos acima apontados confirmam que o que se denominava por ciclo virtuoso, instituído principalmente pelas universidades públicas desde meados dos anos 60, destinado a formar e consolidar grupos de pesquisa (136), passou a ter um comportamento de "ciclo vicioso", explicitado por uma tendência de centralização de poder e das subjetividades de muitas instituições e de seus pesquisadores que, além de tudo, perpetuam e reforçam as iniquidades regionais na produção do conhecimento verificada no cenário da pesquisa em saúde no país. 
Os resultados relativos à localização geográfica e tipos de instituições contempladas pelos editais anteriormente apontados pelo autor, demonstram que a situação da pesquisa destinada às doenças negligenciadas no país está em consonância com a situação das demais pesquisas realizadas pela área da saúde, ou seja, pesquisas realizadas por instituições públicas e com o apoio público na maioria dos casos (125).

De acordo com os dados apontados pela Secretaria de Ciência, Tecnologia e Insumos Estratégicos do Ministério da Saúde (137), os grupos que realizam atividades de pesquisa em saúde no país, $49 \%$ estão localizados na região Sudeste, $23 \%$ na região Sul, $17 \%$ na região Nordeste, $6 \%$ na região Centro-Oeste e $5 \%$ na região Norte.

Como consequência desta configuração, observa-se também que a maioria dos programas de pós-graduação do país estão localizados na região Sudeste (55\%) (138), local onde também ocorre a maior concentração de bolsas de produtividade científica ofertadas pelo CNPq (128).

Sem sombra de dúvidas, quando concebidas a partir dos referenciais apontados pelos Artigos 10 e 14 da Declaração Universal sobre Bioética e Direitos Humanos (2), que consideram a equidade, a justiça e a responsabilidade social dos diferentes grupos interessados como elementos norteadores, as ações, cujo foco destina-se à pesquisa científica, tem a capacidade de suscitar temas relevantes para sociedade que, além de elevar o país a um melhor patamar de desenvolvimento econômico e social, agem como uma espécie de motor propulsor de liberdade (139).

Diante do exposto, verifica-se que a indução à pesquisa em doenças negligenciadas, quando colocada em prática, na opinião do autor deste estudo não pode ser direcionada e ficar restrita apenas aos centros de pesquisa situados nas instituições de maior projeção do país. Estes centros de pesquisas, que trazem nos seus históricos a capacidade instalada e a habilidade para a realização de estudos de relevância para a temática, devem introjetar nas suas práticas mecanismos que possibilitem a aproximação das instituições com menor capacidade instalada, mas com potencial para desenvolver estudos. Desta forma, deve-se superar a lógica da capacidade instalada para a lógica do potencial de quem quer produzir conhecimento científico no país.

Em relação ao sexo, os resultados demonstraram um equilíbrio desta variável para os dois editais. No edital de 2006 foram contemplados 47 (58\%) líderes de projetos do sexo masculino e 35 (42\%) líderes do sexo feminino. No ano de 2008 houve um pareamento ficando metade de líderes de projetos do sexo masculino e a outra metade do sexo feminino (50\% cada). 
Tais resultados corroboraram com as afirmações de Minayo (133) quando apontou que a área de Ciência, Tecnologia e Inovação (C\&T\&I) tem apresentado um caminho positivo quanto à igualdade dos sexos no campo da pesquisa científica, pois, em 2010 a participação percentual das mulheres no setor pareou com a dos homens, tendo havido também crescimento contínuo na condição de liderança de grupos de pesquisa. Em 2010 a situação da pesquisa era a seguinte: 54,9\% de homens líderes de pesquisa e 45,1\% de mulheres líderes de pesquisa; contra 66,8\% e 33,2\%, respectivamente para o ano de 2000.

$\mathrm{O}$ autor do estudo destaca que, apesar de ser considerada como um dos principais meios de enfrentamento para o status de negligência condicionado a determinadas doenças infecciosas, a pesquisa científica não é o único meio. Portanto, uma abordagem mais ampla se faz necessária, principalmente, pela complexidade que envolve o tema. Visões morais que não se prendam apenas às questões atinentes à assistência à saúde devem ser incorporadas para esta temática, pois, apesar de se tratar de entidades nosológicas, não se pode aprisionar o tema apenas à lente das consequências biológicas que o envolve, da sua ocorrência individualizada e dissociada dos fenômenos sociais que o cerca.

Assim, o autor da tese aponta que é impossível estabelecer uma dissociação da relação entre doença e doente, doente e seu meio social, fazendo-se necessária um olhar convergente das abordagens biológicas e sociais relativas ao tema.

Deve ficar claro que, além de existir doenças negligenciadas, existem também indivíduos/coletivos doentes que são negligenciados ou indivíduos/coletivos que apesar de não estarem doentes, caso não haja algum tipo de intervenção, serão enquadrados como possíveis suscetíveis ao acometimento de uma ou de várias doenças negligenciadas. Para que isso não se torne um fato concreto no cotidiano desses indivíduos e de seus coletivos, Junges e Zoboli (70) recomendam que se deva atentar para complexidade da realidade, pois os fenômenos biológicos e sociais apresentam um infindável número de interações e inter-retroações impossível de ser mensurada, sobretudo, quando não são consideradas como fatores determinantes das situações de saúde ou de doenças das populações.

Ao investigar a atuação dos pesquisadores contemplados pelos editais de apoio ao estudo das doenças negligenciadas, o que se verificou foi que a atuação que se demonstrou mais influente sobre o grupo analisado não fugiu dos padrões dos resultados já apontados por esta tese quando analisou os dados quantitativos. O que se 
viu, mais uma vez, foi que a atuação do grupo analisado foi conduzida, principalmente, pelos pesquisadores das instituições da Região Sudeste do Brasil. Vale destacar que, apesar de não estar inserida como uma das regiões mais contempladas pelos editais, o Nordeste do país demonstrou-se como uma influência expressiva para a atuação do grupo analisado, sobretudo, pelos estudos da saúde coletiva e da epidemiologia.

Apesar da complexidade e da necessidade dos olhares das várias disciplinas para o tema das doenças negligenciadas, constatou-se que uma moralidade emergiu a partir da análise da atuação de parte do grupo dos pesquisadores participantes deste estudo. Portanto, o indica-se que uma moralidade estabelecida a partir do olhar biológico e individualizado voltado à doença conduziu a atuação dos pesquisadores analisados ao longo de toda série temporal estudada por esta tese, reproduzindo a visão hegemônica atual da ciência. Vale destacar que a atuação a partir deste enfoque foi exteriorizada, principalmente, pela realização de pesquisas biomédicas, clínicas e de desenvolvimento tecnológico.

De fato, a visão biológica e individualizada com a valorização da doença demonstrou-se como a grande influência para a atuação do grupo de pesquisadores analisados. Entretanto, a visão social e coletiva não foi colocada à margem, ela foi considerada e também influenciou a atuação do grupo de pesquisadores analisados ao longo do recorte temporal proposto por esta tese.

Constatou-se que a pesquisa biomédica, considerada por muitos como o tipo de pesquisa capaz de produzir apenas o conhecimento teórico acerca do objeto de estudo (11), conduziu predominantemente a atuação do grupo estudado, principalmente, no primeiro período analisado por esta tese. No entanto, esta tendência foi modificada, pois, uma atuação orientada pela pesquisa clínica, considerada também por muitos como estratégica e de grande importância, especialmente, pela sua capacidade de pôr em prática o conhecimento teórico adquirido para descobrir meios que podem atuar na reversão das doenças (140), ganhou espaço, sobretudo, ao longo do segundo período analisado por este estudo e influenciou de modo expressivo a atuação dos pesquisadores com práticas voltadas ao enfrentamento das doenças negligenciadas.

Vale destacar que as inferências apontadas acima, tornaram-se concretas com os resultados dos editais analisados por esta tese. Observou-se que a tendência visualizada na atuação foi repetida nos resultados relativos aos tipos de pesquisas contempladas pelos editais anteriormente citados, ou seja, o número de pesquisas clínicas aprovadas no edital de 2008 superou o número de pesquisas biomédicas também contempladas 
pelo mesmo edital. Portanto, os resultados observados por este estudo tomam o mesmo caminho das evidências científicas que apontam para crescente participação do país no cenário da pesquisa clínica $(141 ; 140)$.

Outro fato relativo ao enfoque biológico e individual que merece destaque, diz respeito aos resultados obtidos pela análise dos artigos científicos em português e inglês publicados pelos pesquisadores participantes deste estudo. Constatou-se, inicialmente, que o volume de artigos científicos em inglês com conteúdo associado à atuação biológica foi superior ao da produção em português nos dois períodos analisados. Além disto, a contribuição para a atuação verificada, tanto pela produção em português como pela de inglês, demonstrou comportamentos diferentes. Para o primeiro caso, verificouse que a pesquisa clínica contribuiu apenas no segundo período analisado para a atuação dos pesquisadores. No segundo caso, a pesquisa clínica contribuiu para a atuação logo no primeiro período analisado. Na opinião do autor desta tese, este fato, possivelmente, pode ser demonstrado como um indicativo da preocupação e da necessidade iminente percebida por muitos dos pesquisadores analisados de inserir seus estudos e, consequentemente, o país no contexto internacional da pesquisa clínica.

Ainda em relação aos artigos científicos em português e inglês analisados, no caso da atuação que ocorreu pelo enfoque social e coletivo, os estudos em saúde coletiva apesar de não serem hegemônicos para atuação, na produção em português mostraram-se expressivos ao longo de todo período temporal estudado, fato que não foi constatado na produção em inglês. De fato, os artigos científicos em inglês, em sua maioria, trouxeram mais expressão na atuação biológica. Entretanto, no segundo período temporal analisado, observou-se que a produção científica em inglês contribuiu na atuação cujo enfoque foi o social e coletivo, sobretudo, com as investigações epidemiológicas sobre a tuberculose realizadas por instituições de pesquisa da região Sudeste do país.

Uma das possibilidades verificadas pelo autor que pode ter relação direta com esta tendência, inclusive pode justificá-la, é justamente a grande expressão que determinadas doenças negligenciadas representam diante das populações situadas nas periferias metropolitanas e nos bolsões de miséria das grandes cidades, principalmente, da região Sudeste, como no caso da dengue e da tuberculose, cuja incidência é mais alta no estado do Rio de Janeiro do que em qualquer outra unidade federada do país (126).

De fato, o olhar para a doença enquanto uma entidade isolada torna-se necessário, principalmente, pela necessidade da criação ou do aprimoramento de 
medidas terapêuticas capazes de enfrentá-las. Entretanto, por se tratar de uma temática complexa, ela não deve ficar restrita apenas a parâmetros biológicos. Porto (132, p. 214) corrobora com tal posicionamento quando afirma que temáticas complexas "exigem a integração do conhecimento de diferentes áreas para produzir as respostas que a realidade demanda". Portanto, o diálogo dos parâmetros biológicos com as distintas áreas do conhecimento tende a potencializar os meios de enfrentamento das doenças, sobretudo, quando a abordagem ao processo saúde/doença valoriza a dimensão social e coletiva que é inerente a este.

Desta forma, quando se trata de um tema que repercute diretamente nas condições de vida da porção vulnerada da sociedade (86), valores e princípios variados devem atuar de maneira sinérgica na intenção de proporcionar benefícios, principalmente, aos componentes menos favorecidos da sociedade e com risco eminente de serem acometidos pelas doenças negligenciadas. Por isso, faz-se necessário a inserção de saberes oriundos de áreas do conhecimento distintas, principalmente, pela necessidade de um enfrentamento que leve em consideração a subjetividade e o contexto sociocultural para interpretação da saúde e da doença (70).

Neste sentido, Junges e Zoboli (70) afirmam que quanto mais se tem consciência sobre o contexto das interações biológicas e sociais, mais efetivos se mostrarão os resultados esperados para determinadas ações. Portanto, a preocupação de que boas intenções possam produzir resultados indesejados ocorrem, sobretudo, quando a complexidade atinente ao tema das doenças negligenciadas não é levada em consideração, promovendo a desarticulação das manifestações biológicas dos motivos relacionados com sua deflagração (74).

Para o autor desta tese, é na multiplicidade de visões, como as provenientes da biologia, da epidemiologia, da clínica e das ciências sociais, que nasce a capacidade de captação da subjetividade e do contexto intrinsecamente ligado ao cotidiano das doenças e dos indivíduos/coletivos negligenciados, que de fato, quando não consideradas impedem a compreensão no sentido de proporcionar tomadas de decisões mais adequadas, ou seja, mais apropriadas à complexidade que é inerente ao tema.

Realmente, a superação do status de negligência conferido a determinadas doenças infecciosas está atrelada ao desenvolvimento de métodos de diagnóstico e de medidas terapêuticas condizentes com o estágio atual da ciência e da tecnologia em saúde. No entanto, deve-se atentar para o fato que o desenvolvimento tecnológico não 
deve ser construído sob as bases da dissociação, pois depende, grandemente, dos determinantes sociais, contextuais e ambientais da saúde para lograr o êxito esperado.

De fato, a visão biológica continua sendo mais significativa tanto em quantidade de estudos científicos quanto na produção de artigos acadêmicos (132), fato que gera inegáveis benefícios à saúde da população, portanto, deve ser ressaltado (74). Entretanto, não se pode e nem se deve perder de vista a possibilidade que uma atuação quando vinculada a sua realidade potencializa a capacidade da sua interpretação e consequentemente da ação.

$\mathrm{Na}$ intenção de finalizar, mas de não esgotar o debate que foi estabelecido ao longo deste capítulo, afirma-se que a bioética, cujo foco de atuação é mediar por meio das suas reflexões, muitas vezes contundentes, conflitos que emanam de interações paradoxais. Portanto, cabe a ela o papel de instrumento primordial capaz de deflagrar um debate que promova a reversão das iniquidades e aponte para formas de partilha de poder que facultem vantagens para todos os envolvidos. Portanto, compreender o humano é entender sua unidade na diversidade, sua diversidade na unidade. É preciso idealizar a unidade do múltiplo, a multiplicidade do uno (142). 


\section{CONCLUSÃO}

Conclui-se, portanto, que as reflexões e os discursos dos autores utilizados na construção desta tese, na sua grande maioria, foram fundamentados no discurso bioético determinado a suplantar as injustiças sociais e sanitárias e as assimetrias estabelecidas entre aqueles que detêm o poder e os que não tem poder algum, provenientes, na maioria das vezes, das situações persistentes que ainda acometem a humanidade.

Neste sentido, as visões trazidas para esta tese, na sua grande maioria, além de serem provenientes dos autores que rejeitam o modo de tratamento insensível e indiferente ofertado por muitos a um problema cujo impacto reflete na vida de milhões de pessoas, fundamentam-se no compromisso da construção de uma bioética participativa e engajada na superação dos indesejáveis e persistentes problemas presentes nos países periféricos.

Portanto, a atuação da bioética vista por esta tese estabeleceu um diálogo com as medidas utilizadas para o enfrentamento do pesado ônus causado pelo flagelo das doenças negligenciadas, para amplificar por meio do seu discurso, a voz daqueles que se encontram sem visibilidade, rechaçando as possíveis causas que impedem indivíduos e coletivos, principalmente os que se encontram sob o estado de vulnerabilidade social, ao acesso de cuidados à saúde de qualidade e a medicamentos que sejam essenciais a sua sobrevivência.

Outra conclusão também verificada por este estudo foi que um dos principais meios de superação, porém não o único, do status de negligência que se encontram determinadas doenças infecciosas é a valorização da produção do conhecimento que considere as verdadeiras prioridades sanitárias apontadas no país. Neste sentido, as autoridades sanitárias e a comunidade científica ao longo da implementação da Política Nacional de Ciência, Tecnologia e Inovação em Saúde demonstraram-se eticamente comprometidos, principalmente com a porção pobre e marginalizada da população, ao inserir como ponto prioritário da agenda nacional de pesquisa o tema das doenças negligenciadas.

$\mathrm{Na}$ visão do autor desta tese, o grande desafio lançado ao país no campo da produção do conhecimento destinado as doenças negligenciadas é justamente a construção da relação entre as ações de estímulo destinadas ao fortalecimento da 
capacidade de produção científica voltada ao tema e o estabelecimento de formas equitativas de alocação dos recursos que se destinam a esse tipo de produção.

De fato, quando conduzidas por parâmetros que considerem a ética como ponto de partida, as ações podem tanto potencializar a produção científica da área procedente da região Sudeste, considerada também por este estudo como a região de maior produtividade científica sobre o tema no Brasil, como também a de centros de pesquisa situados nas regiões Norte, Nordeste e Centro-Oeste, que são as regiões menos desenvolvidas e que apresentam números alarmantes relativos a doenças negligenciadas no país.

Além disto, o autor também considera que a produção do conhecimento deve ser sinérgica e estar em consonância com as verdadeiras necessidades da sociedade, fazendo com que seja estabelecida uma estreita e verdadeira relação entre pesquisa, política de saúde e equidade.

Dessa forma, o enfrentamento das doenças negligenciadas pode-se demonstrar como uma oportunidade de desenvolvimento que precisa ser explorada cada vez mais para redução do quadro de pobreza e esquecimento que vem assolando indivíduos e seus coletivos por um longo prazo. Sendo assim, deve-se atentar para o fato de que tal atuação quando eticamente conduzida trará consequências que irão refletir diretamente sobre a realização dos Objetivos de Desenvolvimento do Milênio propostos pela ONU (36), assim como no cumprimento da garantia do mais alto padrão de saúde como direito humano fundamental de todas as nações.

Portanto, defende-se que o conhecimento produzido, particularmente, os produzidos pelas pesquisas realizadas por meio de fomento público, além de serem pensados a partir das necessidades, seus resultados devem ser revertidos em melhorias concretas das condições de saúde dos indivíduos e seus coletivos, tanto por sua aplicação nas medidas assistenciais geradas das demanda das políticas de saúde vigentes no país quanto na implementação de medidas macroestruturais atinentes ao desenvolvimento econômico e social do Brasil.

Para que isso ocorra, indica-se que a atuação frente às doenças negligenciadas não fique restrita apenas a entidade nosológica, que é a visão hegemônica atual da ciência. Uma abordagem mais ampla se faz necessária, pois é impossível dissociar a relação entre doença e doente, doente e seu meio social. Ao longo deste estudo foi esclarecido que além da existência de doenças negligenciadas, existem também indivíduos/coletivos (doentes) negligenciados ou indivíduos/coletivos que, apesar de 
não estarem doentes, estão cercados de fatores que aumentam a suscetibilidade do acometimento de uma ou de várias doenças infecciosas enquadradas na condição de negligência.

Assim, ficou evidente pelos tipos de estudos realizados por meio de apoio público que o país além de necessitar de pesquisas que tenham como resultado medidas terapêuticas capazes de combater as doenças negligenciadas, obtidas, sobretudo, pelas pesquisas clínicas, precisa também de estudos voltados ao conhecimento e aprofundamento acerca dos determinantes sociais envolvidos na ocorrência dessas doenças. Observou-se que além do estímulo a produções do conhecimento, que é algo imprescindível e inadiável para determinados temas, profundas e verdadeiras transformações sociais tornam-se cada vez mais necessárias para favorecer a mudança do status de doenças e de indivíduos e coletivos negligenciados.

Recomenda-se, portanto, a valorização do registro no sítio eletrônico pesquisa em saúde/MS dos resultados dos estudos realizados por meio do fomento público e seus produtos. Desta forma, pode-se favorecer a diminuição da distância estabelecida entre a produção do conhecimento, resultados da pesquisa e a sua aplicabilidade como elemento norteador tanto na construção de políticas públicas quanto nas ações voltadas para atenção à saúde.

Além disto, espaços de diálogo que valorizem os diversos saberes devem ser estimulados na intenção de estabelecer uma sinergia entre as várias frentes de atuação vinculadas a pesquisa em saúde do país.

Apesar do presente estudo ter se limitado à verificação da produção do conhecimento por meio de artigos científicos, reforça-se, mais uma vez, que as atividades de ensino e extensão devem ser valorizadas, pois, na prática é onde se visualiza a aplicabilidade e a avaliação das pesquisas, portanto, capazes também de produzir conhecimento.

Por fim, o autor desta tese reforça que o compromisso assumido pelo Estado brasileiro conjuntamente com parte dos integrantes da comunidade científica nacional, demonstrou-se como moralmente justificado e eticamente comprometido ratificando, mais uma vez, que apesar da condição notória de negligência verificada a muitas doenças infecciosas, elas não estão esquecidas pela ciência. 


\section{REFERÊNCIAS BIBLIOGRÁFICAS}

1.WHO. First Who reporto $\mathrm{n}$ neglected tropical diseases: working to overcome the global impacto f neglected tropical diseases. WHO/HTMA/NTD/2010.1. Geneva. Disponível: http://www.who.int/neglected_diseases/2010report/en/; (acesso 10 jun. 2013).

2. ORGANIZAÇÃO DAS NAÇÕES UNIDAS PARA EDUCAÇÃO, A CIÊNCIA E A CULTURA. Declaração Universal sobre Bioética e Direitos Humanos (internet). Genebra: UNESCO; 2005 (acesso em 30 ago. 2012).

3. SCHRAMM FR. A moralidade da biotecnociência: a bioética da proteção pode dar conta do impacto real e potencial das biotecnologias sobre a vida e/ou a qualidade de vida das pessoas humanas. In: SCHRAMM FR, BRAZ M, PALÁCIOS M, organizadores. Bioética, riscos e proteção. Rio de Janeiro. Editora UFRJ/Editora Fiocruz. 2009, p. 15-28.

4. COMITÊ INTERNACIONAL DE BIOÉTICA. Washington: ONU. Relatório sobre o Princípio da Responsabilidade Social e Saúde do Comitê Internacional de Bioética. Disponível em: www.onu.org/ibc. (acesso em 20 dez. 2013).

5. BERLINGUER G. Bioética Cotidiana. Brasília, Editora Unb, 2004.

6. DECLARAÇÃO DA AMÉRICA LATINA E CARIBE PARA A SEXTA EDIÇÃO DO FÓRUM MUNDIAL DA CIÊNCIA. RIO DE JANEIRO, 2013. Disponível em http://www.sbpcnet.org.br/site/arquivos/arquiv o_369.pdf (acesso em 21 dez. 2013).

7. BERLINGUER G. Questões de vida. Ética, ciência, saúde. São Paulo: APCE/HUCITEC/CEBES, 1993.

8. GARRAFA V. Da Bioética de princípios a uma bioética interventiva. Revista Bioética, 2005, v.13, n.1, p.125-134.

9. MINAYO MC de S. Ciência, técnica e arte: o desafio da pesquisa social. In: MINAYO MC de S et al, organizadores. Pesquisa social: teoria, método e criatividade. 23. ed. Petrópolis, Rio de Janeiro: Editora Vozes, 2004, p. 9-29.

10. BRASIL. Ministério da Saúde. Secretaria de Ciência, Tecnologia e Insumos Estratégicos. Departamento de Ciência e Tecnologia. Programa Pesquisa para o SUS: gestão compartilhada em saúde/PPSUS - Diretrizes Técnicas. Brasília: Ministério da Saúde, 2007. 70 p. 3 ed. revisada (Série A. Normas e Manuais Técnicos). 
11. BRASIL. Ministério da Saúde. Secretaria de Ciência, Tecnologia e Insumos Estratégicos. Departamento de Ciência e Tecnologia. Seleção de prioridades de pesquisa em saúde: guia PPSUS/Ministério da Saúde, Secretaria de Ciência, Tecnologia e Insumos Estratégicos, Departamento de Ciência e Tecnologia. Brasília: Ministério da Saúde, 2008. 74 p. (Série A. Normas e Manuais Técnicos).

12. KUHN T. The structure of Scientific Revolutions. Chicago, 2 ed. Chicago University Press, 1972, p. 30.

13. KOTTOW M. Bioética de proteção: considerações sobre o contexto latino americano. In SCHRAMM FR, REGO S, BRAZ M, PALÁCIOS M, organização. Bioética, risco e proteção. 2 ed. Rio de Janeiro: Editora UFRJ/Editora Fiocruz, 2009.

14. CAMARGO EP. Doenças tropicais. Estudos avançados. São Paulo, 2008, vol.22, n.64, p. 95-110.

15. MOREL CM. Geração de conhecimento, intervenções e ações de saúde. São Paulo em Perspectiva. 2002, vol.16, n.4, p. 57-63.

16. BRASIL. Ministério da Saúde. Secretaria de Ciência, Tecnologia e Insumos Estratégicos. Departamento de Ciência e Tecnologia. Fluxo de recursos financeiros para pesquisa e desenvolvimento em saúde no Brasil: 2000-2002. Brasília: Ministério da Saúde; 2006. (Série C. Projetos e Relatórios).

17. CARVALHEIRO JR. Epidemias em escala mundial e no Brasil. Estudos avançados. São Paulo. 2008, vol.22, n.64, p. 7-17.

18. YAMEY G. Public Sector must Develop Drugs for Neglected Diseases. BMJ. Mar 23, 2002; 324(7339): 698.

19. MOREL CM. Inovação em saúde e doenças negligenciadas. Cad. Saúde Pública, Rio de Janeiro, 2006, 22(8):1522-1523.

20. LOBO DA, VELAYUDHAN R, CHATTERJEE P, KOHLI H, HOTEZ JP. The neglected tropical diseases of India and South Asia: Review of their prevalence, distribution and control or elimination. PLoS Negl Trop Dis 2011 5(10): e 1222. Doi: 10.1371/journal.pndt.0001222. Disponível em http//www.plosntds.or. (acesso em 20 abr. 2012).

21. RILEY LW, KO AI, UNGER A, REIS MG. Slum health: diseases of neglected populations. BMC Int. Health hum. Rights, 2007, 7: 2.

22. FRANCO-PAREDES C, SANTOS-PRECIADO JI. Freedom, justice and neglected tropical diseases. PLoS negl Trop Dis 2011, 5 (8): E1235. 
23. WHO: Neglected Tropical Diseases. Hidden successes, Emerging Opportunities. WHO/CDS/NTD/2006.22006. Disponível em http://whqlibdoc.who.int/hq/2006/WHO_CDS_NTD_2006. 2_eng.pdf. (acesso em 3 abr. 2012).

24. HOTEZ PJ, MOLYNEUX DH, FENWICK A, KUMARESAN J, SACHS SE, SACHS JD et al. Control of neglected tropical diseases. New England Journal of Medicine, 2007; 357:1018-1027.

25. HOTEZ P. The giant anteater in the room: Brazil's neglected tropical diseases problem. PLoS Neglected Tropical Diseases. 2008; 2(1):77.

26. WHO. First Who reporto $\mathrm{n}$ neglected tropical diseases: working to overcome the global impacto f neglected tropical diseases. WHO/HTMA/NTD/2010.1. Geneva. Disponível: http://www.who.int/neglected_diseases/2010report/en/; (acesso 10 jun. 2013).

27. PONTES F. Doenças Negligenciadas: ainda matam 1 milhão por ano no mundo. Revista Inovação em Pauta, FINEP, São Paulo, 2009, n. 6, p. 69-73.

28. AAGAARD-HANSEN J, CHAIGNAT CL. Neglected tropical diseases: equity and social determinants. In Equity, social determinants and public health programmes. Edited by; Blas, Erik, Kurup, Anand Sivasankara. WHO; 2010: Disponível http://www.who.int/neglected_diseases/social_determinants_NTD.pdf (acesso em 3 abr. 2010).

29. HOTEZ PJ et al. Incorporating a Rapid-Impact Package for Neglected Tropical Diseases with Programs for HIV/AIDS, Tuberculosis, and Malaria. PLoS Medicine, 2006a, v. 3, n. 5, p. e102.

30. BATALHA E.; MOROSINI L. Atenção aos esquecidos. RADIS, 2013, n. 124, p.8 17.

31. BEYRER C. Neglected Diseases, civil conflicts, and the right to health. The Lancet 2007; 370: 619-27. Vol 370 August 18.

32. BRASIL. Ministério da Saúde. Fundação Oswaldo Cruz - Instituto Oswaldo Cruz. Nota Técnica n¹/2011/IOC-FIOCRUZ/Diretoria. Rio de Janeiro, Mai 2011.

33. TDR/OMS. Plano de Trabalho do TDR 2008-2013. Aprovado pelo conselho conjunto de coordenação. Genebra - Junho, 2007.

34. MORAES NETO AHA. Vivienda saludable, de cara a Rio +20. In: ROJAS MC, PEREZ CP, compiladores. Red Interamericana de Vivienda Saludable, Avalada por la 
Organización Panamericana de Salud y la Organización Mundial de la Salud, 2012, $110 \mathrm{p}$.

35. FUNDAÇÃO OSWALDO CRUZ. A saúde no Brasil em 2030: diretrizes para a prospecção estratégica do sistema de saúde brasileiro. / Fundação Oswaldo Cruz... [et al.]. Rio de Janeiro: Fiocruz/Ipea/Ministério da Saúde/Secretaria de Assuntos Estratégicos da Presidência da República, 2012.

36. UNITED NATIONS 2002. UN Millennium Development Goals (MDG). Disponível em http://www.un.org/millenniumgoals/. (acesso em 20 abr. 2012).

37. BARRETO ML, TEIXEIRA MG, BASTOS FI, XIMENES RAA, BARATA R, RODRIGUES LC. Sucessos e fracasso no controle de doenças infecciosas no Brasil: o contexto social e ambiental, políticas, intervenções e necessidades de pesquisa. The Lancet - Saúde no Brasil. Mai 2011.

38. STOBBAERTS E. Financiamento negligenciado. Saúde na mídia (internet) 2013 jun; (acesso 07 jun. 2013); Disponível: http://saude.empauta.com/saude/mostra_noticia.php?cod_noticia=1039678930

39. MOREL CM. Pesquisa em saúde e os objetivos do milênio: desafios e oportunidades globais, soluções e políticas nacionais. Ciênc. Saúde Colet. 2004; 9(2):261-70.

40. GFHR. Monitoring financial flows for health research. Global Forum for Health Research; Genebra; 2006.

41. CAETANO R, VIANNA CMM, SAMPAIO MMA, MENDES DA SILVA R, RODRIGUES RRD. Análise dos investimentos do Ministério da Saúde em pesquisa e desenvolvimento do período 2000-2002: uma linha de base para avaliações futuras a partir da implementação da agenda nacional de prioridades de pesquisa em saúde. Ciência \& Saúde Coletiva, 2010, 15(4): 2039-2050.

42. VIANNA CMM, CAETANO R, ORTEGA JÁ, FAÇANHA LOF, MOSEGUI GBG, SIQUEIRA $M$ et al. Flows of financial resources for health research and development in Brazil, 2000-2002. Bull. World Health Organ; 2007, 85:124-130.

43. AlBUQUERQUE EM, SOUZA SGA, BAESSA AR. Pesquisa e Inovação em Saúde: uma discussão a partir da literatura sobre economia da tecnologia. Ciênc. Saúde Coletiva, 2004, 9(2): 277-294.

44. GUIMARÃES R, SERRUYA SJ, DIAFÉRIA A. O Ministério da Saúde e a Pesquisa em Saúde no Brasil. Gazeta Médica da Bahia, 2008, 78(Suplemento 1): 12-21. 
45. GUIMARÃES R. Pesquisa em saúde no Brasil: contexto e desafios. Revista de Saúde Pública, São Paulo, 2006, v. 40, p.3-10, 2006. Número Especial.

46. GFHR. The 10/90 Report on Health Research 2001-2002. Global Forum For Health Research; 2002, Geneva.

47. PARAJE G, SADANA R, KARAM G. Increasing Internacional Gaps in Health Developing Countries Address Neglected Diseases. Science. 2005;308:959-60.

48. NORONHA JS, SILVA TR, SZKLO F, BARATA RB. O que os pesquisadores pensam do sistema de pesquisa em saúde no Brasil: um estudo piloto. RECIIS - R. Eletr. de Com. Inf. Inov. Saúde. Rio de Janeiro, 2012, v.6, n.1, p.13-25.

49. PELlEGRINI FILHO A. Pesquisa em Saúde, política de saúde e equidade na América Latina. Ciênc. Saúde Coletiva, 2004, 9(2): 339-350.

50. GADELHA CAG, COSTA LS, MALDONADO J. O Complexo EconômicoIndustrial da Saúde e a dimensão social econômica do desenvolvimento. Ver Saúde Públca 2012; 46(Supl): 21-8.

51. GARRAFA V, PORTO D. Intervention bioethics: a proposal for peripheral countries in a contexto of Power and injustice. Bioethics 2003; 17(5-6): 399-416.

52. DNDi. Drugs for Neglected Disease iniciative. Disponível http//www.dndi.org.br (acesso em 10 abr. 2012).

53. MORAN M, GUZMAN J, ROPARS AL, MCDONALD A, JAMESON N, OMUNE B et al. et al. Neglected disease research an development: How much are we really spending? PLoS Medicine, 2009, vol. 6, n. 2.

54. CASTILHO AL. Doenças Negligenciadas têm recursos, mas faltam projetos. Agência Fapesp, São Paulo, 01 nov. 2007. Disponível <http://www.agencia.fapesp.br>. (acesso em 30 set. 2010).

55. REMME JHF, BLAS E, CHITSULO L, DESJEUX PMP, ENGERS HD, KAYOK TP et al. Strategic emphases for tropical diseases research: a TDR perspective. Trends in Parasitology, 2002, 18(10): 421-426.

56. MÉDICOS SEM FRONTEIRAS. Desequilíbrio Fatal: a crise em pesquisa e desenvolvimento de drogas para doenças negligenciadas. Geneva: Grupo de Trabalho de Drogas para Doenças Negligenciadas, Médicos Sem Fronteiras; 2001.

57. ASSAD L. Doenças negligenciadas estão nos países pobres e em desenvolvimento. Ciência e Cultura, 2010, São Paulo, vol.62, n. 1, p. 6- 8. 
58. BRASIL. Ministério da Saúde. Secretaria de Ciência, Tecnologia e Insumos Estratégicos. Departamento de Ciência e Tecnologia. Pesquisa em Saúde no Brasil. Rev. Saúde Coletiva, 2008, 42(4):773-5.

59. BRASIL. Ministério da Saúde. Secretaria de Ciência, Tecnologia e Insumos Estratégicos. Departamento de Ciência e Tecnologia. Processo de definição de prioridades de pesquisa em saúde: a experiência brasileira / Ministério da Saúde, Secretaria de Ciência, Tecnologia e Insumos Estratégicos, Departamento de Ciência e Tecnologia - Brasília: Ministério da Saúde, 2006. 44p. - (Série C. Projetos, Programas e Relatórios).

60. BRASIL. Ministério da Saúde. Secretaria de Ciência, Tecnologia e Insumos Estratégicos. Departamento de Ciência e Tecnologia. Doenças Negligenciadas: estratégias do Ministério da Saúde. Rev. Saúde Coletiva, 2010, 44(1): 200-2.

61. SEMERENE B. The economist: Brasil é líder mundial em pesquisa em medicina tropical. Fiocruz. Agência Fiocruz de Notícias. Disponível em http//www.fiocruz.br (Acesso em 15 mar. 2012).

62. BRASIL. Ministério da Saúde. Departamento de Ciência e Tecnologia. Prioridade de Pesquisa em Saúde. Caderno 2 - Doenças Negligenciadas. Decit 2006. http://bvsms.saude.gov.br/bvs/publicacoes/prioridades_invest/i2_tela4_2.html. (Acesso em 4 de abr. 2012).

63. BRASIL. Ministério da Saúde. Oficina de Prioridades de Pesquisas em Saúde de Doenças Negligenciadas. Informativo DECIT - Departamento de Ciência e Tecnologia/SVS da Secretaria de Vigilância em Saúde do Ministério da Saúde. Julho, 2008 .

64. GUIMARÃES JA. A pesquisa médica e biomédica no Brasil. Comparações com o desempenho científico brasileiro e mundial. Ciênc. Saúde Coletiva.2004; 9: 303-27.

65. BARRETO ML. Growth and trends in scientific production in epidemiology in Brazil. Rev. Saúde Pública. 2006; 40: 79-85.

66. CORDEIRO H. Organizador. Prioridades Nacionais, Pesquisa Essencial e Desenvolvimento em Saúde. Rio de Janeiro: Fiocruz; 1990. (Política de Saúde n 10).

67. POTTER, VR. Bioethics, bridge to the future. Englewood Cliffs: Prentice-Hall; 1971.

68. OLIVEIRA AAS. Bioética e Direitos Humanos. Edições Loyola, São Paulo, Brasil, 2011. 
69. SOZA SÁNCHEZ TM. Propuesta de diálogo entre bioético y pensamiento revolucionario en Latinoamérica. Revista Brasileira de Bioética 2010; 6 (1-4): 9-28.

70. JUNGES, JR, ZOBOLLI ELCP. Bioética saúde coletiva: convergências epistemológicas. Ciências e Saúde Coletiva, 2012, 17(4): 1049-1060.

71. SOTOLONGO PL. O tema da complexidade no contexto da bioética. In: GARRAFA V, KOTTOW M, SAADA A, organizadores. Bases conceituais da Bioética: enfoque latino americano. Gaia, São Paulo, 2006.

72. GARRAFA V. Novas fronteiras bioéticas: ética no mundo global. Uma perspectiva do Brasil. Revista Portuguesa de Bioética, 2008: 279-90.

73. PETRAGLIA IC. Edgar Morin: a educação e a complexidade do ser e do saber. Petrópolis, Vozes, 1995, p. 76.

74. GARRAFA V. Multi-inter-transdisciplinaridade, complexidade e totalidade concreta em bioética. In: GARRAFA V, KOTTOW M, SAADA A, organizadores. Bases conceituais da Bioética: enfoque latino americano. Gaia, São Paulo, 2006.

75. MORIN E. Para o pensamento complexo. Ciência com consciência. Rio de Janeiro, Bertrand Brasil, 1996, p. 175-341.

76. POGGE T. World Poverty and Human Rights. Cambridge, 2002. Polity Press: 169.

77. LUNA F. Poverty and inequality: challenges for the IAB: IAB presidential address. Bioethics: 19(5-6): 451-9, 2005 oct. England.

78. OLIVEIRA SSL. As doenças negligenciadas e nós. Saúde Coletiva. 2009, vol. 28. Disponível em http//redalyc.uaemex.mx/src/inicio/artpdfred.jsp?icve=842022802. (Acesso em 30 agos 2012).

79. GARRAFA V, LORENZO C. Ética e Investigación Clínica en los Países en Desarrollo - aspectos conceptuales, técnicos y sociales. I Curso a Distancia de Ética en la Investigación. Módulo IV, Red Latino-Americana y del Caribe de Bioética de UNESCO - REDBIOÉTICA, Córdoba/Argentina, 2006.

80. TROUILLER P, OLLIARO P, TORREELE E, ORBINSKI J, LAING R, FORD N. Drug development for neglected diseases: a deficient market and public-health policy failure. The Lancet, 2002, vol. 22, p. 2188-2194.

81. OPREA L, BRAUNACK-MAYER A, GERICKE CA. Ethical issues in funding research and development of drugs for neglected tropical diseases. Journal of Medical Ethics. 2009, 35: 310-314 doi: 10.1136/jme.2008.027078.

82. CHIRAC P, TORREELE E. The Lancet, may. 2006,1560-1561. 
83. OLIVEIRA EA, LABRA ME, BERMUDEZ J. A produção pública de medicamentos no Brasil. Cad. Saúde Pública, Rio de Janeiro, 2006, 22(11): 2379-2389. 84. FORTES PAC. Como priorizar recursos escassos em países em desenvolvimento, In: GARRAFA V, PESSINI L, organizadores. Bioética: poder e injustiça. Centro Universitário São Camilo/Loyola/Sociedade Brasileira de Bioética: 2003.

85. SCHRAMM F.R. Bioética da proteção: ferramenta válida para os problemas morais na era da globalização. Revista Bioética, Conselho Federal de Medicina, Brasília, 2008, v. 16, n.1, p.11-23.

86. SCHRAMM FR, KOTTOW M. Principios bioéticos en salud pública: limitaciones y propuestas. Cad. Saúde Pública 2001; 17(4):949-56.

87. SEMPLICI S. Um direito fundamental: o mais elevado padrão de saúde. In: PORTO D, GARRAFA V, MARTINS GZ, BARBOSA SN, organizadores. Bioética, poderes, e injustiças: 10 anos depois. Brasília: CFM/Cátedra Unesco de Bioética/SBB; 2012.

88. GARRAFA V, PRADO MM. Tentativas de mudanças na Declaração de Helsinki: fundamentalismo econômico, imperialismo ético e controle social. Cad Saúde Pública. 2001; 17(6): 1489-96.

89. FARMER P, CAMPOS NG. Rethinking medical ethics: a view from below. Dev World Bioeth;4(1):17-41, 2004 May. England.

90. GARRAFA V. Ampliação e politização do conceito internacional de bioética. Revista Bioética (Impr.) 2012; 20(1): 9-20. Brasília, Conselho Federal de Medicina.

91. LORENZO C. Vulnerabilidade em Saúde Coletiva: implicações para as políticas públicas. Revista Brasileira de Bioética, 2006, vol. 2, num 3, p. 299 - 312.

92. PORTO D, GARRAFA V. Bioética de intervenção: considerações sobre economia de mercado. Rev Bioética. 2005; 13(1): 111-123.

93. PORTO D, GARRAFA V. A influência da Reforma Sanitária na construção das bioéticas brasileiras. Ciência e Saúde Coletiva. Rio de Janeiro; 2011, 16(Supl. 1): 719729.

94. SAMAJA JA. A reprodução social e a saúde. Salvador: Ed. Casa de Qualidade; 2000 .

95. SAMAJA JA. Epistemologia de la saúde: Reproducción social, subjetividade y transdiciplina. Buenos Aires: Lugar Social; 2004.

96. FORTES ACF, CARVALHO RRP, TITTANEGRO GR, PEDALINI LM, SACARDO DP. Bioética e saúde global: um diálogo necessário. Revista Bioética. Vol. 20, n. 2 - 2012. Brasília/DF, Brasil, Conselho Federal de Medicina. 
97. JICK, T. Mixing Qualitative and Quantitative Methods: Triangulation in Action. In: MAANEN, J.V. Qualitative Methodology. London: SAGE. 1983, p. 135 - 148.

98. MINAYO, M.C.S.; SANCHEZ,O. Quantitativo - Qualitativo: Oposição ou Complementaridade? Cad. Saúde Públ., Rio de Janeiro,1993, 9 (3): 239-262, jul/set.

99. TURATO, E.R. Métodos qualitativos e quantitativos na área da saúde: definições, diferenças e seus objetos de pesquisa. Rev. Saúde Pública, 2005; 39(3):507-14.

100. DESLAURIERS, J.P.; KÉRISIT, M. O delineamento de pesquisa qualitativa. In: POUPART, J. et al. A pesquisa qualitativa: enfoques epistemológicos e metodológicos / tradução de Ana Cristina Nasser. 3 ed. - Petrópolis, RJ: Vozes, 2012.

101. FLICK, U. Introdução à Pesquisa Qualitativa. Tradução: Joice Elias Costa. - 3. Ed. - Porto Alegre: Artmed, 2009.405p.

102. BRYMAN, A. Quantitative and Qualitative Research: Further Reflections on their Integration. In: BRANNEN, J. Mixing Methods: Quantitative and Qualitative Research. Aldershot: Avebury. p. 57 - 80. 1992.

103. CRESWELL, J.W.; CLARK, V.L.P. Designing and conduction mixed methods research.California: Sage, 2007, p. $58-88$.

104. WOLFF S. Analysis of Documents and Records. In: FLICK, U. ; KARDORFF, E.V.; STEINK IA Companion to Qualitative Research. London: SAGE, 2004b, p. 284290.

105. TRIVIÑOS AMS. Introdução à pesquisa em Ciências Sociais: a pesquisa qualitativa em educação. São Paulo: Atlas, 1992.

106. SCOTT J. A matter of record - Documentary Sources in Social Research. Cambridge: Polity. 1990.

107. ORLANDI EP. Análise de Discurso: princípios e procedimentos. Campinas, SP: Pontes, 1999.

108. MENDES E SILVA MAS. Sobre a Análise do Discurso. Revista de Psicologia da UNESP, 4(1), 2005, p. 16-40.

109. CAREGNATO RCA, MUTTI R. Pesquisa qualitativa: análise de discurso versus análise de conteúdo. Texto Contexto Enferm, Florianópolis, 2006 Out-Dez; 15(4):67984.

110. ROCHA D, DEUSDARÁ B. Análise de Conteúdo e Análise do Discurso: aproximações e afastamentos na (re)construção de uma trajetória. ALEA. 7(2); jul-dez, 2005; p. 305-322. 
111. BRANDÃO HHN. Introdução à análise do discurso. 4a. Ed. Campinas, SP: Editora da UNICAMP; 1986.

112. GARCIA TM. A análise do discurso francesa; uma introdução nada irônica. Working Papers em Linguística, UFSC, n. 7, 2003, p.121-140.

113. KRONBERGER N, WAGNER W. Palavras - chave em contexto: análise estatística de textos. In: BAUER MW, GASKELL G. Pesquisa qualitativa com texto, imagem e som: um manual prático. Petrópolis, RJ: Vozes, 2002; p. 416-441.

114. ORLANDI E. Interpretação: autoria, leitura e efeitos do trabalho simbólico. $4^{\mathrm{a}} \mathrm{ed}$. Campinas (SP): Pontes; 2004.

115. The Lancet. Editorial. Neglected tropical diseases: becoming less neglected. The Lancet; 2014 april; 383(9925): p.1269 [acesso: 22 maio 2014] Disponível:www.thelancet.com/ http://www.thelancet.com/journals/lancet/article/PIIS0140-6736(14)60629-2/fulltext 116. PACHECO SANTOS LM, SOUZA LEPF, SERRUYA SJ, GUIMARÃES RFN. O papel da pesquisa na consolidação do Sistema único de Saúde (SUS). Cad. Saúde Pública, Rio de Janeiro, set, 2010, 2, 26(9):1666-1667

117. SCHRAMM F. Proteger os vulnerados e não intervir aonde não se deve. Ver. Bras. Bioética, 2007, 3 (3): p. $377-89$.

118. GIRALDI A. Enfim mais visíveis. Revista Pesquisa Médica, 2008. Disponível em http://www.revistapesquisamedica.com.brtextos.asp?codigo=11438. Acesso 20 abr. 2012, p

119. SOCIEDADE BRASILEIRA DE MEDICINA TROPICAL. Ministério da Saúde afirma que enfrentamento das doenças negligenciadas é prioridade. 2012. Disponível em http://www.sbmt.org.br/site/corpo_texto/187. Acesso em: 08 out. 2014. 120. MOREL, C.M. et al. Co-authorship Network Analysis: A Powerful Tool for Strategic Planning of Research, Development and Capacity building Programs on Neglected Diseases. PLoS Neglected Tropical Diseases, aug. 2009, vol. 3, n. 8, pag. 18.

121. ASSUNÇÃO, T. Combate às doenças negligenciadas é reforçado. Disponível em http/www.portalsaude.saude.gov.br acesso em 04 agost. 2012.

122. MOLYNEUX, DH; MOREL C. Onchocerciasis and Chagas disease control: the evolution of control via aplied research through changing development scenarios. British Medical Bulletin; 1998, v.54, n.2, p.327-339. 
123. HENDERSON, DA. Eradication: lessons from the pat. Bull. World Health Organ 76, 1998, Suppl 2, p.17-21.

124. SANDERS, D. et al. Making research matter: a civil society perspective on health research. Bulletin of the World Heakth Organization, 2004, v. 82, n.10, p.757-763.

125. ALBUQUERQUE, MV. Política nacional de CT\&I em saúde e a regionalização do SUS: diálogos possíveis. In: VIANA ALD, IBAÑEZ N, BOUSQUAT A. Saúde, desenvolvimento, ciência, tecnologia e inovação. São Paulo: HUCITEC-Cealag, 2012. 174-202.

126. BRASIL. Ministério da Saúde. Secretaria de Vigilância em Saúde. Departamento de Análise de Situação em Saúde. Saúde Brasil 2013: uma análise da situação de saúde e das doenças transmissíveis relacionadas à pobreza. Brasília: Ministério da Saúde, 2014, 384p.

127. CUNHA SANTOS MS; SANTOS LIMA L; MARTELLI DRB; MARTELLI JÚNIOR, H. Perfil dos pesquisadores da Saúde Coletiva no Conselho Nacional de Desenvolvimento Científico e Tecnológico. Physis Revista de Saúde Coletiva, Rio de Janeiro, 2009, v.19, n.3, p. $761-775$.

128. CAVALCANTE LR. Desigualdades regionais em Ciência, Tecnologia e Inovação (CT\&I) no Brasil: uma análise de sua evolução recente. Rio de Janeiro: Instituto de Pesquisa Econômica Aplicada - Ipea, texto para discussão n.1574, 2011.

129. BENATAR SR. Bioética: poder e injustiça. In: GARRAFA V, PESSINI L. Bioética: poder i injustiça. SBB/Centro Universitário São Camilo/Ediçoes Loyola, ed 2, 2004, p. $25-33$.

130. GARRAFA V, PORTO D. Bioética, poder e injustiça: por uma ética de intervenção. In: GARRAFA V, PESSINI L. Bioética: poder i injustiça. SBB/Centro Universitário São Camilo/Ediçoes Loyola, ed 2, 2004, p. 35 - 44.

131. NUNES, A. Alocação equitativa inter-regional de recursos públicos federais do SUS: a receita própria do município como variável moderadora. Brasília: Sistema de Informações sobre Orçamentos Públicos em Saúde, Departamento de Economia da Saúde, Secretaria de Ciência, Tecnologia e Insumos Estratégicos, Ministério da Saúde; 2004.

132. PORTO D. Bioética na América Latina: desafio ao poder hegemônico. Ver. Bioética (Impr.). 2014; 22(2): 213-24. 
133. MINAYO, M.C.S. Global \& Local, Meritocrático \& Social: O papel da Ciência e Tecnologia em Saúde Coletiva no Brasil. Revista Actas de Saúde Coletiva, 2012, v. 6, n. 2 , p. $11-26$.

134. IOZZI FL. Ciência, tecnologia e inovação no Brasil: panorama atual das políticas federais para a saúde. In: VIANA ALD, IBAÑEZ N, BOUSQUAT A. Saúde, desenvolvimento, ciência, tecnologia e inovação. São Paulo: HUCITEC-Cealag, 2012, p.150-173.

135. LETA J. GLANZEL; THUS B. Science in Brazil. Part 2: sectoral and institutional research profiles. Scientometrics, 2006, v. 67, n. 1, p. 87-105.

136. GUIMARÃES JA. A pesquisa médica e biomédica no Brasil. Comparações com o desempenho científico brasileiro e mundial. Ciência \& Saúde Coletiva, 2004, v. 9, n.3, p. 303-327.

137. BRASIL. Ministério da Saúde. Secretaria de Ciência, Tecnologia e Insumos Estratégicos. As ações de CTI em Saúde nos Sistemas Estaduais: PPSUS 2012. Fórum Nacional: Consecti-Confap. Curitiba 8 e 9 de março de 2012. Disponível em www.confp.org.br/palestra/14hs_carlos_gadelha.ppt. Acesso em: 05 dez 2014.

138. KERR-PONTES, L.R.S. et al. Uma Reflexão sobre o Processo de Avaliação das Pós-graduações Brasileiras com Ênfase na Área de Saúde Coletiva. PHYSIS: Rev. Saúde Coletiva, Rio de Janeiro, 2005, 15(1): 83- 94.

139. SEN A. Why health equity? Health Econ. 2002, v. 11, p. $659-666$.

140. MARANDOLA W, PEREIRA MFT, CASTALDELI FF, FALCI M. A pesquisa clínica como caminho para o desenvolvimento do medicamento inovador: experiência de uma empresa nacional. Anais do XXIII Simpósio de Gestão da Inovação Tecnológica, 2004.

141. THIERS F, SINSKEY AJ, BERNDT ER. Trends in the globalization of clinical trials. Nat. Rev. Drug Discov. 2008, v. 7, p. 13 - 14.

142. MORIN E. Los siete saberes necesarios para la educación del futuro. Buenos Aires, Unesco/Nueva Visión, 2001, 67p. 


\section{Doenças negligenciadas e bioética: diálogo de um velho problema com uma nova área do conhecimento}

Bruno Leonardo Alves de Andrade ${ }^{1}$, Dais Gonçalves Rocha ${ }^{2}$

\section{Resumo}

As doenças negligenciadas são demonstradas como um flagelo persistente no histórico das populações excluídas, portanto de interesse da bioética. São classificadas como um grupo de doenças infecciosas que estão fortemente associadas às condições de pobreza verificadas, em sua grande maioria, nos países periféricos. $\mathrm{O}$ objetivo deste estudo foi aproximar duas áreas do conhecimento por meio de um diálogo a fim de demonstrar que, apesar de específicas, elas podem atuar de maneira sinérgica. Trata-se de um estudo de revisão bibliográfica que procurou se aprofundar acerca dos seguintes eixos: 1 . Conceitos e visões das doenças negligenciadas e da bioética; 2. Consequências e contexto das doenças negligenciadas; 3. Doenças negligenciadas nos estudos de Bioética. Verificou-se que um diálogo foi estabelecido e emergiram elementos que ratificaram a bioética como um campo de mediação que deve ser utilizado para a superação do conflito ético que permeia o tema das doenças negligenciadas.

Palavras-chave: Doenças negligenciadas. Bioética. Pobreza. Vulnerabilidade social.

\section{Resumem}

Enfermedades negligenciads y bioética: diálogo de un viejo problema con una nueva área de conocimiento

Las enfermedades desatendidas se muestran como un estigma que persiste en la historia de las poblaciones excluidas, por lo tanto son del interés de la Bioética. Se clasifican como un grupo de enfermedades infecciosas fuertemente asociadas a las condiciones de pobreza verificadas, en su gran mayoría, en los países periféricos. El objetivo de este estudio es acercar dos áreas de conocimiento por medio de un diálogo con el fin de demostrar que, a pesar de ser específicas, pueden actuar de manera sinérgica. Se trata de un estudio de revisión bibliográfica que busca profundizar sobre los siguientes ejes: 1 . Conceptos y visiones para las enfermedades desatendidas y la bioética; 2 . Las consecuencias y el contexto de las enfermedades desatendidas; 3 . Enfermedades desatendidas en los estudios de Bioética. Se verificó que ha sido establecido un dialogo y há surgido elementos que ratifican a la Bioética como un campo de mediación que debe de ser utilizado en la superación del conflicto ético presente en el tema de las enfermedades desatendidas.

Palabras-clave: Enfermedades desatendidas. Bioética. Pobreza. Vulnerabilidad Social.

\section{Abstract}

\section{Neglected diseases and biothics: the dialogue of na old problem with a new knowledge area}

Neglected diseases have been demonstrated over the years as a persisting scourge for excluded population, thus, they have been a bioethical interest. They are classified as a group of infectious diseases which are strongly linked with the poverty conditions verified in most of peripherals countries. The purpose of this study was to approach two areas trough a dialogue with the objective to demonstrate that, despite they have been particular, they can act in a synergic way. This is a bibliographic review which sought to deepen about the following axes: 1 . Concepts and visions for neglected diseases and bioethics; 2. Consequences and context of neglected diseases; 3 . Diseases neglected in studies of Bioethics. It was noticed that the dialogue occurred and it led to elements which should be used to overcoming the ethical conflict which guides the issue on neglected diseases.

Key words: Neglected diseases. Bioethics. Poverty. Social vulnerability.

1. Doutorando blandrade17@hotmail.com 2. Doutora daisrocha@yahoo.com.br - Universidade de Brasília, Brasília/DF, Brasil.

\section{Correspondência}

Bruno Leonardo Alves de Andrade - Área Especial 4, Lote E/F, Edf. Isla Residence, apto 907, Bloco D, Guará II CEP 70070-640. Brasília/DF, Brasil.

Declaram não haver conflito de interesse. 
Há tempos a humanidade é assolada por um grupo de doenças que estão associadas à pobreza e proliferam, principalmente, em ambientes marcados pela exclusão social. Essas doenças são denominadas doenças negligenciadas e de acordo com a Organização Mundial da Saúde (OMS) ${ }^{1}$ formam um conjunto de 17 enfermidades que afetam principalmente pessoas que vivem nos trópicos, mas não são exclusivas a eles. Nessa relação estão incluídas as seguintes enfermidades: tracoma; úlcera de Buruli; tripanossomose africana (doença do sono); doença de Chagas (tripanossomíase americana); dengue; dracunculíase; cisticercose; leishmaniose; hanseníase; filariose linfática; oncocercose; esquistossomose; bouba; geohelmintíase; raiva; equinococose e fasciolíase. Dados da $\mathrm{OMS}^{1}$ sobre o tema apontam que muitas delas já foram altamente prevalentes, mas, na medida em que as sociedades se desenvolveram e as condições de vida melhoraram foram desaparecendo gradualmente.

Diante de tais evidências, exige-se da bioética posicionamento que oriente a tomada de decisões e as práticas desenvolvidas pelo setor público e pelo setor privado para o enfrentamento de tal problema, como expressa a Declaração Universal sobre Bioética e Direitos Humanos (DUBDH) ${ }^{2}$ A promulgação deste documento tornou explícito o dever da bioética de trazer para o centro do debate o problema das doenças negligenciadas que, além de nevrálgico, revela-se ponto que não pode ser mais adiado devido a seu caráter socialmente relevante. Nesse sentido, a crítica da corrente da bioética que convive no mesmo espaço onde as causas e os efeitos das doenças negligenciadas são factuais, torna-se elemento essencial no processo de promover a consciência política voltada a reverter tal condição, sendo capaz de contribuir no combate de males que afetam de maneira incessante a saúde de indivíduos e dos seus coletivos.

A trajetória percorrida pela bioética demonstra que tem se firmado enquanto disciplina autônoma ao longo da sua existência, ampliando seu horizonte de atuação. Inicialmente, seu foco de ação restringia-se à relação profissional de saúde-paciente e às pesquisas envolvendo seres humanos. Ao longo dos anos, a partir da necessidade de uma agenda mais extensa que considerasse a relação entre saúde e sociedade, especialmente as questões prementes dos países em desenvolvimento, sua fundamentação epistemológica foi redesenhada, incluindo, principalmente nas últimas décadas, questões historicamente persistentes relacionadas com a pobreza e a exclusão social, como no caso, as doenças negligenciadas.

A negligência que permeia o histórico de determinadas doenças transmissíveis associadas à pobreza impacta diretamente nas condições sociais e econômicas de populações marginalizadas concentradas, na sua grande maioria, nas áreas pobres de países de baixa e média renda ${ }^{3}$. Hoje, mesmo com o premente risco de contaminação de pelo menos $40 \%$ da população mundial por uma doença negligenciada, verifica-se que elas permanecem na sua grande maioria ocultas, concentradas em áreas rurais remotas ou em favelas urbana ${ }^{3}$.

Por isso, a linha de pensamento bioético defendida pelo presente artigo é justamente aquela que centra a sua atuação na resolução de conflitos éticos que nascem das iniquidades e das injustiças, que em sua maioria são provenientes das assimetrias de poder. Por se tratar de um tema que rompe fronteiras, o presente artigo procurou não se aprisionar apenas às referências daquelas localidades que 
apresentem nos seus quadros sanitários altos índices de contaminação ou aptidão para o desenvolvimento de doenças negligenciadas, como é o caso dos países da América Latina ${ }^{5}$. Outras fontes foram acessadas na tentativa de promover um debate bioético que não ficasse restrito e que pudesse ter uma dimensão internacional.

Corroborando com a perspectiva anteriormente descrita, Kottow ${ }^{6}$ afirma que a bioética desenvolvida pelos países periféricos tem que dialogar com o discurso hegemônico mesmo que vindo de fora, não pode desconsiderá-lo, sob pena de ficar presa em coordenadas de pensamento desconectados dos centros de decisão e vulneráveis ao embate dos interesses que afetam de modo negativo o bem comum, sobretudo das populações socialmente vulneráveis. Assim, quanto mais divergentes e conflitantes se tornam as bioéticas de procedência moral diversa, mais importante é não perder contato com os vários discursos, inclusive daqueles praticados pelos países de maior renda e hegemonia da produção científica mundial, considerados como países centrais. Portanto, propõe-se promover um diálogo com a bioética em torno de um problema de relevância social cujo impacto reflete no desenvolvimento global.

\section{Método}

Trata-se de um estudo de revisão bibliográfica que utilizou a literatura especializada em doenças negligenciadas e bioética para verificar um possível diálogo entre as duas temáticas do campo da saúde. Utilizou-se as bases de dados Scielo, PubMed, Biblioteca Virtual em Saúde (BVS) e o Google Scholar. Para captação das publicações científicas foram utilizados os seguintes descritores: "doenças negligenciadas", "doenças tropicais negligenciadas", "prioridades de pesquisa" e "ética em pesquisa" em português, e "neglected diseases", "neglected tropical diseases", "research priorities" e "research ethics" em inglês.

A partir do levantamento realizado nas diversas fontes, partiu-se para seleção do material relativo ao escopo do estudo. Foram selecionados artigos, capítulos de livros e documentos que apresentaram relevância para construção do diálogo das doenças negligenciadas com a bioética. Após a leitura e apreciação do material, elaborou-se o presente artigo a partir da delimitação dos conceitos acerca do objeto posto a dialogar com a bioética, suas consequências, seu contexto de acometimento e sua íntima relação com as condições de vida da população. Em seguida, foi verificado o modo que os estudos teóricos da bioética percebem e explicitam o tema das doenças negligenciadas. Ou seja, o processo de elaboração do artigo ocorreu justamente a partir da verificação de pontos de convergência de uma nova área do conhecimento com um velho problema no campo da saúde que é permeado por um conflito ético.

\section{As doenças negligenciadas e a bioética}

Ao longo da sua trajetória, o modo de pensar e de agir da bioética vem sendo revisto. Conceitos que há muito tinham sido deixados de lado foram revisitados e incorporados como protagonista do discurso desta disciplina que, na sua essência, prima pela sobrevivência da espécie humana. Nesse 
sentido, cabe lembrar que há mais de 30 anos, o médico estadunidense Van Rensselaer Potter ao criar o neologismo bioética, definiu como uma área científica dedicada a busca do conhecimento e da sabedoria. Segundo ele, a sabedoria representaria o conhecimento necessário para administração do próprio conhecimento com o objetivo de se obter o bem social ${ }^{7}$.

Da sua concepção, que compreendia a bioética como ponte para o futuro, propunha o aperfeiçoamento da ciência por meio da ética para garantir a qualidade de vida, transformando-a numa disciplina capaz de acompanhar o desenvolvimento científico. Calcada na vigilância ética isenta de interesses morais e na necessidade de oferecer contínua democratização do conhecimento científico ${ }^{7}, a$ bioética desde quando foi instituída por Potter até o momento atual, tem buscado consolidar-se como pensamento filosófico agregador, materializado por meio do diálogo contextualizado e plural que se volta à mediação de conflitos de natureza ética que na sua maioria afetam com mais intensidade a porção excluída ou vulnerável da sociedade ${ }^{8}$.

Com mais de 30 anos de existência, a bioética foi o campo da ética aplicada que mais apresentou progressos nas últimas décadas. A análise da sua trajetória demonstra que três referenciais básicos passaram a sustentar seu estatuto epistemológico ${ }^{9}$ :

1) Uma estrutura com olhar pautado obrigatoriamente na multi-inter-transdisciplinaridade entre variados núcleos de conhecimento e diferentes perspectivas das questões observadas, a partir da interpretação da complexidade: a) do conhecimento científico e tecnológico; b) do conhecimento socialmente acumulado; c) da própria realidade concreta em questão e da qual fazemos parte;

2) Respeito ao pluralismo moral constatado nas democracias secularizadas pós-modernas, norteadas pela busca do equilíbrio e observação dos referencias sociais específicos que norteiam pessoas, sociedades e nações no sentido da tolerância, sem imposições de padrões morais de umas sobre as outras;

3) A compreensão da impossibilidade de existência de paradigmas bioéticos universais, que leva a construção de um novo discurso bioético sustentado basicamente pelo diálogo, coerência e argumentação.

A partir desse novo modo de pensar a bioética é que questões que há muito persistem na história da humanidade passaram a ocupar um espaço de destaque na agenda proposta para a disciplina no Século XXI. Nesse sentido, Berlinguer ${ }^{10}$ adotou o termo bioética cotidiana para questões que se referem às situações que acontecem diariamente, mas não deveriam estar mais acontecendo, a exemplo da pobreza, da exclusão social e das doenças negligenciadas. No Brasil, Garrafa e Porto ${ }^{11}$ utilizaram a ideia adaptando o termo anteriormente descrito por bioética das situações persistentes.

$\mathrm{O}$ conceito proposto por Berlinguer ${ }^{10}$ e Garrafa ${ }^{9}$ sublinha necessidade de pensar uma bioética que pudesse abordar os determinantes sociais básicos e, portanto, persistentes e críticos sobre a vida humana, tanto nos indivíduos quanto nas coletividades. O encontro da bioética com o coletivo, com o social, surgiu timidamente a partir de meados dos anos 1990 e se fortaleceu na década seguinte, tendo como protagonistas autores da América Latina que foram em busca de uma bioética que tratasse de questões de desigualdades sociais e equidade, justiça social, responsabilidade individual e coletiva sobre 
os cuidados em saúde, alocação e priorização de recursos escassos, pobreza, racismo, saúde pública e políticas sociais e sanitárias ${ }^{10,11,12,13,14,15}$.

Vale destacar que a bioética enquanto nova forma de valorização da vida deve estabelecer forte relação com as questões sociais que impactam diretamente nas condições de saúde das populações pobres presentes tanto nos países periféricos quanto nos países centrais. Ela não pode ficar limitada a questões estritamente biomédicas. Questões de justiça, solidariedade, humanidade e equidade devem ser protagonistas das análises dos conflitos bioéticos, pois, por meio destes, melhores condições de vida, bem estar e direito a uma vida digna podem se tornar uma realidade ${ }^{16}$.

O breve introdutório sobre a bioética e a sua vinculação com as questões de relevância social que persistem no histórico das populações, apontou a lógica adotada neste artigo para promover o diálogo entre as doenças negligenciadas e a bioética, mesmo diante das especificidades de cada área do conhecimento. Na visão dos autores, três fatos fundamentais atuaram como elementos-chave no estabelecimento do diálogo entre os dois temas.

O primeiro deles é a situação de persistência que as doenças negligenciadas ocupam dentro de um quadro de saúde, não mais restrita a uma situação local e sim global ${ }^{17}$, como mencionado anteriormente. O segundo fato, é que a bioética e as doenças negligenciadas, mesmo nas suas especificidades, trilham caminhos convergentes em alguns pontos. Observa-se que em seus históricos, questões associadas aos determinantes sociais e aos contextos da saúde se fazem presentes, tornandoas, assim, áreas do conhecimento de caráter transdisciplinar, complexas e que precisam ser analisadas em sua totalidade ${ }^{18}$.

A partir do pensamento de Sotolongo ${ }^{19}$, os autores do estudo verificaram que tanto a temática da bioética quanto das doenças negligenciadas tem que lidar, em suas reflexões teóricas e nas suas práticas, com circunstâncias, situações e fenômenos referentes à vida e a sua sustentabilidade, que emanam das interações entre os seres humanos, sobretudo, das interações sociais. Algumas dessas interações têm incidência sobre as outras e fazem com que ocorram circunstâncias ou fenômenos inesperados, surpreendentes e paradoxais, para os quais nem sempre há solução prevista ou pensada, configurando assim, o caráter complexo das duas áreas temáticas.

Pode-se dizer que são transdisciplinares por se tratarem de áreas do saber que superam as fronteiras que delimitam as disciplinas envolvidas no estudo dos seus objetos, nos diálogos que conduzem aos novos conhecimentos, ao enriquecimento recíproco de todos os agentes, em que o todo é maior que as partes ${ }^{20}$. A transdiciplinaridade promove a superação das barreiras que demarcam as fronteiras das diversas disciplinas, ao promover o contínuo exercício de troca que se traduz em distinguir e não separar; associar e interligar e não reduzir ou isolar; complexificar e não simplificar ${ }^{21}$. As duas áreas são complexas, pois tratam de temas que envolvem uma causalidade sensível ao contexto e ao entorno, no que se refere aos componentes naturais, sociais e humanos. Ou seja, trata-se de relação de causalidade sensível tanto ao que está acontecendo agora como também à história ou ao passado desses componentes ${ }^{19}$. 
Vale destacar que a complexidade permite distinguir as qualidades emergentes da interação entre as partes e as suas relações como o todo, projetando-se para além do clássico modelo determinista, ao captar desse ponto em diante a noção de desordem, imprevisibilidade, erro e caos como fomentadores da evolução e das mudanças ${ }^{22}$. Para Morin ${ }^{23}$, enfrentar a complexidade do real significa confrontar-se com os paradoxos da ordem/desordem, da parte/todo, do singular/geral; incorporar o acaso e o particular como componentes de análise científica, integrando a natureza singular e evolutiva do mundo à sua natureza acidental e factual.

Vale destacar que, de acordo com Garrafa ${ }^{22}$, todos os elementos conceituais anteriormente apresentados podem ser trabalhados segundo critérios adequados, contribuindo para a construção de um pensamento bioético novo, amplo e comprometido com as questões éticas persistentes constatadas, em sua grande maioria, na realidade dos países periféricos. Em decorrência desta constatação levanta-se o terceiro e último fato fundamental determinante para o diálogo estabelecido neste artigo. Diante da complexidade e da transdiciplinaridade que permeiam as duas áreas, a bioética tem adotado postura mais crítica e politizada para questões éticas que envolvam os determinantes sociais da saúde e contextos sociais que, em sua grande maioria, congregam populações excluídas com um alto grau de vulnerabilidade social, como é o caso daqueles locais onde ocorrem as doenças e os doentes negligenciados.

Face ao exposto, pode-se dizer que no atual estágio que se encontra a humanidade, a tolerância para as consequências provenientes do legado das doenças negligenciadas tem se tornado algo inaceitável. O paradoxo é explícito. Convive-se com o tratamento de doenças até então incuráveis, com o avanço da engenharia genética, mas logo ali ao lado temos indivíduos que vivem em condições subumanas com total predisposição de serem acometidos por doenças que não precisariam mais ocorrer.

Como indicado, o lócus de preferência das doenças negligenciadas são os contextos que foram deixados para trás pelo progresso socioeconômico e, consequentemente, vivem à margem do desenvolvimento científico e tecnológico alcançado pela humanidade nos últimos anos. Observa-se que a relação estabelecida entre miséria e doenças negligenciadas tem agravado ainda mais o quadro de pobreza de várias populações ao redor do planeta. Ou seja, pode-se considerar a pobreza, simultaneamente, como ponto de partida e resultado final das doenças negligenciadas ${ }^{24}$. Para Pogge ${ }^{25}$ e Luna ${ }^{26}$ a pobreza deve ser considerada como violação dos direitos humanos, principalmente quando causada por muitos dos países ricos ou centrais em sua atuação perversa sobre os países pobres ou periféricos.

O denominador comum do indivíduo pobre e excluído é o desamparo, uma situação vital em que se necessita de proteção e, ainda por cima, dos elementos para obtê-la, de modo que se evite que a pobreza e a exclusão se tornem crônicas ou transformem-se em agravamento progressivo, o que tende a ocorrer quando não existe ajuda externa. A sinergia negativa entre pobreza e doença requer proteção que deve estar disponível e acessível como função protetora do Estado, estabelecendo-se como um direito moral que se estende mais além, de acordo com doutrina política vigente ${ }^{6}$. 
$\mathrm{Na}$ visão dos autores deste artigo, o conflito bioético atrelado à temática das doenças negligenciadas além de relevante, torna-se fato concreto diante da sua magnitude. Isto é confirmado quando se constata que as doenças negligenciadas, além de acometer $80 \%$ da população dos países periféricos, também ocasionam milhões de óbitos por ano. Estima-se que para o enfretamento deste mal que se perpetua na história da humanidade faz-se necessário a existência de um arsenal terapêutico que corresponda a $20 \%$ da produção do mercado farmacêutico mundial ${ }^{27}$.

No entanto, o que se verifica quando se trata de ações voltadas para o enfrentamento das doenças negligenciadas pela indústria farmacêutica mundial, é que esta, na maioria das vezes, destina grande parte do seu arsenal terapêutico para as necessidades do mercado, deixando em segundo plano as necessidades dos milhares de excluídos acometidos ou potencialmente acometidos por doenças presentes exclusivamente na realidade sanitária dos países periféricos ${ }^{28}$. Estudo sobre a realização de pesquisas voltadas para as doenças negligenciadas realizado envolvendo as principais indústrias farmacêuticas mundiais observou que apenas $1 \%$ do orçamento anual de algumas dessas empresas estavam voltados para estudos que contemplam essas doenças ${ }^{29}$.

Corroborando com a situação anteriormente descrita, dos milhares de medicamentos novos lançados nos últimos 25 anos, verifica-se que um percentual muito baixo (menos de 1\%) foi destinado para as doenças relacionadas à pobreza ${ }^{27}$. Ou seja, os dados apontados demonstram e confirmam que as doenças negligenciadas não representam um mercado atraente para a indústria farmacêutica, principalmente pelo público alvo que, na maioria das vezes, não dispõe de recursos para ter acesso a tais medicamentos ${ }^{30}$.

Cabe destacar que no período compreendido entre os anos 1975 e 2004 foram desenvolvidos um total de 1.556 novos medicamentos, desses, apenas 21 para as doenças negligenciadas ${ }^{31}$. Além disso, entre os anos de 2000 e 2005, nenhuma das vinte empresas farmacêuticas com maior faturamento bruto mundial lançou no mercado um único medicamento destinado ao tratamento de doenças relacionadas à pobreza que acometem em maior escala as populações dos países periféricos ${ }^{32}$.

Tal fato é confirmado quando Franco-Paredes e Santos-Apreciado ${ }^{24}$ afirmam que vários indivíduos socialmente excluídos e que vivem com poucas opções e têm raras oportunidades de impedir o próprio adoecimento, não recebem tratamento para evitar a incapacidade e as mortes prematuras associadas às doenças relacionadas com a pobreza. Portanto, baseado nessas necessidades, o Estado enquanto um agente promotor do bem estar social juntamente com a sociedade organizada deve intervir na tentativa de eliminar ou reduzir ao mínimo possível diferenças que apesar de desnecessárias, evitáveis e injustas ${ }^{33}$, são explícitas no histórico das populações pobres e marginalizadas.

Schramm ${ }^{34}$ também afirma a pobreza extrema torna as pessoas reféns e vítimas que têm suas liberdades fundamentais sequestradas, sendo impedidas de realizar seus projetos de vida, ou seja, são obrigadas a viver sob condições que as privam da competência para ter uma vida objetiva e subjetivamente digna. Pode-se dizer que estes indivíduos e populações podem ser considerados afetados, vulnerados ${ }^{35}$ e excluídos do processo de globalização em curso, pois, enquadram-se nas características básicas daqueles que são e estão predispostos a desenvolver algum tipo de doença 
negligenciada. Desta forma, a bioética pode ser pensada como uma práxis capaz de explicitar e debater conflitos morais na intenção de proteger indivíduos e coletividades contra ameaças que podem prejudicar de maneira irreversível suas existências, inclusive, recomendando estratégias para o enfrentamento das iniquidades.

Além disso, por meio do seu discurso a bioética deve reforçar que a assistência à saúde não pode ser comparada a uma mercadoria que pode ser comprada e vendida de maneira inadvertida ${ }^{36}$, pois, na medida em que tais fatos tendem a acontecer, levam à exclusão, ao distanciamento e ao isolamento daqueles grupos populacionais que foram privados dos benefícios proporcionados pelo desenvolvimento ${ }^{37}$.

De acordo com Farmer e Campos ${ }^{38}$, os avanços da ciência no campo da saúde ocorrem de maneira desigual, de acordo com cada contexto social, fazendo com que os frutos desse avanço não estejam disponíveis para muitos dos que mais precisam. Ainda de acordo com esses autores, o direito à saúde e à participação nos avanços científicos são explicitamente díspares quando se observa os países centrais e os periféricos. Na visão de Garrafa ${ }^{39}$ é indispensável que uma nova bioética, mais dinâmica e mais politizada, construa e coloque à disposição das localidades mais necessitadas de bens e consumo mínimos para a sobrevivência humana um conjunto de ferramentas concretas da teoria e do método científico que possibilitem a obtenção da devida dignidade que por muitas vezes a muitos foi negada. Nesse sentido, o acesso universalizado à saúde torna-se uma pauta na nova agenda bioética do século XXI, visto como direito, cidadania, sendo responsabilidade dos Estados proverem o mínimo necessário para que as pessoas vivam com dignidade.

Aos olhos do mundo as doenças negligenciadas continuam imprimindo a sua marca e fazendo cada vez mais vítimas por meio da desfiguração, do estigma, da incapacidade e da mortalidade prematura ${ }^{23}$. Os grupos mais suscetíveis tanto na frequência como na magnitude das lesões são invariavelmente nos grupos sociais em desvantagens socioeconômicas ${ }^{40}$. Basta observar que em virtude de doenças como a oncocercose e o tracoma indivíduos desenvolvem cegueira; que a lepra e a filariose linfática tornam indivíduos deformados e limitados da sua produtividade e de suas vidas sociais; deformidades e amputações ainda acontecem para evitar a morte de indivíduos acometidos por úlcera de Buruli; tripanossomíase humana africana (doença do sono) debilita gravemente antes de provocar a morte; a hidrofobia que provoca encefalite aguda e é sempre fatal; a leishmaniose deixa cicatrizes profundas e permanentes ou destrói totalmente as membranas mucosas do nariz, da boca e da garganta e, em sua forma mais grave, ataca os órgãos internos, fazendo com que, se não for tratada, ocorra rapidamente à morte; a doença de Chagas pode levar adultos jovens a desenvolver problemas cardíacos, ocupando leitos de hospital ao invés de postos no mercado de trabalho; a esquistossomose severa funciona como um empecilho para a frequência à escola, além de contribuir para a desnutrição e prejudicar o desenvolvimento cognitivo das crianças ${ }^{41}$.

Ou seja, o corpo enquanto um espelho para o flagelo das doenças negligenciadas deve ser reconhecido como parâmetro de intervenção ética que não se limita a dimensão fisiológica. Nele identifica-se e incorpora-se a dimensão social, a articulação das dimensões físicas e psíquicas que se 
manifestam de maneira integrada nas relações sociais e nas relações como o meio. Ao considerar o corpo físico como a estrutura de suporte da vida social, pois sem ele a vida social não se concretiza, o conceito de corporeidade e a consequente manutenção da existência concreta das pessoas, passam a ser marcos de intervenção ética 42.

Inúmeras marcas que se apresentam nos corpos e nas vidas dos indivíduos tornam-se claros exemplos de quanto determinados indivíduos e coletividades estão subjugados à condição negligência. Outro fato que salta aos olhos e deve ser levado ao debate é a impossibilidade de dissociar a doença na dimensão biológica da dimensão social que a cerca, pois na maioria dos casos ocorrem de maneira concomitante. Para Porto e Garrafa ${ }^{43}$ os atores sociais produzem e reproduzem a dinâmica da sociedade nos seus corpos e suas vidas, reforçando assim proposta deste artigo.

Uma ampla abordagem da doença deve-se fazer presente, pois, a partir desta, a compreensão do ser humano como simultaneamente biológico, social, cultural e simbólico torna-se mais concreta. As condições de vida de indivíduos e da coletividade determinam as suas condições de saúde, que por sua vez devem ser estudadas numa perspectiva ampla, levando em consideração não só os elementos biológicos, mas também elementos sociais, culturais e simbólicos ${ }^{44,45}$. Nesse sentido, os autores deste artigo constatam que a bioética enquanto área do conhecimento transdisciplinar, complexa, vinculada às questões atinentes à vida, à saúde e ao meio ambiente, tem a capacidade de proporcionar análises de maior clareza e a transparência, revelando os pressupostos que movem os saberes e as práticas em saúde. Ou seja, por meio da sua mediação, do seu debate ético, almeja-se promover a ética do conhecimento que, no caso das doenças negligenciadas, torna-se uma peça-chave para a reversão da sua condição.

$\mathrm{Na}$ atualidade, ao se discutir transplantes, implantes e projeto genoma, que prolongam a vida, é necessário atentar que também persiste a necessidade de encontrar solução para doenças relacionadas à pobreza como no caso da malária, da dengue, da hanseníase e de tantas outras que ainda ceifam vidas precocemente em grande parte do mundo e se mantêm epidêmicas para as pessoas mais vulneráveis e para os povos mais pobres ${ }^{46}$.

Para isso, a bioética deve estimular o diálogo com esses problemas a partir do princípio da justiça, da equidade e da solidariedade, haja vista a necessidade da sensibilização com o sofrimento alheio para que se possam compartilhar recursos de maneira legítima, enfatizando a necessidade de proporcionar condições menos desiguais, promovendo assim o acesso a bens e serviços sem os quais é impossível vislumbrar um futuro mais justo ${ }^{46}$. É compreendendo criticamente a realidade que se pode interpretar o passado e projetar um futuro digno para todos ${ }^{18}$.

\section{Considerações finais}

Diante dos fatos até aqui apresentados, verifica-se que o conflito bioético que circunda e adentra no tema das doenças negligenciadas está posto e clama por reversão da sua condição. Tal afirmação corrobora com o fato de que, por se tratar da ética aplicada voltada para as questões atinentes da vida, a bioética pode e deve ser utilizada como instrumento de mediação com poder de 
impulsionar o processo de reversão da condição que se coloca no histórico de muitas doenças transmissíveis, relacionadas diretamente com as condições de vida presentes principalmente nas populações dos países periféricos.

Para os autores deste estudo, o diálogo do tema das doenças negligenciadas com a bioética se fundamenta tanto pelos referenciais da bioética, que estão dispostos a desnudar os verdadeiros problemas de iniquidades que persistem no mundo contemporâneo, quanto por aqueles que se propõem a efetivar a saúde como um direito fundamental do ser humano, pondo em prática a definição proposta no artigo 14 da Declaração Universal sobre Bioética e Direitos Humanos da Unesco ${ }^{2}$.

De acordo com o referido artigo, além de definir que a promoção da saúde e do desenvolvimento social deve ser objeto central de qualquer governo democrático, considera que usufruir o mais alto padrão de saúde é um dos direitos fundamentais do ser humano e que para isso o acesso a cuidados de saúde de qualidade e a medicamentos essenciais deve ser garantido para todas as pessoas, incluindo especialmente aqueles para a saúde de mulheres e crianças, uma vez que a saúde é essencial à vida em si e deve ser considerada como bem social humano ${ }^{2}$.

Para finalizar, verifica-se que as bases que compõem as reflexões e os discursos dos autores utilizados na construção do presente artigo, na sua grande maioria, estão fundamentadas no discurso bioético determinado a suplantar as injustiças sociais e sanitárias e as assimetrias estabelecidas entre aqueles que detêm o poder e os que não tem poder algum, provenientes, na maioria das vezes, das situações persistentes que ainda acometem a humanidade.

Nesse sentido, constata-se que as visões trazidas para o presente artigo, desenvolvidas na sua grande maioria por autores que rejeitam o modo de tratamento insensível e indiferente ofertado por muitos a um problema cujo impacto reflete na vida de milhões de pessoas, está pautada no compromisso da construção de uma bioética participativa e engajada para superação dos indesejáveis e persistentes problemas presentes nos países periféricos.

Portanto, a atuação da bioética na superação do pesado ônus causado pelo flagelo das doenças negligenciadas, além de amplificar, por meio do seu discurso, a voz daqueles que se encontram sem visibilidade, deve rechaçar as possíveis causas que impeçam indivíduos, principalmente aqueles que se encontram sob o estado de vulnerabilidade social, ao acesso de cuidados à saúde de qualidade e a medicamentos que sejam essenciais a sua sobrevivência.

Trabalho desenvolvido no âmbito do Programa de Pós-Graduação em Bioética da Universidade de Brasilia.

\section{Referências}

1. World Health Organization. Neglected tropical diseases. Hidden successes, emerging opportunities. WHO/CDS/NTD/2006.22006. Disponível: http://whqlibdoc.who.int/hq/2006/WHO_CDS_NTD_2006. 2_eng.pdf [acesso 3 abr. 2012].

2. Organização das Nações Unidas para Educação, a Ciência e a Cultura. Declaração Universal sobre Bioética e Direitos Humanos [internet]. Genebra: Unesco; 2005 [acesso 30 ago. 2012].

3. Brasil. Ministério da Saúde, Secretaria de Vigilância em Saúde. Saúde Brasil 2013: uma análise da situação de saúde e das doenças transmissíveis relacionadas à pobreza. Brasília: Ministério da Saúde, 2014; p.229 - 254.

4. Batalha E, Morosini L. Atenção aos esquecidos. Radis. 2013; n. 124, p.8-17; www.ensp.fiocruz.br/radis. 
5. The Lancet. Editorial. Neglected tropical diseases: becoming less neglected. The Lancet; 2014 april; 383(9925): p.1269 [acesso: 22 maio 2014] Disponível:www.thelancet.com/ http://www.thelancet.com/journals/lancet/article/PIIS0140-6736(14)60629-2/fulltext

6. Kottow M. Bioética de proteção: considerações sobre o contexto latino americano. In: Schramm FR, Rego S, Braz M, Palácios M, organizadores. Bioética, risco e proteção. $2^{\text {a }}$ ed. Rio de Janeiro: Editora UFRJ/Editora Fiocruz; 2009.

7. Potter VR. Bioethics, bridge to the future. Englewood Cliffs: Prentice-Hall; 1971.

8. Oliveira AAS. Bioética e direitos humanos. São Paulo: Edições Loyola; 2011.

9. Garrafa V. Da bioética de princípios a uma bioética interventiva. Revista Bioética. 2005; 13(1): 125-34.

10. Berlinguer G. Questões de vida. Ética, ciência, saúde. São Paulo: APCE/Hucitec/Cebes; 1993.

11. Garrafa V. Dimensão da ética em saúde pública. São Paulo: Faculdade de Saúde Pública USP/Kellogg Foundation; 1995.

12. Schramm FR. A Terceira margem da saúde. Brasília: Editora UnB; 1996.

13. Garrafa V, Oselka G, Diniz D. Saúde pública, bioética e equidade. Bioética 1997; 5(1): 27 - 33.

14. Garrafa V, Porto D. Intervention bioethics: a proposal for peripheral countries in a context of power and injustice. Bioethics; 2003; 17(5-6): 399-416.

15. Oliveira MF. Feminismo, raça/etnia, pobreza e bioética: a busca da justiça de gênero, antirracista e de clase. In Garrafa V, Pessini L, organizadores. Bioética: poder e injustiça. São Paulo: Loyola; 2003. p. 345 - 63.

16. Soza Sánchez TM. Propuesta de diálogo entre bioético y pensamiento revolucionario en Latinoamérica. Revista Brasileira de Bioética. 2010; 6 (1-4): 9-28.

17. Morel CM. Inovação em saúde e doenças negligenciadas. Cad. Saúde Pública; ago. 2006; Rio de Janeiro, 22(8):1522-1523.

18. Junges JR, Zobolli ELCP. Bioética saúde coletiva: convergências epistemológicas. Ciências e Saúde Coletiva. 2012; 17(4): 1.049-60.

19. Sotolongo PL. O tema da complexidade no contexto da bioética. In: Garrafa V, Kottow M, Saada A, organizadores. Bases conceituais da Bioética: enfoque latino americano. São Paulo: Gaia; 2006.

20. Garrafa V. Novas fronteiras bioéticas: ética no mundo globalizado - uma perspectiva do Brasil. Rev. Port Bioética. 2008;6:279-90.

21. Petraglia IC. Edgar Morin: a educação e a complexidade do ser e do saber. Petrópolis: Vozes; 1995. p. 76.

22. Garrafa V. Multi-inter-transdisciplinaridade, complexidade e totalidade concreta em bioética. In: Garrafa V, Kottow M, Saada A, organizadores. Bases conceituais da Bioética: enfoque latino americano. São Paulo: Gaia; 2006. 23. Morin E. Para o pensamento complexo. Ciência com consciência. Rio de Janeiro: Bertrand Brasil; 1996. p. 175341.

24. Franco-Paredes C, Santos-Preciado JI. Freedom, justice and neglected tropical diseases. PLoS negl Trop Dis. 2011, 5 (8): E1235.

25. Pogge T. World poverty and human rights. Cambridge: Polity Press; 2002. p. 169.

26. Luna F. Poverty and inequality: challenges for the IAB: IAB presidential address. Bioethics. 2005 oct; 19(5-6): 451-9.

27. Santos de Souza Oliveira L. As doenças negligenciadas e nós. Saúde Coletiva. 2009; 28. Disponível: http://www.redalyc.org/pdf/842/84202802.pdf [acesso em 30 ago. 2012].

28. Garrafa V, Lorenzo C. Ética e investigación clínica en los países en desarrollo - aspectos conceptuales, técnicos y sociales. I Curso a Distancia de Ética en la Investigación. Módulo IV. Córdoba/Argentina: Red Latino-Americana y del Caribe de Bioética de UNESCO; 2006.

29. Trouiller P, Olliaro P, Torreele E, Orbinskil J, Laing R, Ford N. Drug development for neglected diseases: a deficient market and public-health policy failure. The Lancet. 2002; 359(9324): 2.188-94.

30. Oprea L, Braunack-Mayer A, Gericke CA. Ethical issues in funding research and development of drugs for neglected tropical diseases. Journal of Medical Ethics. 2009, 35(10): 310-4. DOI: 10.1136/jme.2008.027078. [04 de abr 2014].

31. Chirac P, Torreele E. Global framework on essential health R\&D. The Lancet; Mai 2006; 367 (9522): 15601. http://www.thelancet.com/journals/lancet/article/PIIS0140-6736(06)68672-8/fulltext [acesso: 22 maio 2014].

32. Andrade de Oliveira E, Labra ME, Bermudez JAZ. A produção pública de medicamentos no Brasil: uma visão geral. Caderno de Saúde Pública. 2006 nov.; Cad. Saúde Pública, 22(11):2379-2389.

33. Fortes PAC. Como priorizar recursos escassos em países em desenvolvimento, In: Garrafa V, Pessini L, organizadores. Bioética: poder e injustiça. Centro Universitário São Camilo/Loyola/Sociedade Brasileira de Bioética: 2003.

34. Schramm FR. Bioética da proteção: ferramenta válida para os problemas morais na era da globalização. Rev. bioét. (Impr.). 2008; 16(1): 11-23.

35. Schramm FR, Kottow M. Principios bioéticos en salud pública: limitaciones y propuestas. Cad. Saúde Pública 2001; 17(4):949-56.

36. Semplici S. Um direito fundamental: o mais elevado padrão de saúde. In: Porto D, Garrafa V, Martins GZ, Barbosa SN, organizadores. Bioética, poderes, e injustiças: 10 anos depois. Brasília: CFM/Cátedra Unesco de Bioética/SBB; 2012. 
37. Garrafa V, Prado MM. Tentativas de mudanças na Declaração de Helsinki: fundamentalismo econômico, imperialismo ético e controle social. Cad Saúde Pública. 2001;17(6): 1.489-96.

38. Farmer P, Campos NG. Rethinking medical ethics: a view from below. Dev World Bioeth. 2004 May; 4(1):17-41.

39. Garrafa V. Ampliação e politização do conceito internacional de bioética. Rev. bioét. (Impr.). 2012; 20(1): 9-20.

40. Lorenzo C. Vulnerabilidade em saúde coletiva: implicações para as políticas públicas. Revista Brasileira de Bioética. 2006; 2(3): 299 - 312.

41. World Health Organization. First WHO report neglected tropical diseases: working to overcome the global impact of neglected tropical diseases. WHO/HTMA/NTD/2010.1. Geneva. Disponível: http://www.who.int/neglected_diseases/2010report/en/; [acesso 10 jun. 2013].

42. Porto D, Garrafa V. Bioética de intervenção: considerações sobre economia de mercado. Rev Bioética. 2005; 13(1): 111-123.

43. Porto D, Garrafa V. A influência da reforma sanitária na construção das bioéticas brasileiras. Ciência e Saúde Coletiva. 2011; 16(Supl. 1): 719-29.

44. Samaja JA. A reprodução social e a saúde. Salvador: Ed. Casa de Qualidade; 2000.

45. Samaja JA. Epistemologia de la saúde: Reproducción social, subjetividade y transdiciplina. Buenos Aires: Lugar Social; 2004.

46. Fortes ACF, Carvalho RRP, Tittanegro GR, Pedalini LM, Sacardo DP. Bioética e saúde global: um diálogo necessário. Rev. bioét. (Impr.). 2012; 20(2): página inicial-final.

Recebido:

Revisado:

Aprovado:

Participação dos autores

Trabalho derivado de tese de doutoramento. Os autores participaram igualmente de todas as fases da produção do artigo. Bruno Leonardo Alves de Andrade na qualidade de discente doutorando, Dais Gonçalves Rocha como professora orientadora. 


\section{APÊNDICE B}

\section{Tabelas - Atuação dos Pesquisadores}

Tabela 4 - Palavras significativas da classe 2 do corpus 2006 português para subcategoria A

\begin{tabular}{lr}
\hline Palavras significativas & $\boldsymbol{X}^{\mathbf{2}}$ \\
\hline Especialidades & 0.21 \\
Amostra & 0.15 \\
Teste & 0.15 \\
Proteína & 0.12 \\
Sangue & 0.12 \\
Parâmetro & 0.12 \\
Exame & 0.11 \\
Anticorpos & 0.11 \\
Paciente & 0.10 \\
Sorológico & 0.10 \\
Microscópio & 0.10 \\
Biopsia & 0.09 \\
Laboratoriais & 0.07 \\
Plasma & 0.06 \\
Sensibilidade & 0.06 \\
\hline
\end{tabular}

Fonte: Relatório ALCESTE

Tabela 5 - Ausências significativas da classe 2 do corpus 2006 português para subcategoria A

\begin{tabular}{lr}
\hline Ausências significativas & $\boldsymbol{X}^{\mathbf{2}}$ \\
\hline Saúde & -0.38 \\
Município & -0.17 \\
Atenção & -0.13 \\
Epidemiologia & -0.13 \\
Acesso & -0.11 \\
Equipe & -0.11 \\
Coletivo & -0.10 \\
Contexto & -0.10 \\
Sanitária & -0.10 \\
Sociais & -0.09 \\
Planejamento & -0.08 \\
Descentralização & -0.08 \\
Comunitário & -0.07 \\
Gestores & -0.06 \\
Comunidade & -0.06 \\
\hline Fonte: Relatório ALCESTE &
\end{tabular}


Tabela 6 - Variáveis significativas da classe 2 do corpus 2006 português para subcategoria A

\begin{tabular}{lc}
\hline Varáveis significativas & $\boldsymbol{X}^{\mathbf{2}}$ \\
\hline *Sujeito 02 & 0.21 \\
*Sujeito 72 & 0.18 \\
*Sujeito 35 & 0.17 \\
*Sujeito 41 & 0.15 \\
*Sujeito 48 & 0.15 \\
*Sujeito 68 & 0.14 \\
*Sujeito 52 & 0.11 \\
*Sujeito 58 & 0.10 \\
*Sujeito 62 & 0.10 \\
*Sujeito 33 & 0.09 \\
*Sujeito 15 & 0.09 \\
*Sujeito 19 & 0.08 \\
*Sujeito 50 & 0.07 \\
*Sujeito 46 & 0.07 \\
*Sujeito 12 & 0.06 \\
*Sujeito 53 & 0.06 \\
*Sujeito 60 & 0.06 \\
*Sujeito 63 & 0.06 \\
*Sujeito 36 & 0.05 \\
*Sujeito 79 & 0.05 \\
*Sujeito 56 & 0.05 \\
\hline Fonte: Relatório ALCESTE &
\end{tabular}

Tabela 7 - Palavras significativas da classe 2 do corpus 2008 português para subcategoria A

\begin{tabular}{lc}
\hline Palavras significativas & $\boldsymbol{X}^{\mathbf{2}}$ \\
\hline Paciente & 0.28 \\
Resposta & 0.17 \\
Clínica & 0.15 \\
Sintoma & 0.13 \\
Casos & 0.12 \\
Diagnóstico & 0.11 \\
Exame & 0.11 \\
Doença & 0.09 \\
Cura & 0.07 \\
Sangue & 0.07 \\
Casos & 0.06 \\
Infecção & 0.06 \\
\hline
\end{tabular}

Fonte: Relatório ALCESTE 
Tabela 8 - Ausências significativas da classe 2 do corpus 2008 português para subcategoria A

\begin{tabular}{lr}
\hline Ausências significativas & $\boldsymbol{X}^{\mathbf{2}}$ \\
\hline Saúde & -0.32 \\
Coletiva & -0.16 \\
Município & -0.16 \\
Política & -0.13 \\
Epidemiológica & -0.12 \\
Vulnerabilidade & -0.12 \\
Social & -0.11 \\
População & -0.10 \\
Saúde-doença & -0.09 \\
Atenção & -0.09 \\
Comunidade & -0.09 \\
Sociedade & -0.08 \\
Cultura & -0.05 \\
Equipe & -0.05 \\
Indicadores & -0.05 \\
\hline Fonte: Relatório ALCESTE &
\end{tabular}

Tabela 9 - Variáveis significativas da classe 2 do corpus 2008 português para subcategoria A

\begin{tabular}{lr}
\hline Variáveis significativas & $\boldsymbol{X}^{\mathbf{2}}$ \\
\hline *Sujeito 05 & 0.31 \\
*Sujeito 08 & 0.20 \\
*Sujeito 21 & 0.15 \\
*Sujeito 56 & 0.15 \\
*Sujeito 06 & 0.14 \\
*Sujeito 02 & 0.14 \\
*Sujeito 13 & 0.07 \\
*Sujeito 10 & 0.06 \\
*Sujeito 51 & 0.06 \\
*Sujeito 22 & 0.05 \\
\hline Fonte: Relatório ALCESTE &
\end{tabular}


Tabela 10 - Palavras significativas da classe 1 do corpus 2006 inglês para subcategoria A

\begin{tabular}{lr}
\hline Palavras significativas & $\boldsymbol{X}^{\mathbf{2}}$ \\
\hline Resposta & 0.36 \\
Imune & 0.32 \\
Membrana & 0.23 \\
Mitocôndria & 0.18 \\
Ultraestrutura & 0.17 \\
Organela & 0.16 \\
Extracelular & 0.15 \\
Leucócitos & 0.15 \\
Citoplasma & 0.13 \\
Doença & 0.11 \\
Enzima & 0.10 \\
Experimento & 0.08 \\
Bioquímica & 0.08 \\
Patógeno & 0.08 \\
\hline Fo: Retor ALCESTE
\end{tabular}

Fonte: Relatório ALCESTE

Tabela 11 - Variáveis significativas da classe 1 do corpus 2006 inglês para subcategoria A

\begin{tabular}{lr}
\hline Variáveis significativas & $\boldsymbol{X}^{\mathbf{2}}$ \\
\hline *Sujeito 82 & 0.42 \\
*Sujeito 05 & 0.31 \\
*Sujeito 71 & 0.19 \\
*Sujeito 62 & 0.17 \\
*Sujeito 10 & 0.15 \\
*Sujeito 68 & 0.14 \\
*Sujeito 57 & 0.12 \\
*Sujeito 69 & 0.11 \\
*Sujeito 41 & 0.11 \\
*Sujeito76 & 0.10 \\
*Sujeito 22 & 0.08 \\
*Sujeito 02 & 0.07 \\
*Sujeito 72 & 0.07 \\
*Sujeito 39 & 0.05 \\
*Sujeito 37 & 0.05 \\
*Sujeito 63 & 0.02 \\
*Sujeito 49 & 0.02 \\
*Sujeito 17 & 0.02 \\
*Sujeito 61 & 0.02 \\
\hline Fonte: Relatório ALCESTE
\end{tabular}

Fonte: Relatório ALCESTE 
Tabela 12 - Palavras significativas da classe 2 do corpus 2006 inglês para subcategoria A

\begin{tabular}{lr}
\hline Palavras significativas & $\boldsymbol{X}^{\mathbf{2}}$ \\
\hline PCR & 0.30 \\
Polimorfonucleares & 0.30 \\
Amostras & 0.25 \\
Paciente & 0.23 \\
Detecção & 0.21 \\
Individual & 0.18 \\
Clínica & 0.14 \\
Diagnóstico & 0.14 \\
Método & 0.12 \\
Laboratoriais & 0.11 \\
Sangue & 0.07 \\
Confirmação & 0.06 \\
\hline Fonte: Relatório ALCESTE &
\end{tabular}

Tabela 13 - Palavras significativas da classe 1 do corpus 2008 inglês para subcategoria A

\begin{tabular}{lr}
\hline Palavras significativas & $\boldsymbol{X}^{\mathbf{2}}$ \\
\hline Células & 0.37 \\
Cobaias & 0.30 \\
Imune & 0.21 \\
Macrófago & 0.19 \\
Proteína & 0.17 \\
Leucócitos & 0.11 \\
Plasma & 0.10 \\
Intracelular & 0.08 \\
Experimento & 0.07 \\
Molécula & 0.07 \\
Núcleo & 0.06 \\
Sangue & 0.06 \\
\hline Fo: Relán ALCESTE
\end{tabular}

Fonte: Relatório ALCESTE 
Tabela 14 - Palavras significativas da classe 4 do corpus 2008 inglês para subcategoria A

\begin{tabular}{lr}
\hline Palavras significativas & $\boldsymbol{X}^{\mathbf{2}}$ \\
\hline Compostos & 0.30 \\
Síntese & 0.23 \\
Enzima & 0.22 \\
Química & 0.22 \\
Droga & 0.20 \\
Substrato & 0.13 \\
Propriedades & 0.12 \\
Composição & 0.12 \\
Mecanismos & 0.10 \\
Moléculas & 0.09 \\
Farmacologia & 0.06 \\
\hline Fonte: Relatório ALCESTE &
\end{tabular}

Tabela 15 - Ausências significativas da classe 4 do corpus 2008 inglês para subcategoria A

\begin{tabular}{lr}
\hline Ausências significativas & $\boldsymbol{X}^{\mathbf{2}}$ \\
\hline Paciente & -0.15 \\
Risco & -0.09 \\
Saúde & -0.09 \\
População & -0.09 \\
Prevalência & -0.09 \\
Individual & -0.09 \\
Idade & -0.09 \\
Responsabilidade & -0.07 \\
Clínica & -0.07 \\
Epidemiologia & -0.06 \\
Subjetividade & -0.06 \\
\hline Fonte: Relatório ALCESTE &
\end{tabular}

Tabela 16 - Palavras significativas da classe 3 do corpus 2006 português para subcategoria B

\begin{tabular}{lr}
\hline Palavras significativas & $\boldsymbol{X}^{\mathbf{2}}$ \\
\hline Saúde & 0.29 \\
Vida & 0.20 \\
Atenção & 0.18 \\
População & 0.18 \\
Sociais & 0.17 \\
Contexto & 0.16 \\
Acesso & 0.14 \\
Saneamento & 0.14
\end{tabular}




\begin{tabular}{ll} 
Integral & 0.13 \\
Descentralização & 0.12 \\
Necessidade & 0.11 \\
Econômica & 0.10 \\
Realidade & 0.10 \\
Prioridade & 0.10 \\
Socioeconômicas & 0.10 \\
Comunidade & 0.09 \\
Indicadores & 0.08 \\
Gestores & 0.07 \\
Município & 0.07 \\
Educação & 0.07 \\
\hline Fonte: Relatório ALCESTE &
\end{tabular}

Tabela 17 - Ausências significativas da classe 3 do corpus 2006 português para subcategoria B

\begin{tabular}{lr}
\hline Ausências significativas & $\boldsymbol{X}^{\mathbf{2}}$ \\
\hline Especialidades & -0.11 \\
Proteína & -0.09 \\
Sorológico & -0.08 \\
Sangue & -0.07 \\
Exame & -0.07 \\
Genótipos & -0.07 \\
Anticorpos & -0.07 \\
Fármaco & -0.06 \\
Paciente & -0.06 \\
Histopatológico & -0.05 \\
\hline Fonte: Relatório ALCESTE &
\end{tabular}

Tabela 18 - Variáveis significativas da classe 3 do corpus 2006 português para subcategoria B

\begin{tabular}{lc}
\hline Variáveis significativas & $\boldsymbol{X}^{\mathbf{2}}$ \\
\hline *Sujeito 74 & 0.29 \\
*Sujeito 37 & 0.23 \\
*Sujeito 27 & 0.18 \\
*Sujeito 73 & 0.13 \\
*Sujeito 55 & 0.12 \\
*Sujeito 65 & 0.10 \\
*Sujeito 51 & 0.08 \\
*Sujeito 45 & 0.07 \\
*Sujeito 47 & 0.07 \\
*Sujeito 04 & 0.07
\end{tabular}


*Sujeito 06

*Sujeito 23

*Sujeito $44 \quad 0.04$

Fonte: Relatório ALCESTE

Tabela 19 - Palavras significativas da classe 4 do corpus 2006 português para subcategoria B

\begin{tabular}{lr}
\hline Palavras significativas & $\boldsymbol{X}^{\mathbf{2}}$ \\
\hline Pneumologia & 0.40 \\
Tuberculose & 0.35 \\
Notificados & 0.22 \\
Epidemiologia & 0.21 \\
Perfil & 0.20 \\
Público & 0.19 \\
Mycobacterium & 0.18 \\
Coletiva & 0.17 \\
Saúde & 0.17 \\
Coorte & 0.15 \\
Agravos & 0.15 \\
Retrospectivo & 0.15 \\
Quimioprofilaxia & 0.15 \\
Vigilância & 0.13 \\
Doença & 0.13 \\
Comunitário & 0.10 \\
Tratamento & 0.09 \\
Epidemiologia & 0.08 \\
Incidência & 0.07 \\
Mortalidade & 0.07 \\
Pobreza & 0.06 \\
Município & 0.06 \\
Programa & 0.06 \\
Descritivo & 0.06 \\
Socioeconômico & 0.06 \\
Sociodemográfico & 0.06 \\
\hline Fonte: Relatório ALCESTE &
\end{tabular}

Fonte: Relatório ALCESTE 
Tabela 20 - Variáveis significativas da classe 4 do corpus 2006 português para subcategoria B

\begin{tabular}{lr}
\hline Variáveis significativas & $\boldsymbol{X}^{\mathbf{2}}$ \\
\hline *Sujeito 23 & 0.37 \\
*Sujeito 01 & 0.20 \\
*Sujeito 78 & 0.13 \\
*Sujeito 14 & 0.08 \\
*Sujeito 55 & 0.08 \\
*Sujeito 67 & 0.08 \\
*Sujeito 51 & 0.07 \\
\hline Fonte: Relatório ALCESTE &
\end{tabular}

Tabela 21 - Palavras significativas da classe 3 do corpus 2008 português para subcategoria B

\begin{tabular}{lc}
\hline Palavras significativas & $\boldsymbol{X}^{\mathbf{2}}$ \\
\hline Saúde & 0.43 \\
Necessidade & 0.24 \\
Coletiva & 0.22 \\
Vulnerabilidade & 0.19 \\
Política & 0.17 \\
Social & 0.17 \\
Município & 0.16 \\
Atenção & 0.13 \\
Comunidade & 0.13 \\
Estratégia & 0.13 \\
Planejamento & 0.10 \\
Prevenção & 0.09 \\
Pública & 0.09 \\
Equidade & 0.08 \\
Desigualdade & 0.07 \\
\hline Fon Reló
\end{tabular}

Fonte: Relatório ALCESTE 
Tabela 22 - Ausências significativas da classe 3 do corpus 2008 português para subcategoria B

\begin{tabular}{lr}
\hline Ausências significativas & $\boldsymbol{X}^{\mathbf{2}}$ \\
\hline Paciente & -0.17 \\
Teste & -0.15 \\
Resposta & -0.12 \\
Clínica & -0.10 \\
Cirúrgico & -0.09 \\
Experimento & -0.08 \\
Administração & -0.07 \\
Sensibilidade & -0.07 \\
Exame & -0.07 \\
Sangue & -0.06 \\
Resultados & -0.06 \\
\hline Fonte: Relatório ALCESTE &
\end{tabular}

Tabela 23 - Palavras significativas da classe 3 do corpus 2008 inglês para subcategoria B

\begin{tabular}{lc}
\hline Palavras significativas & $\boldsymbol{X}^{\mathbf{2}}$ \\
\hline Prevalência & 0.28 \\
Saúde & 0.18 \\
Comunidade & 0.14 \\
Urbano & 0.14 \\
Rural & 0.14 \\
Epidemiologia & 0.13 \\
Intervenção & 0.12 \\
Sanitária & 0.12 \\
Socioeconômica & 0.11 \\
Social & 0.11 \\
Público & 0.10 \\
Demografia & 0.09 \\
Pobre & 0.07 \\
Prevenção & 0.07 \\
\hline Fonte: Relatório ALCESTE &
\end{tabular}


Tabela 24 - Variáveis significativas da classe 3 do corpus 2008 inglês para subcategoria B

\begin{tabular}{lr}
\hline Palavras significativas & $\boldsymbol{X}^{\mathbf{2}}$ \\
\hline *Sujeito 42 & 0.36 \\
*Sujeito 24 & 0.35 \\
*Sujeito 58 & 0.13 \\
*Sujeito 40 & 0.09 \\
*Sujeito 36 & 0.09 \\
*Sujeito 05 & 0.08 \\
*Sujeito 54 & 0.07 \\
*Sujeito 23 & 0.06 \\
*Sujeito 22 & 0.03 \\
*Sujeito 35 & 0.02 \\
*Sujeito 34 & 0.02 \\
\hline Fonte: Relatório ALCESTE &
\end{tabular}

Fonte: Relatório ALCESTE

Tabela 25 - Variáveis significativas da classe 1 do corpus 2006 português para categoria 2

\begin{tabular}{lr}
\hline Variáveis significativas & $\boldsymbol{X}^{\mathbf{2}}$ \\
\hline *Sujeito 76 & 0.32 \\
*Sujeito 74 & 0.20 \\
*Sujeito 46 & 0.17 \\
*Sujeito 07 & 0.14 \\
*Sujeito 70 & 0.07 \\
*Sujeito 79 & 0.07 \\
*Sujeito 20 & 0.06 \\
*Sujeito 33 & 0.05 \\
*Sujeito 63 & 0.05 \\
\hline
\end{tabular}

Fonte: Relatório ALCESTE 


\title{
APÊNDICE C
}

\section{Promoção da equidade na produção do conhecimento sobre as doenças negligenciadas no Brasil}

\begin{abstract}
RESUMO
As doenças negligenciadas classificam-se como um grupo de doenças infecciosas fortemente associadas às condições de pobreza verificadas, em sua grande maioria, nos países periféricos. Dessa forma, elas são enquadradas como um clássico exemplo do déficit existente na produção do conhecimento destinado a determinados temas. Este artigo tem por objetivo analisar o atendimento das diretrizes de promoção da equidade na produção do conhecimento em doenças negligenciadas a partir do perfil dos pesquisadores com projetos aprovados pelos editais de pesquisa sobre o tema, publicados em 2006, 2008 e 2012 pelo Ministério da Saúde. Os dados investigados são públicos e foram captados dos referidos projetos e da Plataforma Lattes. O presente estudo de caráter transversal e descritivo obteve os seguintes resultados: 216 projetos contemplados nos três editais; houve praticamente a equivalência na participação do gênero masculino e feminino na coordenação das pesquisas; as instituições públicas de ensino superior e de pesquisa foram as mais contempladas pelos editais; a maior parte dos estudos foi proveniente de autores com formação na área das ciências da saúde e concentrou-se principalmente nas instituições situadas na região Sudeste, que vale destacar, não é a região do país que concentra o maior número de casos das doenças negligenciadas.
\end{abstract}

Palavras-chaves: doenças negligenciadas, doenças tropicais negligenciadas, produção cientifica e pesquisa e desenvolvimento em saúde. 


\begin{abstract}
Promoting equity in the production of knowledge on neglected diseases in Brazil Neglected diseases are classified as an infectious disease group that is strongly associated to poverty conditions, mostly in peripheral countries. From this perspective, neglected diseases are shown as a classic example of science production deficits in certain research topics. This article analyzes the promotion of equity within knowledge production about neglected diseases based on researcher profiles, institutions with projects approved on the subject, and published in 2006, 2008, and 2012 by the Brazilian Ministry of Health. The data investigated are public and collected from these projects and the Lattes Platform. This cross-sectional descriptive study obtained the following results: 216 projects included in the three calls for application; almost equal gender participation in coordinating research; predominantly developed by mostly public higher education institutions (universities) and research centers. Most of the studies were conducted by authors trained in health sciences and were mainly concentrated in institutions of the southeastern region of Brazil, which is notably not the part of the country with the largest number of neglected disease cases.
\end{abstract}

Key-words: Neglected diseases. Neglected tropical diseases. Equity. 


\section{INTRODUÇÃO}

Há tempos a humanidade é assolada por um grupo de doenças que estão associadas à pobreza e proliferam, principalmente, em ambientes marcados pela exclusão social. Essas doenças são denominadas doenças negligenciadas e de acordo com a Organização Mundial da Saúde (OMS) formam um conjunto de 17 enfermidades que afetam principalmente pessoas que vivem nos trópicos, mas não são exclusivas a eles. Nessa relação estão incluídas as seguintes enfermidades: tracoma; úlcera de Buruli; tripanossomose africana (doença do sono); doença de Chagas (tripanossomíase americana); dengue; dracunculíase; cisticercose; leishmaniose; hanseníase; filariose linfática; oncocercose; esquistossomose; bouba; geohelmintíase; raiva; equinococose e fasciolíase. Dados da OMS sobre o tema apontam que muitas delas já foram altamente prevalentes, mas, na medida em que as sociedades se desenvolveram e as condições de vida melhoraram foram desaparecendo gradualmente.

A negligência que permeia o histórico de determinadas doenças transmissíveis associadas à pobreza impacta diretamente nas condições sociais e econômicas de populações marginalizadas concentradas, na sua grande maioria, nas áreas pobres de países de baixa e média renda. Hoje, mesmo com o premente risco de contaminação de pelo menos $40 \%$ da população mundial por uma doença negligenciada, verifica-se que elas permanecem na sua grande maioria ocultas, concentradas em áreas rurais remotas ou em favelas urbanas (BATALHA; MOROSINI, 2013).

De fato, dentre os países da América Latina e Caribe, o Brasil é o país que apresenta o maior número de casos de doenças negligenciadas. Desta forma, grandes partes dos milhares de brasileiros que se encontram em situação de pobreza estão ou serão contaminados por uma ou mais de uma dessas doenças (HOTEZ, 2008).

O breve quadro apontado pelos autores deste artigo reforça que as iniquidades e as injustiças sanitárias que acometem, preferencialmente, os países periféricos persistem, na maioria das vezes, quando não são adotados mecanismos de enfrentamento, principalmente, por parte das autoridades sanitárias. 
No Caso do Brasil, apesar da tendência a estabilidade verificada para este grupo de doenças (NORONHA, 2012), um olhar ético e ações governamentais que estimulem as pesquisas e suas consequentes aplicações devem ser estimuladas e direcionadas por uma justa divisão de recursos, sobretudo, para as regiões do país com menor estrutura para produção científica.

Para os autores deste artigo, ações deste tipo são corroboradas, sobretudo, quando se encara a pesquisa como um investimento e não como uma despesa. Pois, em se tratando de pesquisa em saúde, ela é essencial para elucidação da natureza e do contexto dos problemas, para desenvolvimento e implementação de intervenções que salvam vidas, na busca de melhorias para os determinantes sociais da saúde e consequentemente na promoção da celeridade no acesso aos benefícios, principalmente, para as populações pobres e marginalizadas que se encontram a margem do processo científico e tecnológico.

O que se observa é que a deficiência no processo de estabelecimento e de execução de prioridades no processo de produção do conhecimento em saúde ainda é um fato presente, apesar de já ter sido demonstrado no final da década de 90 pela Comissão de Pesquisa em Saúde para o Desenvolvimento (1999) quando apontou a existência de uma dissociação entre carga de doenças das populações desfavorecidas e a concentração de investimento global em pesquisa em saúde nos problemas do mundo industrializado.

De fato, existe um desajuste onde menos de $10 \%$ dos investimentos de recursos destinados para pesquisa e desenvolvimento em saúde são direcionados às doenças ou condições que atingem $90 \%$ da população mundial, determinando um desequilíbrio que foi batizado de déficit 10/90 - The 10/90 Gap (GLOBAL FORUM FOR HEALTH RESEARCH, 2002).

Desta forma, as doenças negligenciadas são consideradas como um clássico exemplo desse desajuste. Vive-se a sombra da contradição. Enquanto milhares de pessoas necessitam urgentemente de medidas de intervenção para combater doenças relacionadas às suas precárias condições de vida, a produção do conhecimento, mais especificamente a pesquisa $e$ desenvolvimento (P\&D) em saúde, desenvolvida principalmente pela indústria 
farmacêutica mundial, volta sua atenção para as doenças globais, sempre na intenção de produzir e comercializar para obter lucros.

Dito isto, a produção do conhecimento no país necessita do direcionamento para áreas prioritárias e deve ser concebida à luz dos referenciais da equidade para promover tratamento diferente para os diferentes, promovendo uma justa distribuição desigual com a menor exclusão possível das partes envolvidas (SIQUEIRA-BATISTA; SCHRAMM; 2005).

Nesse sentido, no ano de 2003 foi iniciado no país pelo Ministério da Saúde (MS) um processo de indução a produção de conhecimento destinado às doenças relacionadas à pobreza denominadas por doenças negligenciadas. Inicialmente foram lançados editais por doenças específicas (tuberculose 2003; dengue 2004 e hanseníase 2005), sendo em seguida lançados três editais (2006, 2008 e 2012) para doenças consideradas negligenciadas e prioritárias (dengue, doença de Chagas, esquistossomose, hanseníase, leishmanioses, malária, tuberculose, tracoma e geohelmintíases) na visão dos gestores, pesquisadores e profissionais da área da saúde (BRASIL, 2008; 2012).

Face ao exposto, os autores do presente artigo se propõem a analisar o atendimento das diretrizes de promoção da equidade na produção do conhecimento sobre o tema das doenças negligenciadas, a partir do apoio dos editais para as pesquisas da área, publicados no país nos anos de 2006, 2008 e 2012.

\section{METODOLOGIA}

O presente estudo foi de caráter transversal e descritivo. Para obtenção dos resultados deste estudo foram utilizados dados captados dos projetos de pesquisas aprovados pelos editais de fomento à pesquisa e desenvolvimento na área das doenças negligenciadas lançados pelo Ministério da Saúde e parceiros nos anos de 2006, 2008 e 2012. Vale ressaltar que a escolha dos editais anteriormente descritos como um marco de referência para o presente estudo ocorreu, sobretudo, pela expressividade destes editais no cenário da pesquisa em saúde do país.

Os dados que compuseram este estudo são públicos e se encontram alojados no sítio eletrônico www.pesquisasaude.saude.gov.br e na Plataforma 
Lattes/CNPq. Vale destacar que a consulta à base de dados foi realizada inicialmente entre os meses de novembro e dezembro de 2012 e complementada no mês dezembro de 2014.

Para a construção do perfil dos pesquisadores, os autores deste estudo optaram pelas seguintes variáveis: gênero e formação dos coordenadores das pesquisas, tipo de instituição as quais estão vinculados (caráter e atuação) e região de localização no país destas instituições.

O levantamento bibliográfico iniciou-se em janeiro de 2012 e foi finalizado em dezembro de 2014. A busca ocorreu na literatura científica e técnica da área "Ciências da Saúde em Geral" da Biblioteca Virtual em Saúde (BVS), cuja captação reúne as seguintes bases: LILACS, IBECS, MEDLINE, Biblioteca Cochrane e SciELO. Para tal, utilizaram-se os seguintes descritores: doenças negligenciadas, doenças tropicais negligenciadas, produção cientifica e pesquisa e desenvolvimento em saúde, em português, e neglected diseases, neglected tropical diseases, scientific production, research priorities, health research and development em inglês.

Por fim, os autores do estudo destacam que este artigo trata-se do primeiro produto da tese intitulada de "A produção do conhecimento em doenças negligenciadas no Brasil: uma análise bioética dos dispositivos normativos e da atuação dos pesquisadores brasileiros" e que a submissão e aprovação do projeto desta tese ocorreu em outubro de 2012 pelo Comitê de Ética em Pesquisa da Faculdade de Ciências da Saúde da Universidade de Brasília (CEP FS-UnB) sob o número 142/12.

\section{RESULTADOS}

O universo de pesquisadores contemplados nos editais de fomento para pesquisa e desenvolvimento para as doenças negligenciadas, lançado pelo Ministério da Saúde e parceiros nos anos de 2006, 2008 e 2012 foi de 216 pesquisadores. Em 2006, 47(58\%) dos contemplados eram do gênero masculino e $35(42 \%)$ do gênero feminino gerando um total de 82 pesquisadores para este ano. No ano de 2008, o gênero masculino apresentou 29 contemplados (50\%) e o gênero feminino também apresentou $29(50 \%)$ 
contempladas, com um total de 58 pesquisadores. Já em 2012, foram 38 do gênero feminino e 38 do gênero masculino.

Em relação à formação dos pesquisadores, no ano de 2006 foram observados os seguintes resultados: $67(82 \%)$ pesquisadores foram formados na área das ciências da saúde, 14(17\%) pesquisadores das ciências exatas e $1(1 \%)$ pesquisador não apresentou registro do seu currículo na Plataforma Lattes para verificação. Para o ano de 2008 foi observado que 48 (83\%) dos pesquisadores eram das ciências da saúde, 8 (14\%) pesquisadores tinham formação na área das ciências exatas e $2(3 \%)$ pesquisadores não tinham seu currículo registrado na Plataforma Lattes. Para o ano de 2012, 74 (97\%) pesquisadores tinham formação na área das ciências da saúde e 2(3\%) pesquisadores apresentaram formação na área das ciências humana. Tratando-se da formação de pós-graduação, do universo de 216 pesquisadores contemplados nos três editais, 212(98\%) apresentaram o título de doutor, $1(0,6 \%)$ de especialista e $3(1,4 \%)$ não tinham registro dos seus currículos na Plataforma Lattes.

Os autores verificaram que as instituições contempladas pelos editais eram as de ensino superior, os institutos de pesquisa, os hospitais de ensino, os serviços de saúde e as organizações sem fins lucrativos (ONG, OSCIP, etc). No ano de 2006, a contemplação ocorreu da seguinte forma: 51(62\%) instituições de ensino superior, $30(36 \%)$ institutos de pesquisa e $1(2 \%)$ serviço de saúde. Em 2008 foram contempladas as seguintes instituições: 39(67\%) instituições de ensino superior, 16(27,5\%) institutos de pesquisa, 2 (3,5\%) hospitais de ensino e 1(2\%) organização sem fins lucrativos. No ano de 2012 foram $51(67 \%)$ instituições de ensino superior, $24(31,7 \%)$ institutos de pesquisa e $1(1,3 \%)$ serviço de saúde. Vale destacar que a maioria das instituições contempladas nos três editais era de caráter público. Para finalizar, a região Sudeste do país foi a região com o maior número de instituições contempladas, seguida pela região Nordeste do Brasil (Tabelas 1, 2 e 3).

\section{DISCUSSÃO}

O modo de produção do conhecimento na área da saúde do país atravessa um período de transformações significativas, aonde as verdadeiras 
necessidades da sociedade deixam de ser latentes para se tornarem explícitas e assumirem o lugar de destaque que the é devido dentre as ações de responsabilidade do Estado. Nesse sentido, o tema das doenças negligenciadas, cujas consequências são consagradas pela literatura científica mundial, foi incorporado na agenda de pesquisa em saúde instituída para o país, tornando-se uma "prioridade das prioridades".

Como consequência, a atitude tomada pelo Estado brasileiro para enfrentamento de tal problema demonstrou-se como uma forte aliada na reversão de uma lacuna existente no campo da pesquisa e desenvolvimento em saúde, usualmente denominada de 10/90 GAP, que pode ser descrita como um desequilíbrio aonde $10 \%$ de todo financiamento mundial da pesquisa científica em saúde vai para doenças ou condições que afetam $90 \%$ da população mundial.

Ao que se vê, a recorrência dos editais públicos de apoio as pesquisas das doenças negligenciadas tem propiciado um cenário favorável para a produção do conhecimento sobre o tema no Brasil. Desta forma, profundas transformações no modo nacional de produção do conhecimento e a relação estabelecida entre ciência e sociedade, que são justamente aquelas que concedem uma maior integração entre necessidades sociais e pesquisa científica outrora afirmada por Pellegrini (2004), começam a refletir na totalidade do processo de apoio à pesquisa em saúde em andamento no país.

De fato, apesar de não estarmos no mesmo patamar dos países de alta renda, considerados como países centrais, existe o empenho para que as deficiências presentes na situação da pesquisa do país sejam superadas e, cada vez mais, o estímulo à produção do conhecimento acerca de temas que refletem diretamente nas condições de desenvolvimento de uma nação, como no caso do tema das doenças negligenciadas, ganhe mais espaço nas agendas de pesquisa e tornem-se prioritários.

As evidencias apontam que as ações governamentais voltadas para a pesquisa de doenças enquadradas no status de negligência são uma prática verificada no país, a exemplo dos editais publicados nos anos de 2003(tuberculose), 2004 (dengue) e 2005(hanseníase).

No entanto, o presente estudo constatou que nenhuma ação de apoio à pesquisa tinha sido tão expressiva quanto às promovidas nos anos de 2006, 
2008 e 2012. Nenhum edital, até então, tinha contemplado tantas linhas de pesquisa para um número tão expressivo de doenças (trouxe sete doenças como prioridade no conteúdo dos editais de 2006 e 2008 e nove doenças no edital de 2012). De acordo com o Departamento de Ciência e Tecnologia do Ministério da Saúde (2006), o edital temático das doenças negligenciadas foi considerado como a mais importante iniciativa do ano de 2006, tanto pela relevância do tema quanto ao aporte de recursos destinado para o edital.

Nesse sentido, verifica-se que em termos de financiamento público, o Brasil está em sexto lugar no ranking dos países que mais investem no segmento das doenças negligenciadas, e o primeiro, se considerarmos apenas os países em desenvolvimento onde essas doenças são endêmicas (ASSAD, 2010). Atualmente, as medidas adotadas pelo país relativas à pesquisa em doenças negligenciadas, refletem na sua liderança mundial em pesquisas sobre o tema (SBMT, 2014), demonstrando, inclusive, a supressão do abismo científico (Morel et al, 2009) instituído no país entre a área das doenças negligenciadas com outras áreas da saúde.

Apesar dos cortes promovidos pelo Governo Federal para as áreas de Ciência, Tecnologia e Inovação, as autoridades da área afirmam que nunca se investiu tanto em pesquisas, principalmente quando se trata desse tipo de doenças (SBMT, 2014).

Destaca-se que além de investir de modo expressivo em pesquisas sobre o tema, o país também passou a investir na produção de insumos utilizados no combate e no tratamento de determinadas doenças negligenciadas, a exemplo do medicamento Benzonidazol utilizado no combate da doença de Chagas e dos medicamentos para tuberculose (SBMT, 2014).

De fato, as evidências científicas confirmam que a vinculação de programas de combate a doenças, como nos casos dos bem sucedidos programas de controle da varíola, oncocercose e doença de Chagas (MOLYNEUX; MOREL, 1998; HENDERSON, 1998) devem, em parte, seu sucesso ao fato de terem incluído como parte das suas ações atividades de pesquisa, reforçando a ideia que a produção do conhecimento científico tornase um forte componente para superação das iniquidades na medida em que integram as verdadeiras necessidades da sociedade a agenda de pesquisa vigente no país. 
Nesse sentido, Sanders e colaboradores (2004) reforçam que as ações de saúde, como no caso das pesquisas, devem ter seu ordenamento baseado tanto na crescente dívida existente entre localidades ricas e pobres, como também no espaço existente entre a disponibilidade do conhecimento científico e sua efetiva aplicação para solucionar problemas de saúde que acometem principalmente as populações expostas à pobreza.

A louvável tentativa do país em estabelecer uma nova ordem no campo da pesquisa em saúde, além de considerar as necessidades prementes na realidade dos coletivos socialmente excluídos, considerou também as diferenças regionais presentes nas cinco regiões do país aonde as pesquisas seriam produzidas. Como consequência, foi prescrita uma medida pelos editais na intenção de abrandar tais diferenças e incentivar o acesso dos estudos provenientes das regiões menos estruturadas e com altos índices de doenças negligenciadas.

Realmente, um incentivo pautado no combate das iniquidades regionais da pesquisa foi instituído para todas as regiões do país, inclusive, para as regiões com maior prevalência das doenças negligenciadas e com menor capacidade para pesquisa, como é o caso das regiões geográficas do Norte, Nordeste e Centro-Oeste (MOREL et al, 2009).

$\mathrm{Na}$ visão de Morel e colaboradores (2009), esse tipo de incentivo funciona para estimular a produção do conhecimento em regiões aonde às iniquidades regionais no campo da pesquisa em saúde são visíveis e inversamente proporcionais a prevalência de muitas doenças. No entanto, constatou-se que a maioria das pesquisas contempladas com recursos públicos foram os estudos realizados por instituições de pesquisas da região mais desenvolvida, com melhor estrutura e que não se enquadra na maior prevalência de casos de doenças negligenciadas no país, no caso, a região Sudeste.

De fato, a realidade apontada por este artigo não foge aos padrões da situação da produção do conhecimento vigente no país. Quando se analisa a produção relativa ao tema das doenças negligenciadas, verifica-se que esta ainda se concentra, principalmente, nas instituições situadas no Rio de Janeiro e São Paulo, estados da região Sudeste (CUNHA SANTOS et al, 2009; 
NORONHA et al, 2012; SVS, 2010), seguidas pela produção das regiões Nordeste, Norte e Centro-Oeste.

Os dados analisados pelos autores deste artigo confirmam que 0 apoio público à produção científica nacional acerca do tema das doenças negligenciadas além de ascendente é um dos mais expressivos da área da saúde (SBMT, 2014). Entretanto, nem todos os grupos de pesquisas conseguem desfrutar de tal apoio. Percebe-se que os grupos de pesquisa mais estruturados, localizados na sua grande maioria em instituições de pesquisas situadas na região Sudeste do país, detêm o maior poder de captação dos recursos públicos para o desenvolvimento dos seus estudos.

Apesar da tentativa de fortalecimento da capacidade de pesquisa pelo apoio público das regiões com maiores necessidades, como no caso do Norte, Nordeste e Centro-Oeste, verifica-se ainda que o crescimento da produção científica voltada às doenças negligenciadas nestas regiões é aquém da que ocorre na região de maior desenvolvimento e capacidade de captação de recursos do país.

O que se verificou entra as regiões foi uma divisão bastante desigual e ainda pouco articulada, permanecendo algumas dificuldades de cooperação interinstitucional para formação de redes nacionais e regionais de pesquisa que integrem as de maior densidade tecnológica e produtividade com as regiões de menor densidade e menos produtivas (CAVALCANTE, 2011).

A despeito das investidas do Estado, constatou-se que uma repartição injusta e ineficaz dos recursos destinados à área ainda é algo que deixa 0 Norte, Nordeste e Centro-oeste do país, que são regiões que apresentam alta prevalência de doenças negligenciadas (MOREL et al, 2009; BRASIL, 2014), num certo descompasso do processo vigente no país de incentivo a produção conhecimento da área.

Apesar da tentativa de se estabelecer um parâmetro que considere a equidade como ponto de partida para divisão dos projetos em doenças negligenciadas por região do país, poucas modificações foram observadas no cenário da pesquisa acerca deste tema. Com isso, verifica-se que 0 descumprimento do critério de equidade estabelecido pelas normativas foi algo presente. A quantidade de projetos contemplados das regiões Norte, Nordeste e Centro-Oeste, além de não representarem nem a metade dos projetos 
contemplados pela região Sudeste, não chegou ao patamar estabelecido pelas normativas vigente para a pesquisa em saúde no país.

O que se pôde observar foi que as instituições que ocupam lugar de destaque no ranking de produção do conhecimento foram às mesmas contempladas pelos dois editais, concentradas em sua grande maioria nos estados de São Paulo e Rio de Janeiro. Deste modo, há uma sugestão que as mesmas instituições perpetuam o seu poder e suas subjetividades, ferem o que se considera por equidade nas ações de saúde e confirmam a máxima de quem tem o conhecimento, detém o poder.

Para os autores deste artigo, na hora da contemplação de instituições de pesquisa, critérios de igualdade não devem ser considerados, e sim a diferença das condições existentes, levando-se em conta as necessidades diferenciadas. Assim, uma ação que pretende ser guiada pela equidade deveria proporcionar à satisfação não apenas aos mais fortes e, sim, as necessidades de todos os envolvidos.

Nesse caso, critérios de equidade deveriam prevalecer, pois, além de respeitar as diferenças, poderia ser um caminho para que se atingisse a igualdade das partes envolvidas. Corroborando com a visão dos autores deste estudo, Fortes (2008) afirmou que a equidade pode ser considerada como "a cada um conforme as suas necessidades". Nunes (2004), por sua vez, complementou tal visão, pois afirma que a eleição dos mais necessitados é central na elaboração de qualquer metodologia que pretenda alocar ou alterar alocação de recursos, que no primeiro momento, para ser mais equitativa, a alocação deverá ocorrer pela seleção de necessidades.

$\mathrm{Na}$ visão dos autores deste estudo, apesar da distribuição não equitativa dos projetos por regiões, o incentivo do Estado à produção do conhecimento voltada ao combate das doenças negligenciadas pode atuar como uma ação cujas consequências possibilitam a promoção de bem estar para um maior número de pessoas, principalmente, para indivíduos e os coletivos que são socialmente excluídos.

É interessante observar que o processo de produção do conhecimento estimulado pelos editais de 2006, 2008 e 2012 foi exercido, na sua grande maioria, pelas instituições universitárias, consideradas o lócus privilegiado de construção científica e de desenvolvimento tecnológico, não só no Brasil, mas 
em todo mundo (Minayo, 2012), foi corroborado pelas evidências apontadas por lozi (2013) ao afirmar que as atividades de pesquisa no Brasil ocorrem em instituições universitárias e em instituições de pesquisa específicas da área da saúde, com uma incipiente participação das unidades de serviço, com exceção dos hospitais de ensino, e das empresas privadas do setor.

Seguindo esta tendência, as universidades e centros de pesquisas da região Sudeste do país mantiveram-se como o locus preferencial da produção do conhecimento em doenças negligenciadas no país ao longo da série temporal analisada por este estudo. Leta e colaboradores (2006) já haviam demonstrado esta dinâmica ao afirmar que a produção de pesquisa do país estaria concentrada nas universidades e em alguns centros de pesquisa da região mais desenvolvida do país.

Desta forma, os fatos acima apontados confirmam que o ciclo virtuoso, instituído principalmente pelas universidades públicas desde meados dos anos 60 , destinado a formar e consolidar grupos de pesquisa (GUIMARÃES, 2004), passou a ter um comportamento de "ciclo vicioso", explicitado pela tendência da supremacia e das subjetividades de muitas instituições e de seus pesquisadores na perpetuação e consequente reforço das desigualdades regionais na produção do conhecimento verificada no cenário da pesquisa em saúde no país.

Os resultados relativos à localização geográfica e tipos de instituições contempladas pelos editais anteriormente apontados pelos autores, demonstram que a situação da pesquisa destinada às doenças negligenciadas no país está em consonância com a situação das demais pesquisas realizadas pela área da saúde, ou seja, pesquisas realizadas por instituições públicas e com o apoio público na maioria dos casos.

De acordo com os dados apontados pela Secretaria de Ciência, Tecnologia e Insumos Estratégicos do Ministério da Saúde (2012), os grupos que realizam atividades de pesquisa em saúde no país, $49 \%$ estão localizados na região Sudeste, $23 \%$ na região Sul, $17 \%$ na região Nordeste, $6 \%$ na região Centro-Oeste e $5 \%$ na região Norte.

Como consequência desta configuração, observa-se também que a maioria dos programas de pós-graduação do país estão localizados na região Sudeste (55\%) (KERR-PONTES et al 2005), local aonde também ocorre a 
maior concentração de bolsas de produtividade científica ofertadas pelo CNPq (CUNHA SANTOS et al, 2009).

Diante do exposto, verifica-se que a indução à pesquisa em doenças negligenciadas, quando colocada em prática, na opinião dos autores deste artigo não pode ser direcionado e ficar restrito apenas aos centros de pesquisa situados nas instituições de maior projeção do país. Os centros de pesquisas do país que trazem nos seus históricos a aptidão para a realização de estudos de relevância para a temática devem introjetar nas suas práticas mecanismos capazes de aproximá-los das instituições que, apesar de capazes, apresentamse com menor aptidão para o desenvolvimento das pesquisas. Ou seja, devese partir de uma lógica de aptidão institucional para a lógica da capacidade de quem quer produzir conhecimento científico no país.

Em relação ao gênero, os resultados demonstraram um equilíbrio desta variável para os três editais e corroboraram com as afirmações de Minayo (2012) quando apontou que à área de Ciência, Tecnologia e Inovação (C\&T\&I) tem apresentado um caminho positivo quanto à igualdade de gênero. De acordo com esta autora, em 2010 a participação percentual das mulheres no setor pareou com a dos homens, tendo havido também crescimento contínuo na condição de liderança de grupos de pesquisa. Em 2010 a situação da pesquisa era a seguinte: $54,9 \%$ de homens líderes de pesquisa e $45,1 \%$ de mulheres líderes de pesquisa; contra $66,8 \%$ e $33,2 \%$, respectivamente para o ano de 2000.

O autor do estudo destaca que, apesar de ser considerada como um dos principais meios de enfrentamento para o status de negligência condicionado a determinadas doenças infecciosas, a pesquisa científica não é o único meio. Portanto, uma abordagem mais ampla se faz necessária, principalmente, pela complexidade que envolve o tema. Visões que não se prendam apenas as questões atinentes à assistência à saúde devem ser incorporadas para esta temática, pois, apesar de se tratar do enfrentamento a uma entidade nosológica, não se pode aprisionar o tema apenas à lente da causalidade biológica que o envolve, da sua ocorrência individualizada e dissociada dos fenômenos sociais que o cerca.

Por isso, os autores deste artigo apontam que é impossível estabelecer uma dissociação da relação entre doença e doente, doente e seu meio social, 
fazendo-se necessária um olhar convergente dos vários tipos de pesquisas (biomédicas, clínica, desenvolvimento tecnológico, saúde coletiva e ciências sociais e humanas) para o tema. Deve ficar claro que, além de existir doenças negligenciadas, existem também indivíduos/coletivos (doentes) negligenciados ou indivíduos/coletivos que apesar de não estarem doentes, caso não haja algum tipo de intervenção, serão enquadrados como possíveis suscetíveis ao acometimento de uma ou de várias doenças negligenciadas.

\section{CONSIDERAÇÕES FINAIS}

$\mathrm{Na}$ visão dos autores do presente artigo, o grande desafio lançado ao país no campo da produção do conhecimento destinado as doenças negligenciadas é justamente a construção da relação entre as ações de estímulo destinadas ao fortalecimento da capacidade de produção científica voltada ao tema e o estabelecimento de formas equitativas de alocação dos recursos que se destinam a este tipo de produção.

De fato, quando adequadamente conduzidas, as ações podem tanto potencializar a produção científica da área no país, inclusive de centros de pesquisa das regiões menos desenvolvidas como o Norte, Nordeste e CentroOeste, como também ser revertida em melhorias para saúde da população em geral.

Além disto, os autores também consideram que a produção do conhecimento deve ser sinérgica e estar em consonância com as verdadeiras necessidades da sociedade, fazendo com que seja estabelecida uma estreita e verdadeira relação entre pesquisa, política de saúde e equidade.

Os autores deste artigo destacam que por se tratar de um estudo de caráter descritivo, indicasse que outros estudos, quer sejam de caráter analítico ou prospectivo, produzidos pela área da saúde ou por outras áreas do conhecimento, sejam concebidos para possibilitar o aprofundamento acerca do tema da produção do conhecimento em doenças negligenciadas no país

Por fim, recomenda-se aprofundar a compreensão e utilização de formas para diminuir a distância estabelecida entre a produção do conhecimento/resultados da pesquisa e a sua aplicabilidade como elemento 
norteador tanto na construção de políticas públicas quanto nas ações voltadas para atenção à saúde.

\section{REFERÊNCIAS BIBLIOGRÁFICAS}

BATALHA E, MOROSINI L. Atenção aos esquecidos. Radis. 2013; n. 124, p.817; www.ensp.fiocruz.br/radis.

BARRETO, M.L. Growth and trends in scientific production in epidemiology in Brazil. Rev. Saúde Pública 2006; 40: 79-85.

BRASIL. Ministério da Saúde. Departamento de Ciência e Tecnologia. Prioridade de Pesquisa em Saúde. Caderno 2 - Doenças Negligenciadas. Departamento de Ciência e Tecnologia - Decit 2006. http://bvsms.saude.gov.br/bvs/publicacoes/prioridades_invest/i2_tela4_2.html. Acesso em 4 de abr 2012.

BRASIL. Ministério da Saúde. Oficina de Prioridades de Pesquisas em Saúde de Doenças Negligenciadas. Informativo DECIT - Departamento de Ciência e Tecnologia/SVS da Secretaria de Vigilância em Saúde do Ministério da Saúde. Julho, 2008.

BRASIL. Ministério da Saúde. Secretaria de Ciência, Tecnologia e Insumos Estratégicos. Departamento de Ciência e Tecnologia. Pesquisa em Saúde no Brasil. Rev. Saúde Coletiva, 42(4):773-5; 2008.

CORDEIRO, H. Organizador. Prioridades Nacionais, Pesquisa Essencial e Desenvolvimento em Saúde. Rio de Janeiro: Fiocruz; 1990. (Política de Saúde $\left.n^{\circ} 10\right)$.

CUNHA SANTOS, M.S., SANTOS, LIMA L., MARTELLI, D.R.B., MARTELLI JÚNIOR, H. Perfil dos pesquisadores da Saúde Coletiva no Conselho Nacional de Desenvolvimento Científico e Tecnológico. Physis Revista de Saúde Coletiva, Rio de Janeiro, 19(3): 761 - 775, 2009. 
DUJARDIN, J.C.; HERRERA, S.; DO ROSARIO, V. et al. Research priorities for neglected infectious diseases in Latin America and Caribbean region. PLoS Negl Trop Dis 2010; 4: e780.

Fundação Oswaldo Cruz. A saúde no Brasil em 2030: diretrizes para a prospecção estratégica do sistema de saúde brasileiro. / Fundação Oswaldo Cruz... [et al.]. Rio de Janeiro : Fiocruz/lpea/Ministério da Saúde/Secretaria de Assuntos Estratégicos da Presidência da República, 2012. p. $97-110$.

GUIMARÃES, J.A. A pesquisa médica e biomédica no Brasil. Comparações com o desempenho científico brasileiro e mundial. Ciência \& Saúde Coletiva, v. 9, n.3, p. 3-3-27, 2004.

GLOBAL FORUM FOR HEALTH RESEARCH 2002. The 10/90 Report on Health Research 2001-2002. GFHR; 2001.

HOTEZ, P. The giant anteater in the room: Brazil's neglected tropical diseases problem. PLoS Neglected Tropical Diseases. 2(1):77. 2008.

KERR-PONTES, L.R.S. et al. Uma Reflexão sobre o Processo de Avaliação das Pós-graduações Brasileiras com Ênfase na Área de Saúde Coletiva. PHYSIS: Rev. Saúde Coletiva, Rio de Janeiro, 15(1):83- 94, 2005.

LETA, J. GLANZEL, THUS, B. Science in Brazil. Part 2: sectoral and institutional research profiles. Scientometrics, v. 67, n. 1, p. 87-105, 2006.

MÉDICOS SEM FRONTEIRAS. Desequilíbrio Fatal: a crise em pesquisa e desenvolvimento de drogas para doenças negligenciadas. Geneva: Grupo de Trabalho de Drogas para Doenças Negligenciadas, Médicos Sem Fronteiras; 2001.

MINAYO, M.C.S. Global \& Local, Meritocrático \& Social: 0 papel da Ciência e Tecnologia em Saúde Coletiva no Brasil. Revista Actas de Saúde Coletiva. V. 6, n.2, 2012. 
MOREL, C. M. Inovação em saúde e doenças negligenciadas. Cad.Saúde Pública, Rio de Janeiro, 22(8):1522-1523, ago, 2006.

MOREL, C.M., SERRUYA S.J., PENNA G.O., GUIMARÃES R. Co-authorship Network Analysis: A Powerful Too for Strategic Planning of Research, Development and Capacity Building Program on Neglected Diseases. PLoS Negl Trop Dis. Switzerland, 3(8): e501, ago 2009.

NORONHA, J.S., SILVA, T.R., SZKLO, F., BARATA, R.B. 0 que os pesquisadores pensam do sistema de pesquisa em saúde no Brasil: um estudo piloto. RECIIS - R. Eletr. De Com. Inf. Inov. Saúde. Rio de Janeiro, v.6, n.1, p.13-25, mar. 2012.

SANDERS, D. et al. Making research matter: a civil society perspective on health research. Bulletin of the World Heakth Organization, v. 82, n.10, p.757763, 2004.

SEMERENE, B. The economist: Brasil é líder mundial em pesquisa em medicina tropical. Fiocruz. Agência Fiocruz de Notícias. Disponível em http//www.fiocruz.br acesso em 15 mar 2012.

SIQUEIRA-BATISTA, R.; SCHRAMM, F. R. A saúde entre a iniqüidade e a justiça: contribuições da igualdade complexa de Amartya Sen. Ciência \& Saúde Coletiva, Rio de Janeiro, v. 10, n. 1, p. 129-142, 2005.

WHO: Neglected Tropical Diseases. Hidden successes, Emerging Opportunities. WHO/CDS/NTD/2006.22006. Disponível em http://whqlibdoc.who.int/hq/2006/WHO_CDS_NTD_2006. 2_eng.pdf. Acesso em 3 abr. 2012. 
Tabela 1 - Distribuição das instituições contempladas no Edital de apoio à pesquisa para doenças negligenciadas por regiões do país no ano de 2006

\begin{tabular}{l|cccccc}
\hline \multirow{2}{*}{ Tipo de Instituição } & \multicolumn{5}{c}{ Região } \\
\cline { 2 - 7 } & SE & NE & CO & S & $\mathbf{N}$ & Total \\
\hline Instituto de Pesquisa & 23 & 2 & 1 & 2 & 3 & 31 \\
Ensino Superior & 30 & 12 & 0 & 7 & 1 & 50 \\
Hospital de ensino & 0 & 0 & 0 & 0 & 0 & 0 \\
Serviço de Saúde & 1 & 0 & 0 & 0 & 0 & 1 \\
Outras organizações sem fins lucrativos (ONG, OSCIP etc.) & 0 & 0 & 0 & 0 & 0 & 0 \\
\hline Total & $\mathbf{5 4}$ & $\mathbf{1 5}$ & $\mathbf{1}$ & $\mathbf{9}$ & $\mathbf{3}$ & $\mathbf{8 2}$ \\
\hline
\end{tabular}

Fonte: MS/SCTIE/DECIT

Tabela 2 - Distribuição das instituições contempladas no Edital de fomento à pesquisa para doenças negligenciadas por regiões do país no ano de 2008

\begin{tabular}{l|ccccccc}
\hline & \multicolumn{5}{c}{ Região } \\
\cline { 2 - 8 } \multicolumn{1}{c|}{ Tipo de Instituição } & SE & NE & CO & S & N & Total \\
\hline Instituto de Pesquisa & 15 & 1 & 0 & 0 & 0 & 16 \\
Ensino Superior & 20 & 9 & 2 & 4 & 4 & 39 \\
Hospital de ensino & 2 & 0 & 0 & 0 & 0 & 2 \\
Outras organizações sem fins lucrativos (ONG, OSCIP etc.) & 1 & 0 & 0 & 0 & 0 & 1 \\
\hline Total & $\mathbf{3 8}$ & $\mathbf{1 0}$ & $\mathbf{2}$ & $\mathbf{4}$ & $\mathbf{4}$ & $\mathbf{5 8}$ \\
\hline Fonte: MS/SCTIE/DECIT & & & & & &
\end{tabular}

Fonte: MS/SCTIE/DECIT

Tabela 3 - Distribuição das instituições contempladas no Edital de apoio à pesquisa para doenças negligenciadas por regiões do país no ano de 2012

\begin{tabular}{l|cccccc}
\hline \multirow{2}{*}{ Tipo de Instituição } & \multicolumn{5}{c}{ Região } \\
\cline { 2 - 8 } & SE & NE & CO & S & N & Total \\
\hline Instituto de Pesquisa & 17 & 3 & 0 & 0 & 4 & 24 \\
Ensino Superior & 26 & 12 & 3 & 8 & 2 & 51 \\
Hospital de ensino & 0 & 0 & 0 & 0 & 0 & 0 \\
Serviço de Saúde & 0 & 0 & 0 & 0 & 1 & 1 \\
Outras organizações sem fins lucrativos (ONG, OSCIP etc.) & 0 & 0 & 0 & 0 & 0 & 0 \\
\hline Total & $\mathbf{4 3}$ & $\mathbf{1 5}$ & $\mathbf{3}$ & $\mathbf{8}$ & $\mathbf{7}$ & $\mathbf{7 6}$ \\
\hline
\end{tabular}

Fonte: MS/SCTIE/DECIT 
APÊNDICE D - Carta ao CEP/FS-Unb

Brasília, 15 de abril de 2013.

Sr. Coordenador,

Solicito que o projeto de doutorado O Programa de Pesquisa e Desenvolvimento em Doenças Negligenciadas no Brasil: normativa, visão e ações sob a perspectiva da Bioética Social, aprovado pelo Comitê de Ética da Faculdade de Ciências da Saúde da Universidade de Brasília (CEP - FS/UnB) sob o número 142/2012, tenha seu título modificado para Produção do conhecimento das doenças negligenciadas no Brasil: normativa, visão e ações dos atores sob a perspectiva da bioética latino-americana, devido à mudança de foco verificado no transcorrer do projeto. Vale ressaltar que os outros tópicos do projeto não sofreram alterações.

Atenciosamente,

Bruno Leonardo Alves de Andrade

Autor do projeto - Pós Graduação em Bioética/Doutorado 